\title{
Synthesis and Pharmacological Evaluation of Identified and Putative Metabolites of the A1 Adenosine Receptor Antagonist 8-Cyclopentyl-3-(3-fluoropropyl)-1-propylxanthine (CPFPX)
}

\author{
Marcus H. Holschbach ${ }^{1}$, Dirk Bier $^{1}$, Wiebke Sihver ${ }^{2}$, Annette Schulze ${ }^{1}$, Bernd Neumaier ${ }^{1}$ \\ ${ }^{1}$ Institut für Neurowissenschaften und Medizin-Nuklearchemie (INM-5), Wilhelm-Johnen-Straße, \\ Forschungszentrum Jülich GmbH, D-52428 Jülich, Germany \\ ${ }^{2}$ Institut für Radiopharmazeutische Krebsforschung, Helmholtz-Zentrum Dresden-Rossendorf, \\ Bautzener Landstraße 400, D-01328 Dresden
}

*Address for correspondence: Tel. +49 2461 61-6961; Fax +49 2461 61-2535; e-mail m.holschbach@fz-juelich.de

This is the peer reviewed version of the following article: M. H. Holschbach, D. Bier, W. Sihver, A. Schulze, B. Neumaier, ChemMedChem 2017, 12, 770., which has been published in final form at http://doi.org/10.1002/cmdc.201600592. This article may be used for non-commercial purposes in accordance with Wiley Terms and Conditions for Self-Archiving.

Dedicated to Professor Dr. Ray A. Olsson, a good friend and excellent teacher, in acknowledgement of his contributions to purine chemistry 


\begin{abstract}
The $A_{1}$ adenosine receptor $\left(A_{1} A R\right)$ antagonist $\left[{ }^{18} \mathrm{~F}\right]$ cyclopentyl-3-(3-fluoropropyl)-1propylxanthine $\left(\left[{ }^{18} \mathrm{~F}\right] \mathrm{CPFPX}\right)$, used in imaging human brain $\mathrm{A}_{1} \mathrm{ARs}$ by PET, is stable in the brain but rapidly undergoes transformation into one major (M1) and several minor metabolites in blood. This report describes the synthesis of putative metabolites of CPFPX as standards for the identification of those metabolites.

Analysis by (radio)HPLC revealed that extracts of human liver microsomes incubated with n.c.a. $\left[{ }^{18} \mathrm{~F}\right] \mathrm{CPFPX}$ contained the major metabolite, M1, as well as radioactive metabolites corresponding to derivatives functionalized at the cyclopentyl moiety, but no $N^{l}$-despropyl species or metabolites resulting from functionalizations of the $N^{3}$-fluoropropyl chain. The putative metabolites displaced the binding of $\left[{ }^{3} \mathrm{H}\right] \mathrm{CPFPX}$ to the $\mathrm{A}_{1} \mathrm{AR}$ in pig brain cortex at $\mathrm{K}_{\mathrm{i}}$ s between 1.9 and $380 \mathrm{nM}$ and the binding of $\left[{ }^{3} \mathrm{H}\right] \mathrm{ZM} 241385$ to the $\mathrm{A}_{2 \mathrm{~A}} \mathrm{AR}$ in pig striatum at $\mathrm{K}_{\mathrm{i}} \mathrm{s}$ greater than $180 \mathrm{nM}$. One metabolite, a derivative functionalized at the $\omega$-position of the $N^{l}$ propyl chain, showed high affinity $\left(K_{i} 2 \mathrm{nM}\right)$ to and very good selectivity (>9000) for the $A_{1} A R$.
\end{abstract}

Keywords: $A_{1}$ adenosine receptor ligand, $\left[{ }^{18} \mathrm{~F}\right] \mathrm{CPFPX}$, in-vitro metabolism, binding properties, ligand design 


\section{Introduction}

The radiofluorinated $\mathrm{A}_{1}$ adenosine receptor $\left(\mathrm{A}_{1} \mathrm{AR}\right)$ antagonist $\left[{ }^{18} \mathrm{~F}\right] 8$-cyclopentyl-3-(3fluoropropyl)-1-propylxanthine ([ $\left.\left.{ }^{18} \mathrm{~F}\right] \mathrm{CPFPX}\right)$ (chart) is the lead diagnostic agent to image that receptor in human brain by means of positron emission tomography (PET). ${ }^{1,2}$ Although $\left[{ }^{18} \mathrm{~F}\right] \mathrm{CPFPX}$ is not metabolized in the brain, it rapidly undergoes metabolism in the periphery to one main metabolite, M1 (chart), and a number of more polar metabolites. ${ }^{3,4}$

Chart Structures of radiofluorinated CPFPX and the main metabolite M1.

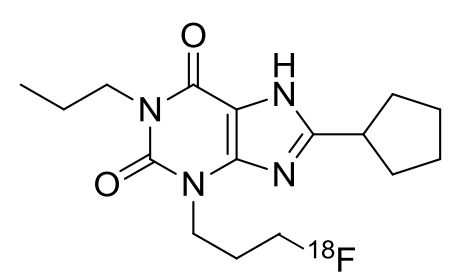

$\left[{ }^{18} \mathrm{~F}\right] \mathrm{CPFPX}$

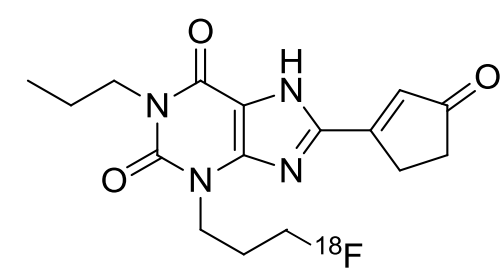

M1

The rate of metabolism (metabolic stability) of a drug indicates the need for structural modifications to reduce metabolism. Metabolite identification followed by detection of soft spots provides information on the sites to be modified or blocked and thus indicates possible chemical modifications or even new scaffolds. Overall, the information obtained serves as a basis for taking key decisions in the developmental phase of a ligand.

The aim of the present work was to synthesize and evaluate identified and putative CPFPXmetabolites with regard to the development of metabolically stabilized second generation (follow up) ligands. Thus, in the present study putative oxidative (phase I) metabolites of CPFPX were synthesized to provide reference standards for the studies directed toward elucidating the structures of the authentic drug metabolites found in human liver microsome preparations. Pharmacological evaluation of this putative metabolite family was also performed to determine receptor binding affinity and subtype selectivity in comparison to the parent compound. 
Since $\left[{ }^{18} \mathrm{~F}\right] \mathrm{CPFPX}$ for human applications is prepared under no-carrier-added (n.c.a.) conditions, the amounts of $\left[{ }^{19} \mathrm{~F}\right] \mathrm{CPFPX}$ administered are in the low-nanogram range, thus making direct identification of the radioactive metabolites by LC-MS from human blood samples impossible. In recent work it has been shown that human liver microsomes are a convenient and reliable model for the Phase I metabolism of CPFPX. ${ }^{4}$

A comparison by HPLC of extracts from human plasma obtained from blood samples drawn 30 min post tracer injection with extracts from human liver microsomes incubated with unlabelled CPFPX for 30 min showed that the microsome extracts contained compounds having chromatographic behavior similar to all of the radioactive metabolites found in human plasma. LC-MS showed that they had $\mathrm{m} / \mathrm{z}$ ratios of hydroxy-, oxo-, and unsaturated derivatives but did not allow unambiguous structure determination of the metabolites. ${ }^{4}$ The compounds described in the present work should allow to bridge that gap. In liver microsomes, CPFPX was shown to undergo monohydroxylations on three positions of the cyclopentane ring. The synthesized reference compounds should give detailed information about the alcohol regioisomers formed in vitro.

Cytochrome P450-mediated oxidation in the liver is the main route of alkylxanthine metabolism, ${ }^{5}$ and, presumably, that of CPFPX as well. Cytochrome P450-mediated oxidations of $\mathrm{sp}^{3}$ carbons such as those in the propyl and cyclopentyl groups of CPFPX have been described in detail. ${ }^{6-8}$ Those consist of hydroxylations and oxidations of methyl and methylene groups except those adjacent (alpha) to heteroatoms such as $N, O$ or $S$. In the latter instance the initially formed hydroxylation product is unstable and the alkyl group is eliminated by hydrolytic cleavage to form the desalkyl xanthine. According to these rules, there are a number of plausible metabolites of CPFPX. Table 1 shows some possible functionalization positions and -products. Besides the already identified metabolites many of these are the targets of the syntheses described below. 
Table 1. Possible CYP 450 functionalization products of CPFPX

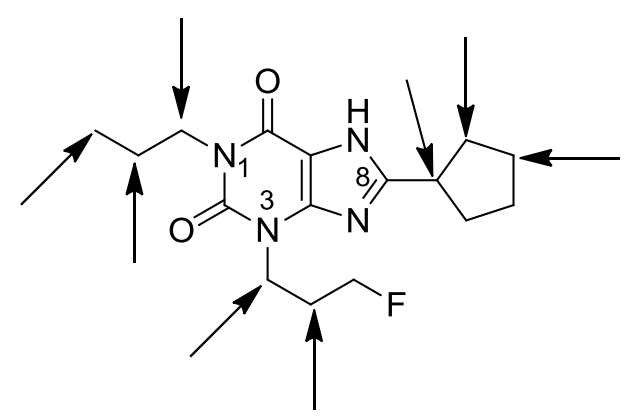

$m / z[\mathrm{M}+\mathrm{H}]^{+} \quad$ Species Represents

species found in human blood

323

339

337

$323-2 \times n$

CPFPX

CPFPX-OH

$\mathrm{CPFPX}=\mathrm{O}$

unsaturated species intact ligand

$s p^{3}$-carbon hydroxylation

oxygenation

dehydrogenation

species not found human blood

354

281

262

$323+16 \times \mathrm{n}$

$323+14 \times n$
CPFPX-COOH

CPFPX-despropyl

CPFPX-desfluoropropyl

poly-OH species

poly $=\mathrm{O}$ species oxidation of $-\mathrm{CH}_{3}$ dealkylation of $N^{1}$-propyl dealkylation of $N^{3}$-fluoropropyl multiple hydroxylation multiple oxygenation

Since all the metabolites found in human blood contain radiofluorine and because there is no significant radiofluorine deposition in bone, it appears that the $N^{3}$-fluoropropyl moiety of $\left[{ }^{18} \mathrm{~F}\right] \mathrm{CPFPX}$ resists cleavage and further metabolism. The only carbon in the fluoropropyl chain prone to functionalization is carbon $C^{2}$ (beta to fluorine) to give the respective $\beta$-hydroxy / oxo derivative, which LC-MS did not detect. Accordingly, any stable metabolites must contain alterations of the $N^{l}$-propyl and / or $C^{8}$-cyclopentyl substituents. Analysis by LC-MS indicated that these metabolites are exclusively Phase I but not Phase II metabolites, that is, they reflect hydroxylation and oxidation but not conjugation. 
With regard to the development of new potent $\mathrm{A}_{1} \mathrm{AR}$ selective radioligands and with respect to possible fine tuning of their lipophilicities the synthesized target compounds should be useful for further development. 


\section{Results and discussion}

\subsection{Chemistry}

Earlier work using extracts from human liver microsome preparations incubated with unlabelled CPFPX had already identified CPFPX metabolites by HPLC and LC-MS analysis. ${ }^{4}$ Scheme 1 outlines the synthesis of 8-cyclopentyl-3-(3-fluoropropyl)-7-pivaloyloxymethylxanthine, 13, the key intermediate for the synthesis of 1-substituted 8-cyclopentyl-3-(3-fluoropropyl)xanthines. This synthesis exploited the different reactivities of xanthine $N^{1}, N^{3}$, and $N^{7}$ toward alkylation, which is $3 \approx 7 \gg 1$. The first stages of the synthesis prepared 3-benzyl-8-cyclopentylxanthine, $\mathbf{6}$, in several steps from benzylurea, $\mathbf{1}$, and a cyanoacetic ester. ${ }^{9-11}$ The synthesis of $\mathbf{6}$ differed in some details from the approach used earlier. ${ }^{12}$ The condensation of benzylurea with methyl cyanoacetate in sodium methoxide rather than with cyanoacetic acid in acetic anhydride cyclized the cyanoacetylurea in one step rather than requiring a separate cyclization in alkali. Nitrosation of 6-amino-1-benzyluracil 2 used isoamyl nitrite rather than $\mathrm{NaNO}_{2}$ and the acylation of 5,6diaminouracil 4 employed cyclopentane carboxylic acid, a water soluble carbodiimide (EDCI) and 4-dimethylaminopyridine (DMAP) as a catalyst rather than cyclopentane carbonyl chloride and $\mathrm{Et}_{3} \mathrm{~N}$. Collectively, these modifications improved the overall yield of $\mathbf{6}$ to $40 \%$. Alkylation of $\mathbf{6}$ with one equivalent of chloromethyl pivalate (POM-Cl) for 3 hours protected $N^{7}$ by regioselectively forming the 7-pivaloyloxymethyl (POM) derivative, 7. Since this reaction is apparently without literature precedent, it was carried out primarily to confirm the preferential alkylation of $N^{7}$ over $N^{l}$. As expected, using a 3-fold excess of POM-Cl and prolonging the alkylation of 7 for additional 5 hours produced the 1,7-bis-POM derivative, 8. Alternatively, alkylation of $\mathbf{6}$ overnight with 3.5 equivalents of POM-Cl gave $\mathbf{8}$ in one step. Debenzylation by catalytic transfer hydrogenation $(\mathrm{CTH})$ over $\mathrm{Pd}-\mathrm{C}$ using ammonium formate as the hydrogen donor generated the 1,7-bis-POM, 3-unsubstituted xanthine 9. ${ }^{13}$ Cleavage of both POM groups gave 8-cyclopentylxanthine, 10. The regioselective introduction of a 3-fluoropropyl group through alkylation of 9 with 1-bromo-3-fluoropropane formed the protected 3-(3-fluoropropyl)xanthine, 11. Alkaline hydrolysis removed the POM groups, giving one of the putative metabolites, 8- 
cyclopentyl-3-(3-fluoropropyl)xanthine, 12. A short-term alkylation with POM-Cl protected $N^{7}$ of $\mathbf{1 2}$ to give key intermediate $\mathbf{1 3}$.

Scheme 1 Synthesis of compound 10 and key intermediate 13<smiles>CC(C)(C)C(=O)Nc1c(N)c(=O)[nH]c(=O)n1Cc1ccccc1</smiles>

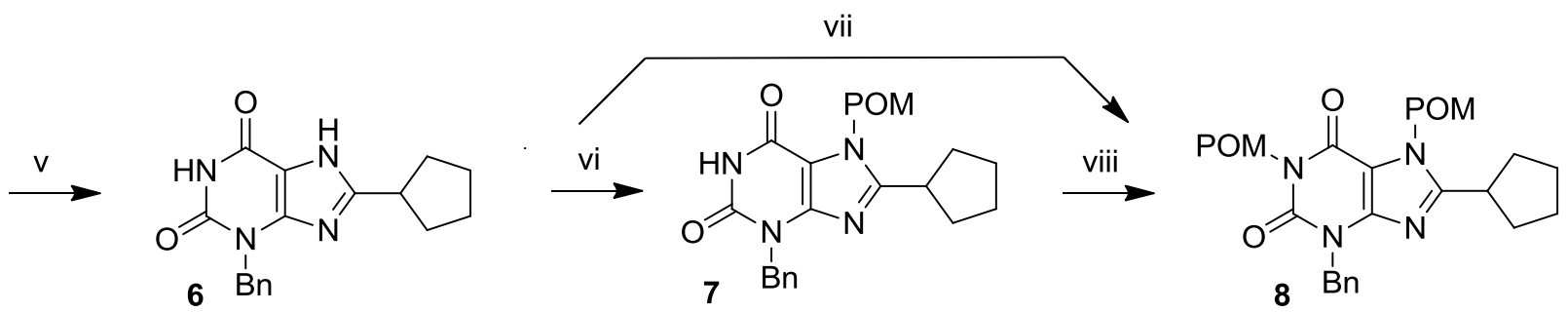<smiles>[R][C@H](C)CC</smiles>

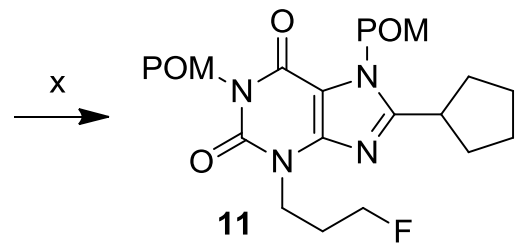<smiles>[Y][Y]([Y])([H])CCCn1c(=O)[nH]c(=O)c2[nH]c(C3CCCC3)nc21</smiles><smiles>O=c1[nH]c(=O)c2[nH]c(C3CCCC3)nc2[nH]1</smiles><smiles>O=c1[nH]c(=O)n(CCCF)c2nc(C3CCCC3)n([O+])c12</smiles>

Abbreviations: Bn, benzyl; POM, pivaloyloxymethyl

i: $\mathrm{NaOMe}, \mathrm{NCCH}_{2} \mathrm{CO}_{2} \mathrm{Me}, \mathrm{AcOH}$; ii: isoamyl nitrite; iii: $\mathrm{Na}_{2} \mathrm{~S}_{2} \mathrm{O}_{4}, \mathrm{NH}_{4} \mathrm{OH}$; iv: $\mathrm{CPCO}_{2} \mathrm{H}$, EDCl, DMAP, DMF; v: $2 \mathrm{~N}$ $\mathrm{NaOH}$, reflux; vi: 1eq POMCl, $\mathrm{K}_{2} \mathrm{CO}_{3}$, DMF; vii, viii: 3.5 eq POMCl, $\mathrm{K}_{2} \mathrm{CO}_{3}$, DMF; ix: $\mathrm{NH}_{4} \mathrm{HCO}_{2}, \mathrm{Pd} / \mathrm{C}, \mathrm{MeOH}$, reflux; x: 1-bromo-3-fluoropropane, $\mathrm{K}_{2} \mathrm{CO}_{3}$, DMF; xi: $\mathrm{NaOH} / \mathrm{EtOH}$; xii: 1eq $\mathrm{POMCl}, \mathrm{K}_{2} \mathrm{CO}_{3}$, DMF.

Scheme 2 summarizes the syntheses of the target xanthines. Alkylation of $\mathbf{1 3}$ with 3-bromo-1propanol gave the 1-(3-hydroxypropyl)xanthine 14a and, after deprotection, the 7-H xanthine, 15a. Alkylation of 13 with 2-(2-bromoethyl)-1,3-dioxolane and double deprotection gave the 1- 
(3-oxopropyl)xanthine 15b. Alkylation of 13 with chloroacetone and deprotection of the product afforded 1-(2-oxopropyl)xanthine 15c. Alkylation with chloroacetone followed by reduction with $\mathrm{NaBH}_{4}$ and deprotection without isolation of intermediates yielded the 1-(2-hydroxypropyl)-7Hxanthine, 15d, as a mixture of the $R$ and $S$ enantiomers. Alkylation of 1-propyl-8-cyclopentyl-7pivaloylmethylxanthine 16 with epifluorohydrin in the presence of a catalytic amount of base gave, after deprotection, racemic 3-(3-fluoro-2-hydroxypropyl)-1-propylxanthine, 1 17.15 $^{14}$

Scheme 2 Synthesis of putative metabolites functionalized at the $N-1$ and $N-3$ propyl chains<smiles>[R9]CCn1c(=O)c2c(nc(C3CCCC3)n2CCCF)n(CCCO)c1=O</smiles>

i: $\mathrm{K}_{2} \mathrm{CO}_{3}$, DMF, 3-bromopropanol, ii: 2-(2-bromoethyl)-1,3-dioxolane (14b), chloroacetone (14c); iii: $\mathrm{NH}_{3} / \mathrm{MeOH}$; iv: $\mathrm{NaOH} / \mathrm{EtOH}$ (14c to 15c); v: 1) $\mathrm{NaOH} / \mathrm{EtOH}, 2) \mathrm{HCl}$, reflux (14b to 15b); vi: 1) $\left.\mathrm{NaBH}_{4} / \mathrm{MeOH}, 2\right) \mathrm{NaOH} /$ $\mathrm{EtOH}(\mathbf{1 4 c}$ to $15 \mathrm{~d})$<smiles>[3H]C(O)Cn1c(=O)n(CCC)c(=O)c2[nH]c(C3CCCC3)nc21</smiles>

vii: 1) cat $\mathrm{K}_{2} \mathrm{CO}_{3}$, DMF, epifluorohydrin, 2) $\mathrm{NaOH} / \mathrm{EtOH}$;

Scheme 3 depicts the synthesis of the xanthines modified at the cyclopentyl ring. Since the presence of double bonds in the cyclopentenyl moieties and an $O$-benzyl protecting group in the cyclopentyl building block used in the synthesis of compounds $\mathbf{2 4 a - c}$ was incompatible with the 
hydrogenation conditions necessary to remove an amide benzyl protecting group, the acid labile 2,4-dimethoxybenzyl (DMB) protecting group was alternatively installed. ${ }^{16}$ Thus, carbodiimide / DMAP induced condensation of the key intermediate 5,6-diamino-1-(2,4-dimethoxybenzyl)-3propyluracil 18 with with either cyclopent-2-enecarboxylic acid or the isomeric cyclopent-3enecarboxylic acid followed by alkali induced ring closure of amides 19a and 19b as described for the synthesis of $\mathbf{6}$ furnished xanthines $20 \mathrm{a}$ and 20b. ${ }^{16}$ Xanthine 20c was obtained by the reaction of diamine 18 with cis-2-benzyloxycyclopentane-1-carboxylic acid using the mixed anhydride method followed by alkali induced cyclization of the intermediate amide 19c. Cis-2benzyloxycyclopentane-1-carboxylic acid was synthesized by benzylation of commercially available cis-ethyl 2-hydroxyoxycyclopentane-1-carboxylate with benzyl-2,2,2-

trichloroacetimidate followed by ester hydrolysis. ${ }^{17}$

POM protection of $N^{7}$ in xanthines 20a-c yielded compounds 21a-c which were subsequently deprotected at $N^{3}$ by hydrolysis of the DMB groups with TFA to provide 22a-c. Alkylation with 1-bromo-3-fluoropropane furnished derivatives 23a-c which upon alkaline hydrolysis of the POM protecting groups at $N^{7}$ gave the unsaturated target compounds $\mathbf{2 4 a}$ and $\mathbf{2 4 \mathbf { b }}$ and the benzyl ether 24c. Alcohol 25 was synthesized by hydroboration of cyclopentene derivative $24 a$ with 9-BBN, ${ }^{18}$ followed by oxidation with hydrogen peroxide, as a mixture of the cis and trans isomers. The regioisomeric cis-alcohol $\mathbf{2 6}$ was obtained by methanesulfonic acid induced debenzylation of $\mathbf{2 4 c}$.

\section{Scheme 3 Synthesis of putative metabolites functionalized at the cyclopentyl ring}


<smiles>[R5]On1c(N)c(N)c(=O)n(CCC)c1=O</smiles>

18<smiles>CC(C)C(C)(C)C</smiles><smiles>[R15]On1c(N)c(NC([R])=O)c(=O)n(CCC)c1=O</smiles>

$19 \mathrm{a}-\mathrm{c}$<smiles>[R]c1nc2c([nH]1)c(=O)n(CCC)c(=O)n2O</smiles>

$20 \mathrm{a}-\mathrm{c}$<smiles>[R6]O[R6]n1c([R16])nc2c1c(=O)n(CCC)c(=O)n2[Y16]</smiles><smiles>[R]c1nc2c([nH]1)c(=O)n(CCCF)c(=O)n2CCCF</smiles>

a: $R=$<smiles>[CH-]C1CC=CC1</smiles><smiles>[R]C#CC1=CCCC1</smiles><smiles>C#CC1CCC[C@@H]1OBr</smiles>

$24 a-c$

i: $\mathrm{RCO}_{2} \mathrm{H}, \mathrm{EDCl}, \mathrm{DMAP}(\mathrm{R}=\mathrm{a}, \mathrm{b})$, isobutyl chloroformate/NMM $(\mathrm{R}=\mathrm{c})$; ii: $2 \mathrm{~N} \mathrm{NaOH}$, dioxane, reflux; iii: $\mathrm{POMCl}, \mathrm{K}_{2} \mathrm{CO}_{3}$, DMF; iv: TFA, $70^{\circ} \mathrm{C}$; v: 1-bromo-3-fluoropropane, $\mathrm{K}_{2} \mathrm{CO}_{3}$, DMF; vi: $\mathrm{NH}_{3} / \mathrm{MeOH}$.<smiles>CCCn1c(=O)c2[nH]c(C3CC=CC3)nc2n(CCCF)c1=O</smiles>

24a<smiles>CCCn1c(=O)c2[nH]c(C3CC[C@H](O)C3)nc2n(CCCF)c1=O</smiles>

25

vii: 1) 4 eq 9-BBN, 2) $\mathrm{H}_{2} \mathrm{O}_{2}, \mathrm{NaOH}$.<smiles>CCCn1c(=O)c2[nH]c(C3CCC[C@H]3OCc3ccccc3)nc2n(CCCF)c1=O</smiles>

24c<smiles>CCCn1c(=O)c2[nH]c(C3CCC[C@H]3O)nc2n(CCCF)c1=O</smiles>

26

viii: $\mathrm{MeSO}_{3} \mathrm{H}, \mathrm{DCM}, 25^{\circ} \mathrm{C}$.

Abbreviations: Bn, benzyl; DMB, 2,4-dimethoxybenzyl; POM, pivaloyloxymethyl 
Analysis of the xanthines by electrospray ionization-mass spectroscopy detected, in addition to the $[\mathrm{M}+\mathrm{H}]^{+}$species, a second species of $m / z 60$ units greater. This appears to be an adduct of the $[\mathrm{M}+\mathrm{H}]^{+}$species with acetic acid, added to the solvent to increase sensitivity. All the xanthines but not their precursors formed these adducts, whether or not $N^{l}$ and $N^{7}$ were protected.

\subsection{Human liver microsomes}

Human liver microsome stability is meanwhile a standard indicator for predicting in vivo pharmacokinetic parameters of a compound. ${ }^{19,20}$ To generate a chromatographic profile of $\left[{ }^{18} \mathrm{~F}\right] \mathrm{CPFPX}$ metabolites formed in vitro, human liver microsomes were incubated with n.c.a. $\left[{ }^{18} \mathrm{~F}\right] \mathrm{CPFPX}$ and analyzed by (radio)HPLC. The figure shows superimposed chromatograms from the incubation of n.c.a. $\left[{ }^{18} \mathrm{~F}\right] \mathrm{CPFPX}$ with human liver microsomes (red radioactive trace) and the same sample spiked with the potential metabolites (blue UV trace). Due to the minute amounts of non radioactive CPFPX present in $\left[{ }^{18} \mathrm{~F}\right] \mathrm{CPFPX}$ preparations of low activity $( \pm 500 \mathrm{KBq})$ the radiolabeled isotopomer and its metabolites are not visible with UV detection at $275 \mathrm{~nm}$. Thus, simultaneous chromatography of the non radioactive and radioactive components allows the direct and unambigous comparison between the synthesized compounds and the in vitro formed metabolites in a single HPLC run. 
Figure (Radio)HPLC chromatogram of a human liver microsome preparation extract after metabolization of $\left[{ }^{18} \mathrm{~F}\right] \mathrm{CPFPX}$. The extract was subsequently spiked with a mixture of the nonradioactive putative metabolites $\mathbf{1 2}, \mathbf{1 5 a}-\mathbf{d}, \mathbf{1 7}, \mathbf{2 4 a}-\mathbf{b}, \mathbf{2 5}$ and $\mathbf{2 6}$ and analyzed in a single run. Blue: UV trace, red: radioactive trace.

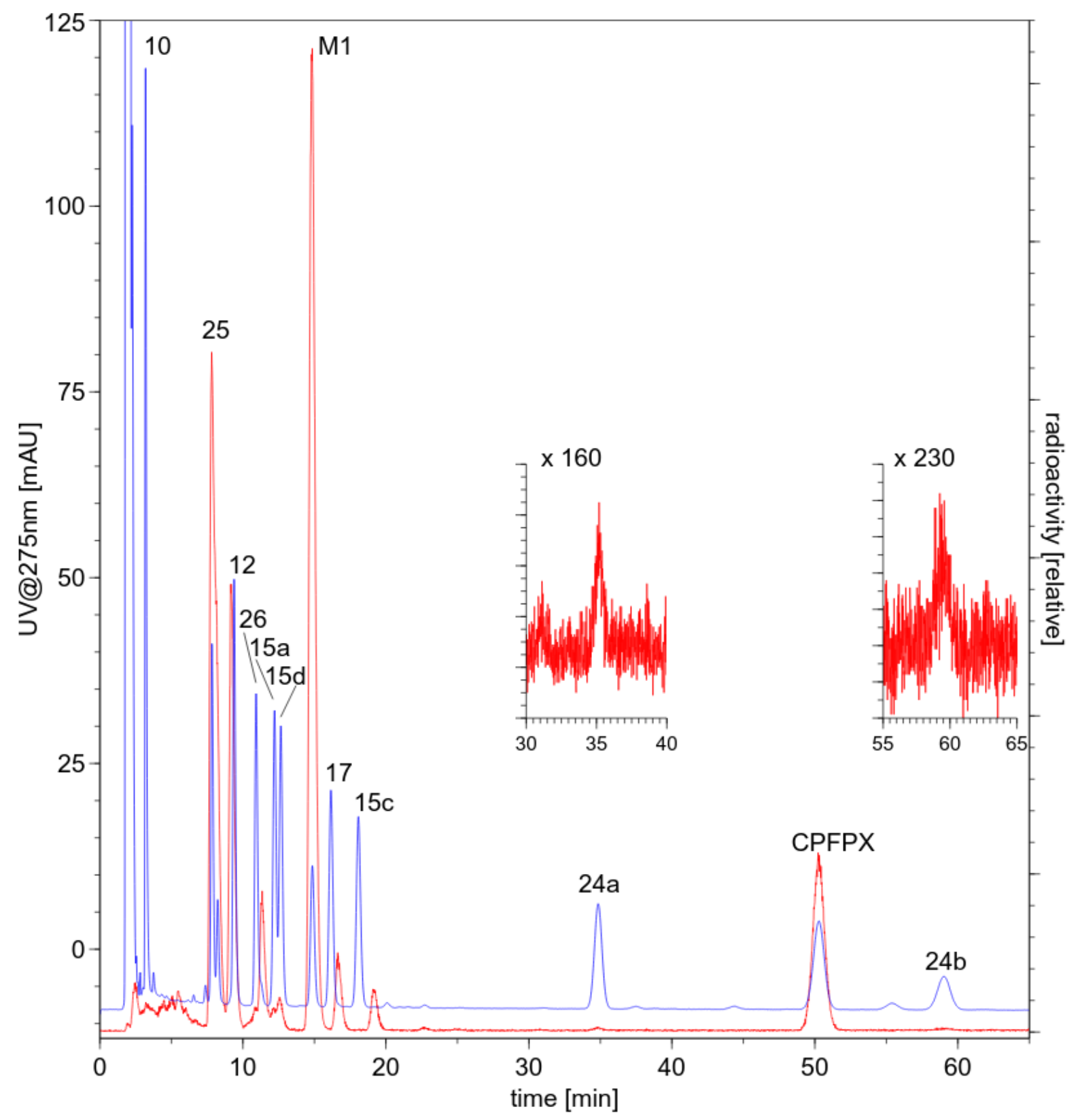




\subsubsection{Derivatives formed through multiple functionalizations}

The most prominent metabolite belonging to this class has already been described earlier. ${ }^{21}$ It is the main metabolite of $\left[{ }^{18} \mathrm{~F}\right] \mathrm{CPFPX}$ in human blood, M1, most likely arising from dehydrogenation, double allylic oxygenation and loss of water from the intermediately formed geminal diol (ketone hydrate) resulting in a highly conjugated double bond system.

\subsubsection{Unsaturated derivatives}

Representatives of unsaturated metabolites containing double bonds in the alicyclic cyclopentane ring are compounds $\mathbf{2 4 a}$ and $\mathbf{2 4 b}$. Earlier MS investigations ${ }^{4}$ had identified these metabolites with an exact mass of $322[\mathrm{M}+\mathrm{H}]^{+}$, which is 2 Da lower than CPFPX. A decrease of two mass

units corresponds to a dehydrogenation reaction. ${ }^{\mathbf{2 2}}$ The inserts in the figure indicate the presence of $\mathbf{2 4 a}$ and $\mathbf{2 4 b}$, albeit to a small extent.

\subsubsection{Dealkylated derivatives}

Compounds 10 and 12 belong to this group of metabolites. In contrast to the naturally occurring methylxanthines where $\mathrm{N}$-demethylation is the main metabolic pathway, ${ }^{5}$ no metabolites originating from $N$-dealkylation of $\left[{ }^{18} \mathrm{~F}\right] \mathrm{CPFPX}$ could be found. Moreover, since compound 10 does not contain fluorine-18, it would not be detectable in the radioactive channel. The absence of compound $\mathbf{1 2}$ makes the existence of compound $\mathbf{1 0}$ as well as that of the $N^{3}$-dealkylated congener most unlikely.

\subsubsection{Oxidative derivatives}

\subsubsection{Alkyl chains}

Metabolites functionalized at the N-1-propyl and/or at the N-3-fluoropropyl side chains of the xanthine core are compounds $\mathbf{1 5 a}-\mathbf{d}$ and $\mathbf{1 7}$, respectively. Whereas the N-1-propyl derived metabolites 15a and 15d are formed, the putative metabolites 17, originating from hydroxylation 
of $C^{2}$ in the $N^{3}$-fluoropropylchain, and ketone $\mathbf{1 5 c}$ are completely absent. These results are in agreement with earlier findings. ${ }^{4}$ The observation that compound $\mathbf{1 7}$ is not detected might be exploited as a potential strategy in drug design to mask alkyl chain metabolic hotspots through incorporation of a fluorine atom at the terminal carbon ( $\omega$-fluorination). ${ }^{23,24}$

\subsubsection{Cyclopentyl ring}

The in vitro formation of oxidative metabolites corresponding to the functionalization of cyclopentyl groups has scarcely been described in the literature. ${ }^{25,26}$

In principle there are three chemically different carbon atoms in the cyclopentyl ring of CPFPX prone to monohydroxylation, namely $C^{l}, C^{2(5)}$, and $C^{3(4)}$. MS studies using extracts of microsome preparations incubated with unlabeled CPFPX have revealed the existence of three hydroxylated regioisomers. ${ }^{4}$ Consequently ring-hydroxylated metabolites $\mathbf{2 5}$ and $\mathbf{2 6}$ have been synthesized. In the first instance one would expect a chromatographic match of the UV-HPLC peaks of 25 and 26 with those of the radioactive trace. However, only compound $\mathbf{2 5}$ matched with a radioactivity signal in the chromatogram in the figure. It is well known that stereoisomers are observed in certain disubstituted (and higher substituted) cyclic compounds. Thus, substituted cycloalkanes must be viewed as three-dimensional configurations in order to consider the spatial orientations of the substituents. In non planar ring systems like cyclopentane substituents can adapt equatorial and/or axial orientations resulting in configurational isomers (cis-trans isomers) which sometimes can be separated by chromatographic methods. The reaction sequence for the synthesis of compound 25 from the cyclopent-3-en precursor $\mathbf{2 4 a}$ (hydroboration-oxidation) yields a mixture of $c i s$ and trans stereoisomers with a preference for the trans isomer (cis:trans $\sim 20: 80),{ }^{27-29}$ whereas the cis configuration of compound $\mathbf{2 6}$ is predetermined by the starting material cis-2hydroxycyclopentanecarboxylic acid. Cis-trans isomerism might explain the marginal difference in the HPLC retention times of $\mathbf{2 6}$ (cis) and the putative radioactive metabolite (trans). This leads to the assumption that the hydroxyl functions on the cyclopentyl moiety in metabolites $\mathbf{2 5}$ and 26 assume trans orientation.

These findings are in good agreement with the results of a study on the in vitro metabolism of the cyclic nucleotide phosphodiesterase type IV inhibitor RP $73401 .^{25}$ The authors clearly showed 
that the predominant ring hydroxylated metabolite formed by human liver microsomes was the trans alcohol, with the cis isomer constituting less than $3 \%$ of the amount of total hydroxycyclopentyl metabolite formed.

\subsubsection{Binding studies}

In binding studies (table 2) using pig brain membranes all examined compounds had lower affinities (higher $K_{i}$ values) for the $A_{1}$ and $A_{2 A}$ adenosine receptors than the parent compound CPFPX ( $\left.\mathrm{K}_{\mathrm{i}} 0.47 \mathrm{nM}\right)$. Differences in $\mathrm{K}_{\mathrm{i}}$ values for the $\mathrm{A}_{1} \mathrm{AR}$ ranged from 1.9 to $380 \mathrm{nM}$. The most efficient deactivation was found for metabolite M1, the main metabolite in human blood, showing a 800 fold reduction in affinity compared to CPFPX, but four compounds, 12, 15a, 15d, and 17 showed higher subtype selectivity $\left(A_{2 A} / A_{1}\right)$ for the $A_{1} A R$. The four mentioned compounds are exclusively functionalized at the $\mathrm{N}$-alkyl chains of the xanthine heterocycle. Functionalization at the cyclopentyl ring invariably led to a distinct reduction in subtype selectivity, with the main metabolite M1 being the most unselective compound. Interestingly compound 15a has both a high affinity for the $\mathrm{A}_{1} \mathrm{AR}\left(\mathrm{K}_{\mathrm{i}} 2 \mathrm{nM}\right)$ and a tenfold higher subtype selectivity (> 9000) compared to CPFPX (800), making 15a a useful hydrophilic $A_{1} A R$ ligand for the examination of this receptor outside the brain. Moreover, because of its potentially low unspecific binding, 15a might be a good candidate for in vitro experiments.

Table 2. Affinity of CPFPX metabolites 10, 12, 15a-d, 17, 24a-b, 25 and 26 at pig brain membranes.

\begin{tabular}{|c|c|c|c|}
\hline Cpd & $\begin{array}{l}\mathrm{A}_{1} \mathrm{AR}(\text { cortex }) \\
{\left[{ }^{3} \mathrm{H}\right] \mathrm{CPFPX}, \mathrm{K}_{\mathrm{i}}[\mathrm{nM}]^{\mathrm{a}}}\end{array}$ & $\begin{array}{l}\mathrm{A}_{2 \mathrm{~A}} \mathrm{R} \text { (striatum) } \\
{\left[{ }^{3} \mathrm{H}\right] \mathrm{ZM} 241385, \mathrm{~K}_{\mathrm{i}}[\mathrm{nM}]^{\mathrm{a}}}\end{array}$ & selectivity, $A_{2 A} / A_{1}$ \\
\hline CPFPX & $\begin{array}{l}0.47 \\
(0.36 \text { to } 0.61)\end{array}$ & $\begin{array}{l}375 \\
(279 \text { to } 504)\end{array}$ & 798 \\
\hline M1 & $\begin{array}{l}378 \\
(273 \text { to } 525)\end{array}$ & $\begin{array}{l}7842 \\
(2538 \text { to } 24229)\end{array}$ & 21 \\
\hline 10 & 147 & $>100000$ & $>700$ \\
\hline
\end{tabular}




\begin{tabular}{|c|c|c|c|}
\hline & (81 to 265$)$ & & \\
\hline 12 & $\begin{array}{l}34 \\
(24 \text { to } 47)\end{array}$ & $>100000$ & $>3000$ \\
\hline $15 \mathbf{a}$ & $\begin{array}{l}1.12 \\
(0.97 \text { to } 1.28)\end{array}$ & $>10000$ & $>9000$ \\
\hline $15 b$ & $\begin{array}{l}16.6 \\
(13.6 \text { to } 20.1)\end{array}$ & $>10000$ & $>600$ \\
\hline $15 \mathrm{c}$ & $\begin{array}{l}15 \\
(11 \text { to } 21)\end{array}$ & $>10000$ & $>650$ \\
\hline$( \pm) 15 d$ & $\begin{array}{l}6.5 \\
(4.8 \text { to } 8.8)\end{array}$ & $>10000$ & $>1500$ \\
\hline$( \pm) 17$ & $\begin{array}{l}1.9 \\
(1.5 \text { to } 2.4)\end{array}$ & $\begin{array}{l}1939 \\
(1021 \text { to } 3684)\end{array}$ & 1020 \\
\hline $24 a$ & $\begin{array}{l}2.8 \\
(1.1 \text { to } 2.9)\end{array}$ & $\begin{array}{l}847 \\
(550 \text { to } 1305)\end{array}$ & 303 \\
\hline $24 b$ & $\begin{array}{l}6.9 \\
(2.8 \text { to } 17)\end{array}$ & $\begin{array}{l}185 \\
(133 \text { to } 258)\end{array}$ & 27 \\
\hline$( \pm) 25$ & $\begin{array}{l}6.5 \\
(3.7 \text { to } 12)\end{array}$ & $\begin{array}{l}189 \\
\text { (117 to } 306)\end{array}$ & 29 \\
\hline$( \pm) 26$ & $\begin{array}{l}17.6 \\
\text { (13.4 to } 22)\end{array}$ & $\begin{array}{l}453 \\
\text { (381 to } 507)\end{array}$ & 26 \\
\hline
\end{tabular}

${ }^{a}$ Mean and $95 \%$ confidence limits of at least three separate assays. 


\section{Conclusion}

This report describes the in vitro metabolic functionalization of the $\mathrm{A}_{1} \mathrm{AR}$ antagonist $\left[{ }^{18} \mathrm{~F}\right] \mathrm{CPFPX}$ in human liver microsome preparations. Ten putative metabolites were synthesized by the classical Traube synthesis followed by a series of derivatization steps and evaluated as $\mathrm{A}_{1}$ - and $\mathrm{A}_{2 \mathrm{~A}}$ adenosine receptor ligands. Metabolic profiling by co-chromatography of the synthesized standards and extracts from human liver microsome incubations revealed, additionally to the known main metabolite M1, the formation of one metabolite resulting from $\omega$-hydroxylation of the $N^{l}$-propyl chain and two metabolites arising from oxygenation of the cyclopentyl substituent. The present data suggest that monohydroxylations of the cyclopentyl moiety are stereoselective to give the respective trans alcohols. Furthermore two minor metabolites, unsaturated in the cyclopentyl ring, were formed.

The affinity data of the metabolites for the $\mathrm{A}_{1}$ - and $\mathrm{A}_{2 \mathrm{~A}}$ adenosine receptor indicate that enzymatic functionalization of either the pendent $N^{l}$-side chain or the cyclopentane ring results in the formation of phase I metabolites with lower affinities to both receptor subtypes than the parent compound CPFPX.

Two points can be made about the potential future significance of this study:

- the metabolites are biologically active via a broad affinity range although less affine than the parent compound CPFPX

- the biologically highly active and subtype selective hydroxylated metabolite 15a provides a convenient starting point for further drug development and the altered lipophilicity of 15a may offer advantages in terms of unspecific binding and its use as a radioligand. 


\section{Experimental Section}

Melting points were measured on a Büchi Melting Point B 545 apparatus (Büchi Labortechnik, Flawil, Switzerland) and are uncorrected. Elemental analyses were performed by the Central Division of Analytical Chemistry at the Forschungszentrum Jülich. Analyses indicated by the symbols of the elements are within $\pm 0.4 \%$ of the theoretical values (table 3 ). Low resolution mass spectra (MS) were obtained in the ElectroSpray Ionisation (ESI+) mode on a Thermo Finnigan Surveyor MSQ mass spectrometer (Thermo Fisher Scientific GmbH, Dreieich, Germany). Thin layer chromatography (TLC) employed $0.2 \mathrm{~mm}$ precoated silica sheets (4 x $8 \mathrm{~cm}$, Alugram SIL G/UV254, Macherey-Nagel, Düren, Germany) developed with ethyl acetate / hexane $50 / 50$ (v/v). Visualization was by quenching of UV fluorescence at $254 \mathrm{~nm}$ and iodine staining. For flash chromatography a Grace Reveleris ${ }^{\circledR} \mathrm{iES}$ flash chromatography system equipped with RevealX ${ }^{\mathrm{TM}}$ detection, allowing for multisignal (UV/ELSD) collection, and Reveleris ${ }^{\circledR}$ flash silica cartridges (size $40 \mu \mathrm{m}$ ) as stationary phase was employed. ${ }^{1} \mathrm{H},{ }^{13} \mathrm{C}$, and ${ }^{19} \mathrm{~F}$ NMR spectra were recorded at 200.13, 50.32, and 188.31 MHz, respectively, by means of a Bruker DPX-200 Avance instrument (Bruker Bio Spin GmbH, Rheinstetten, Germany) in $5 \%$ solution at $25^{\circ} \mathrm{C}$. Chemical

shifts are reported in ppm relative to the residual solvent signal $\left({ }^{1} \mathrm{H}\right.$ NMR: $\delta 7.26 ;{ }^{13} \mathrm{C}$ NMR: 77.0 for $\mathrm{CDCl}_{3}$, ${ }^{1} \mathrm{H}$ NMR: $\delta$ 2.52; ${ }^{13} \mathrm{C}$ NMR: 50.32 for DMSO- $\left.d_{6}\right)$. Multiplicities are reported by using the following abbreviations: s; singlet, d; doublet, t; triplet, q; quartet, m; multiplet, br; broad. Coupling constants $J$ (in Hertz) for protons are given in the form ${ }^{\mathrm{n}} J_{\mathrm{HX}}$, those for carbons as ${ }^{\mathrm{n}} J_{\mathrm{CF}}$. The protons were assigned with the aid of COSY, and the carbons with the aid of DEPT and HMQC experiments. All solvents and reagents in the highest state of purity available were obtained commercially (Sigma-Aldrich, Taufkirchen, Germany; Alfa Aesar, Karlsruhe, Germany) and used as supplied by the vendor. Methanol for CTH was dried by refluxing over $\mathrm{Mg}$ turnings and distillation. Ammonium formate was dried in a dessiccator over $\mathrm{P}_{4} \mathrm{O}_{10}$ at room temperature and ambient pressure. For CTH equal weights of substrate and 10\% Pd-C and a 10-fold molar excess of ammonium formate was used. Times and temperatures are indicated in individual experiments. Purification of dimethylformamide (DMF) consisted of distillation from calcium hydride and storage in a lightproof container over $4 \AA$ molecular sieves. Dichloromethane and toluene were dried by storage over $4 \AA$ molecular sieves. Other solvents, chemicals and biochemical reagents were obtained from and used as supplied by Sigma-Aldrich (Taufkirchen, 
Germany). Pig brains for membrane preparations were from a local abattoir. The syntheses of $\left[{ }^{3} \mathrm{H}\right] \mathrm{CPFPX}$ and $\left[{ }^{18} \mathrm{~F}\right] \mathrm{CPFPX}$ were by the methods cited. ${ }^{21,30}$ Reactions were carried out at ambient temperature $\left( \pm 23^{\circ} \mathrm{C}\right)$ under an atmosphere of argon unless otherwise stated.

Table 3. Elemental Analyses of New Compounds

\begin{tabular}{|c|c|c|c|c|c|c|}
\hline Cpd & Formula & & Carbon & Hydrogen & Nitrogen & Oxygen \\
\hline \multirow[t]{2}{*}{7} & \multirow{2}{*}{$\mathrm{C}_{23} \mathrm{H}_{28} \mathrm{~N}_{4} \mathrm{O}_{4}$} & Calcd & 65.08 & 6.65 & 13.20 & 15.08 \\
\hline & & Found & 65.11 & 6.61 & 13.14 & 15.16 \\
\hline \multirow[t]{2}{*}{8} & \multirow[t]{2}{*}{$\mathrm{C}_{29} \mathrm{H}_{38} \mathrm{~N}_{4} \mathrm{O}_{6}$} & Calcd & 64.67 & 7.11 & 10.40 & 17.62 \\
\hline & & Found & 64.71 & 7.04 & 10.48 & 17.77 \\
\hline \multirow[t]{2}{*}{9} & \multirow{2}{*}{$\mathrm{C}_{22} \mathrm{H}_{32} \mathrm{~N}_{4} \mathrm{O}_{6}$} & Calcd & 58.91 & 7.19 & 12.49 & 21.40 \\
\hline & & Found & 58.88 & 7.24 & 12.53 & 21.32 \\
\hline \multirow[t]{2}{*}{11} & \multirow{2}{*}{$\mathrm{C}_{25} \mathrm{H}_{37} \mathrm{FN}_{4} \mathrm{O}_{6}$} & Calcd & 59.04 & 7.33 & 11.02 & 18.88 \\
\hline & & Found & 58.97 & 7.29 & 10.94 & 19.01 \\
\hline \multirow[t]{2}{*}{12} & \multirow[t]{2}{*}{$\mathrm{C}_{13} \mathrm{H}_{17} \mathrm{FN}_{4} \mathrm{O}_{2}$} & Calcd & 55.70 & 6.11 & 19.99 & 11.42 \\
\hline & & Found & 55.75 & 6.20 & 19.88 & 11.52 \\
\hline \multirow[t]{2}{*}{13} & \multirow{2}{*}{$\mathrm{C}_{19} \mathrm{H}_{27} \mathrm{FN}_{4} \mathrm{O}_{4}$} & Calcd & 57.85 & 6.90 & 14.20 & 16.22 \\
\hline & & Found & 57.87 & 6.92 & 14.16 & 16.27 \\
\hline \multirow[t]{2}{*}{$15 \mathbf{a}$} & \multirow{2}{*}{$\mathrm{C}_{16} \mathrm{H}_{23} \mathrm{FN}_{4} \mathrm{O}_{3}$} & Calcd & 56.79 & 6.85 & 16.56 & 14.18 \\
\hline & & Found & 56.74 & 6.91 & 16.38 & 14.21 \\
\hline \multirow[t]{2}{*}{$15 b$} & \multirow[t]{2}{*}{$\mathrm{C}_{16} \mathrm{H}_{21} \mathrm{FN}_{4} \mathrm{O}_{3}$} & Calcd & 57.13 & 6.29 & 16.66 & 14.32 \\
\hline & & Found & 56.98 & 6.14 & 16.62 & 14.24 \\
\hline \multirow[t]{2}{*}{$15 \mathrm{c}$} & \multirow{2}{*}{$\mathrm{C}_{16} \mathrm{H}_{21} \mathrm{FN}_{4} \mathrm{O}_{3}$} & Calcd & 57.13 & 6.29 & 16.66 & 14.32 \\
\hline & & Found & 57.21 & 6.23 & 16.72 & 14.24 \\
\hline \multirow[t]{2}{*}{ 15d } & \multirow[t]{2}{*}{$\mathrm{C}_{16} \mathrm{H}_{23} \mathrm{FN}_{4} \mathrm{O}_{3}$} & Calcd & 56.79 & 6.85 & 16.56 & 14.18 \\
\hline & & Found & 56.81 & 6.79 & 16.51 & 14.24 \\
\hline \multirow[t]{2}{*}{16} & \multirow[t]{2}{*}{$\mathrm{C}_{16} \mathrm{H}_{23} \mathrm{FN}_{4} \mathrm{O}_{3}$} & Calcd & 56.79 & 6.85 & 16.56 & 14.18 \\
\hline & & Found & 56.81 & 6.87 & 16.48 & 14.22 \\
\hline \multirow[t]{2}{*}{17} & \multirow[t]{2}{*}{$\mathrm{C}_{16} \mathrm{H}_{23} \mathrm{FN}_{4} \mathrm{O}_{3}$} & Calcd & 56.79 & 6.85 & 16.56 & 14.18 \\
\hline & & Found & 56.86 & 6.81 & 16.52 & 14.24 \\
\hline
\end{tabular}




\begin{tabular}{|c|c|c|c|c|c|c|}
\hline 19a & $\mathrm{C}_{22} \mathrm{H}_{28} \mathrm{~N}_{4} \mathrm{O}_{5}$ & $\begin{array}{l}\text { Calcd } \\
\text { Found }\end{array}$ & $\begin{array}{l}61.67 \\
61.73\end{array}$ & $\begin{array}{l}6.59 \\
6.51\end{array}$ & $\begin{array}{l}13.08 \\
12.99\end{array}$ & $\begin{array}{l}18.67 \\
18.74\end{array}$ \\
\hline 19b & $\mathrm{C}_{22} \mathrm{H}_{28} \mathrm{~N}_{4} \mathrm{O}_{5}$ & $\begin{array}{l}\text { Calcd } \\
\text { Found }\end{array}$ & $\begin{array}{l}61.67 \\
61.69\end{array}$ & $\begin{array}{l}6.59 \\
6.56\end{array}$ & $\begin{array}{l}13.08 \\
13.14\end{array}$ & $\begin{array}{l}18.67 \\
18.65\end{array}$ \\
\hline $20 a$ & $\mathrm{C}_{22} \mathrm{H}_{26} \mathrm{~N}_{4} \mathrm{O}_{4}$ & $\begin{array}{l}\text { Calcd } \\
\text { Found }\end{array}$ & $\begin{array}{l}64.37 \\
64.43\end{array}$ & $\begin{array}{l}6.38 \\
6.44\end{array}$ & $\begin{array}{l}13.65 \\
13.52\end{array}$ & $\begin{array}{l}15.59 \\
15.44\end{array}$ \\
\hline $20 b$ & $\mathrm{C}_{22} \mathrm{H}_{26} \mathrm{~N}_{4} \mathrm{O}_{4}$ & $\begin{array}{l}\text { Calcd } \\
\text { Found }\end{array}$ & $\begin{array}{l}64.37 \\
64.40\end{array}$ & $\begin{array}{l}6.38 \\
6.38\end{array}$ & $\begin{array}{l}13.65 \\
13.66\end{array}$ & $\begin{array}{l}15.59 \\
15.53\end{array}$ \\
\hline $20 \mathrm{c}$ & $\mathrm{C}_{29} \mathrm{H}_{34} \mathrm{~N}_{4} \mathrm{O}_{5}$ & $\begin{array}{l}\text { Calcd } \\
\text { Found }\end{array}$ & $\begin{array}{l}67.16 \\
67.03\end{array}$ & $\begin{array}{l}6.61 \\
6.57\end{array}$ & $\begin{array}{l}10.80 \\
10.74\end{array}$ & $\begin{array}{l}15.43 \\
15.48\end{array}$ \\
\hline $21 \mathbf{a}$ & $\mathrm{C}_{28} \mathrm{H}_{36} \mathrm{~N}_{4} \mathrm{O}_{6}$ & $\begin{array}{l}\text { Calcd } \\
\text { Found }\end{array}$ & $\begin{array}{l}64.10 \\
63.99\end{array}$ & $\begin{array}{l}6.92 \\
6.81\end{array}$ & $\begin{array}{l}10.68 \\
10.52\end{array}$ & $\begin{array}{l}18.30 \\
18.19\end{array}$ \\
\hline $21 b$ & $\mathrm{C}_{28} \mathrm{H}_{36} \mathrm{~N}_{4} \mathrm{O}_{6}$ & $\begin{array}{l}\text { Calcd } \\
\text { Found }\end{array}$ & $\begin{array}{l}64.10 \\
64.04\end{array}$ & $\begin{array}{l}6.92 \\
6.88\end{array}$ & $\begin{array}{l}10.68 \\
10.63\end{array}$ & $\begin{array}{l}18.30 \\
18.24\end{array}$ \\
\hline $21 c$ & $\mathrm{C}_{35} \mathrm{H}_{44} \mathrm{~N}_{4} \mathrm{O}_{7}$ & $\begin{array}{l}\text { Calcd } \\
\text { Found }\end{array}$ & $\begin{array}{l}66.44 \\
66.34\end{array}$ & $\begin{array}{l}7.01 \\
6.98\end{array}$ & $\begin{array}{l}8.85 \\
8.83\end{array}$ & $\begin{array}{l}17.70 \\
17.54\end{array}$ \\
\hline $22 \mathbf{a}$ & $\mathrm{C}_{19} \mathrm{H}_{26} \mathrm{~N}_{4} \mathrm{O}_{4}$ & $\begin{array}{l}\text { Calcd } \\
\text { Found }\end{array}$ & $\begin{array}{l}60.95 \\
61.03\end{array}$ & $\begin{array}{l}7.00 \\
6.90\end{array}$ & $\begin{array}{l}14.96 \\
14.72\end{array}$ & $\begin{array}{l}17.09 \\
17.01\end{array}$ \\
\hline $22 b$ & $\mathrm{C}_{19} \mathrm{H}_{26} \mathrm{~N}_{4} \mathrm{O}_{4}$ & $\begin{array}{l}\text { Calcd } \\
\text { Found }\end{array}$ & $\begin{array}{l}60.95 \\
60.99\end{array}$ & $\begin{array}{l}7.00 \\
7.05\end{array}$ & $\begin{array}{l}14.96 \\
14.88\end{array}$ & $\begin{array}{l}17.09 \\
17.07\end{array}$ \\
\hline $22 \mathrm{c}$ & $\mathrm{C}_{26} \mathrm{H}_{34} \mathrm{~N}_{4} \mathrm{O}_{5}$ & $\begin{array}{l}\text { Calcd } \\
\text { Found }\end{array}$ & $\begin{array}{l}64.71 \\
64.64\end{array}$ & $\begin{array}{l}7.10 \\
7.14\end{array}$ & $\begin{array}{l}11.61 \\
11.52\end{array}$ & $\begin{array}{l}16.58 \\
16.66\end{array}$ \\
\hline $23 \mathbf{a}$ & $\mathrm{C}_{22} \mathrm{H}_{31} \mathrm{FN}_{4} \mathrm{O}_{4}$ & $\begin{array}{l}\text { Calcd } \\
\text { Found }\end{array}$ & $\begin{array}{l}60.81 \\
61.00\end{array}$ & $\begin{array}{l}7.19 \\
7.11\end{array}$ & $\begin{array}{l}12.89 \\
12.83\end{array}$ & $\begin{array}{l}14.73 \\
14.65\end{array}$ \\
\hline $23 b$ & $\mathrm{C}_{22} \mathrm{H}_{31} \mathrm{FN}_{4} \mathrm{O}_{4}$ & $\begin{array}{l}\text { Calcd } \\
\text { Found }\end{array}$ & $\begin{array}{l}60.81 \\
60.77\end{array}$ & $\begin{array}{l}7.19 \\
7.16\end{array}$ & $\begin{array}{l}12.89 \\
12.96\end{array}$ & $\begin{array}{l}14.73 \\
14.81\end{array}$ \\
\hline $23 c$ & $\mathrm{C}_{29} \mathrm{H}_{39} \mathrm{FN}_{4} \mathrm{O}_{5}$ & $\begin{array}{l}\text { Calcd } \\
\text { Found }\end{array}$ & $\begin{array}{l}64.19 \\
64.07\end{array}$ & $\begin{array}{l}7.24 \\
7.19\end{array}$ & $\begin{array}{l}10.32 \\
10.33\end{array}$ & $\begin{array}{l}14.74 \\
14.69\end{array}$ \\
\hline $24 \mathbf{a}$ & $\mathrm{C}_{16} \mathrm{H}_{21} \mathrm{FN}_{4} \mathrm{O}_{2}$ & $\begin{array}{l}\text { Calcd } \\
\text { Found }\end{array}$ & $\begin{array}{l}59.99 \\
60.02\end{array}$ & $\begin{array}{l}6.61 \\
6.81\end{array}$ & $\begin{array}{l}17.49 \\
17.42\end{array}$ & $\begin{array}{l}9.99 \\
10.14\end{array}$ \\
\hline
\end{tabular}




\begin{tabular}{|c|c|c|c|c|c|c|}
\hline $24 b$ & $\mathrm{C}_{16} \mathrm{H}_{21} \mathrm{FN}_{4} \mathrm{O}_{2}$ & $\begin{array}{l}\text { Calcd } \\
\text { Found }\end{array}$ & $\begin{array}{l}59.99 \\
59.99\end{array}$ & $\begin{array}{l}6.61 \\
6.57\end{array}$ & $\begin{array}{l}17.49 \\
17.53\end{array}$ & $\begin{array}{l}9.99 \\
10.06\end{array}$ \\
\hline $24 c$ & $\mathrm{C}_{23} \mathrm{H}_{29} \mathrm{FN}_{4} \mathrm{O}_{3}$ & $\begin{array}{l}\text { Calcd } \\
\text { Found }\end{array}$ & $\begin{array}{l}64.47 \\
64.37\end{array}$ & $\begin{array}{l}6.82 \\
6.69\end{array}$ & $\begin{array}{l}13.08 \\
12.93\end{array}$ & $\begin{array}{l}11.20 \\
11.19\end{array}$ \\
\hline 25 & $\mathrm{C}_{16} \mathrm{H}_{23} \mathrm{FN}_{4} \mathrm{O}_{3}$ & $\begin{array}{l}\text { Calcd } \\
\text { Found }\end{array}$ & $\begin{array}{l}56.79 \\
56.72\end{array}$ & $\begin{array}{l}6.85 \\
6.95\end{array}$ & $\begin{array}{l}16.56 \\
16.55\end{array}$ & $\begin{array}{l}14.18 \\
14.11\end{array}$ \\
\hline 26 & $\mathrm{C}_{16} \mathrm{H}_{23} \mathrm{FN}_{4} \mathrm{O}_{3}$ & $\begin{array}{l}\text { Calcd } \\
\text { Found }\end{array}$ & $\begin{array}{l}56.79 \\
56.87\end{array}$ & $\begin{array}{l}6.85 \\
6.89\end{array}$ & $\begin{array}{l}16.56 \\
16.53\end{array}$ & $\begin{array}{l}14.18 \\
14.26\end{array}$ \\
\hline
\end{tabular}

6-Amino-1-benzyluracil (2). ${ }^{31}$

A solution of sodium methanolate in methanol $(30 \%, 357 \mathrm{~mL}, 2 \mathrm{~mol})$ was diluted with methanol to a final volume of $600 \mathrm{~mL}$ and heated to reflux. Under efficient stirring N-benzylurea $(\mathbf{1}, 100 \mathrm{~g}$, $0.66 \mathrm{~mol})$ was added, followed by cyanoacetic acid methyl ester (66 g, $0.66 \mathrm{~mol})$. The reaction mixture was stirred at reflux for $6 \mathrm{~h}$, cooled to room temperature and evaporated. Stirring in boiling water $(1400 \mathrm{~mL})$ dissolved the syrupy yellow residue and the hot solution was carefully acidified with acetic acid (CAUTION! VIGOROUS FOAMING!). After cooling the voluminous precipitate was filtered off, washed with water and dried at $120^{\circ} \mathrm{C}$. Recrystallization from $50 \%$ aqueous ethanol gave an analytical sample. Yield: $89 \mathrm{~g}(62 \%), \mathrm{mp} 286^{\circ} \mathrm{C}(50 \% \mathrm{EtOH})$. ${ }^{1} \mathrm{H}-\mathrm{NMR}\left(\mathrm{DMSO}-d_{6}\right): \delta 4.68(\mathrm{~s}, 1 \mathrm{H}, \mathrm{C}-5-H), 5.08$ (s, 2H, Ph-CH $\left.H_{2}\right), 6.89$ (s, 2H, NH$\left.H_{2}\right), 7.27(\mathrm{~m}$, $\left.5 \mathrm{H}, \mathrm{C}_{6} H_{5}\right), 10.69$ ( $\left.\mathrm{s}_{\mathrm{br}}, 1 \mathrm{H}, \mathrm{NH}\right) .{ }^{13} \mathrm{C}-\mathrm{NMR}\left(\mathrm{DMSO}-d_{6}\right): \delta 44.4\left(\mathrm{Ph}-\mathrm{CH}_{2}\right), 76.4(C-5), 127.2,128$, 129.3 (Ph-C-4, $C-2, C-3$ ), 137.5 (Ph-C-1), 152.3 (C-2), $156.7(C-6), 163.3(C-4)$. MS (ESI+) m/z: $[\mathrm{M}+\mathrm{H}]^{+}$Calcd for $\mathrm{C}_{11} \mathrm{H}_{11} \mathrm{~N}_{3} \mathrm{O}_{2}$ 218.22; Found 218.23.

\section{6-Amino-5-nitroso-1-benzyluracil (3). ${ }^{32}$}

Crude 2 (4.34 g, $20 \mathrm{mmol})$ was suspended by stirring in ethanol $(100 \mathrm{~mL})$ and isoamyl nitrite (5 $\mathrm{mL}, 36$ mmole) was added dropwise. Acidification with ethanolic $\mathrm{HCl}(2.5 \mathrm{~N}, 1 \mathrm{~mL})$ changed the color from yellow to violet. The reaction mixture was stirred for $0.5 \mathrm{~h}$ and cooled in the refrigerator for $2 \mathrm{~h}$. The microcrystalline solid collected by filtration was air-dried. Yield: $4.5 \mathrm{~g}$ $(92 \%), \mathrm{mp}>300^{\circ} \mathrm{C}$ (violet crystals).

${ }^{1} \mathrm{H}-\mathrm{NMR}\left(\mathrm{DMSO}-d_{6}\right): \delta 5.17\left(\mathrm{~s}, 2 \mathrm{H}, \mathrm{Ph}-\mathrm{CH}_{2}\right), 6.89\left(\mathrm{~s}, 2 \mathrm{H}, \mathrm{NH} H_{2}\right), 7.31\left(\mathrm{~m}, 5 \mathrm{H}, \mathrm{C}_{6} H_{5}\right), 11.28\left(\mathrm{~s}_{\mathrm{br}}\right.$, $\left.1 \mathrm{H}, \mathrm{N}^{3}-H\right) .{ }^{13} \mathrm{C}-\mathrm{NMR}\left(\mathrm{DMSO}-d_{6}\right): \delta 44.2\left(\mathrm{Ph}-\mathrm{CH}_{2}\right), 127.4,128.3,129.4\left(\mathrm{Ph}-C^{4}, C^{2}, C^{3}\right), 135.5$ 
$\left(\mathrm{Ph}-C^{1}\right), 139.5\left(\mathrm{C}^{5}\right), 147.7\left(C^{2}\right), 149.8\left(C^{6}\right), 161.3\left(C^{4}\right) . \mathrm{MS}(\mathrm{ESI}+) \mathrm{m} / \mathrm{z}:[\mathrm{M}+\mathrm{H}]^{+}$Calcd for $\mathrm{C}_{11} \mathrm{H}_{10} \mathrm{~N}_{4} \mathrm{O}_{3}$ 247.22; Found 247.23.

\section{1-Benzyl-5,6-diaminouracil (4). ${ }^{15}$}

Compound $3(7.4 \mathrm{~g} 30 \mathrm{mmol})$ was dissolved in $\mathrm{NH}_{4} \mathrm{OH}(10 \%$, ca. $70 \mathrm{ml})$ at $50-60^{\circ} \mathrm{C}$ to give a brownish solution. The addition of solid $\mathrm{Na}_{2} \mathrm{~S}_{2} \mathrm{O}_{4}(10 \mathrm{~g}, 90 \mathrm{mmol})$ in small portions over $0.3 \mathrm{~h}$ discharged the color. Stirring for $2 \mathrm{~h}$ longer at $50-60^{\circ} \mathrm{C}$, followed by cooling, precipitated greenish-grey product, which was filtered off by suction, washed with a small amount of ice-cold water and dichloromethane, and used immediately in the next step. Yield $6.3 \mathrm{~g}(90 \%)$. MS (ESI+) m/z: $[\mathrm{M}+\mathrm{H}]^{+}$Calcd for $\mathrm{C}_{11} \mathrm{H}_{12} \mathrm{~N}_{4} \mathrm{O}_{2}$ 232.24; Found 233.24.

\section{N-(6-Amino-1-benzyl-2,4-dioxo-3-propyl-1,2,3,4-tetrahydropyrimidin-5-yl)- cyclopentanecarboxamide (5). ${ }^{15}$}

Crude 4 (2.4 g, $10 \mathrm{mmol}$ ) was suspended in DMF (50 mL) and 1-(3-dimethylaminopropyl)-3ethylcarbodiimide hydrochloride (EDAC, $1.92 \mathrm{~g}, 10 \mathrm{mmol}$ ) and a catalytic amount ( 150 mg) of 4-dimethylaminopyridine (DMAP) was added. Under efficient stirring cyclopentanecarboxylic acid $(1.08 \mathrm{~mL}, 10 \mathrm{mmol}$ ) was added, and the mixture was stirred for $20 \mathrm{~h}$ at ambient temperature. During this time the greenish suspension became a clear brown solution, and sometimes a yellow precipitate formed. The mixture was poured onto ice-water $(150 \mathrm{~mL})$, the yellow precipitate was collected by filtration, washed with water $(50 \mathrm{~mL})$, and oven-dried at $120^{\circ} \mathrm{C}$. Yield $2.82 \mathrm{~g}(86 \%)$. ${ }^{1} \mathrm{H}-\mathrm{NMR}$ (DMSO- $d_{6}$ ): $\delta 1.46-1.84\left(\mathrm{~m}, 8 \mathrm{H}, \mathrm{Cp}-\mathrm{CH}_{2}\right.$ ), 2.77 (m, 1H, Cp-CH), 5.13 (s, 2H, Ph$\left.\mathrm{CH}_{2}\right), 6.44\left(\mathrm{~s}, 2 \mathrm{H}, \mathrm{NH}_{2}\right), 7.34\left(\mathrm{~m}, 5 \mathrm{H}, \mathrm{C}_{6} H_{5}\right), 8.22(\mathrm{~s}, 1 \mathrm{H}, \mathrm{N} H \mathrm{CO}), 10.74\left(\mathrm{~s}, 1 \mathrm{H}, \mathrm{N}^{3}-H\right) .{ }^{13} \mathrm{C}-\mathrm{NMR}$ (DMSO- $\left.d_{6}\right): \delta 26.6\left(\mathrm{Cp}-\mathrm{CH}_{2}\right), 30.8\left(\mathrm{Cp}-\mathrm{CH}_{2}\right), 44.9(\mathrm{Cp}-\mathrm{CH}), 53.6\left(\mathrm{Ph}-\mathrm{CH}_{2}\right), 89.2\left(C^{5}\right), 127.2$, 128, $129.3\left(\mathrm{Ph}-C^{4}, C^{2}, C^{3}\right), 137.5\left(\mathrm{Ph}-C^{1}\right), 151.2\left(C^{2}\right), 153.5\left(C^{6}\right), 160.7\left(C^{4}\right), 176.9(C=\mathrm{O}) . \mathrm{MS}$ (ESI+) m/z: [M+H] $]^{+}$Calcd for $\mathrm{C}_{17} \mathrm{H}_{20} \mathrm{~N}_{4} \mathrm{O}_{3}$ 329.37; Found 329.39.

\section{3-Benzyl-8-cyclopentyl-1 $H$-purine-2,6(3H,7H)-dione $(6) .{ }^{15}$}

Compound 5 was refluxed for $4 \mathrm{~h}$ in aqueous $2 \mathrm{~N} \mathrm{NaOH}$ (oil bath $115^{\circ} \mathrm{C}$ ) and cooled to room temperature. Bringing the clear brownish solution to $\mathrm{pH} 4-5$ with concentrated $\mathrm{HCl}$ precipitated a solid that was filtered off, washed with water and triturated with boiling ethanol to remove 
coloured impurities. Filtration and oven drying gave almost colourless product. The xanthine was recrystallized from acetic acid $( \pm 25 \mathrm{~mL} / \mathrm{g})$, filtered, washed with ethanol and oven-dried. Yield $2.43 \mathrm{~g}(91 \%), \mathrm{mp}>300^{\circ} \mathrm{C}$. TLC: $\operatorname{Rf} 0.21$.

${ }^{1} \mathrm{H}-\mathrm{NMR}\left(\mathrm{DMSO}-d_{6}\right): \delta 1.61-2.01\left(\mathrm{~m}, 8 \mathrm{H}, \mathrm{Cp}-\mathrm{CH}_{2}\right), 3.12(\mathrm{~m}, 1 \mathrm{H}, \mathrm{Cp}-\mathrm{CH}), 5.09(\mathrm{~s}, 2 \mathrm{H}, \mathrm{Ph}-$ $\left.\mathrm{CH}_{2}\right), 7.33\left(\mathrm{~m}, 5 \mathrm{H}, \mathrm{C}_{6} H_{5}\right), 11.07\left(\mathrm{~s}, 1 \mathrm{H}, \mathrm{N}^{1}-H\right) 13.18\left(\mathrm{~s}, 1 \mathrm{H}, \mathrm{N}^{7}-H\right) .{ }^{13} \mathrm{C}-\mathrm{NMR}$ (DMSO- $\left.d_{6}\right): \delta 25.9$ $\left(\mathrm{Cp}-\mathrm{CH}_{2}\right), 32.8\left(\mathrm{Cp}-\mathrm{CH}_{2}\right), 39.6(\mathrm{Cp}-\mathrm{CH}), 45.8\left(\mathrm{Ph}-\mathrm{CH}_{2}\right), 107.4\left(C^{5}\right), 128.2,128.5,129.3\left(\mathrm{Ph}-C^{4}\right.$, $\left.C^{2}, C^{3}\right), 138.1\left(\mathrm{Ph}-C^{1}\right), 150.1\left(C^{8}\right), 151.7\left(C^{4}\right), 155.1\left(C^{2}\right), 158.7\left(C^{6}\right) . \mathrm{MS}(\mathrm{ESI}+) \mathrm{m} / \mathrm{z}:[\mathrm{M}+\mathrm{H}]^{+}$ Calcd for $\mathrm{C}_{17} \mathrm{H}_{18} \mathrm{~N}_{4} \mathrm{O}_{2} 311.35$; Found 311.32.

\section{3-Benzyl-8-cyclopentyl-7-pivaloyloxymethyl-1H-purine-2,6(3H,7H)-dione (7).}

A slurry of 6 (3.1 g, $10 \mathrm{mmol}), \mathrm{K}_{2} \mathrm{CO}_{3}(1.38 \mathrm{~g}, 10 \mathrm{mmol})$ and chloromethyl pivalate (POM-Cl, $1.45 \mathrm{~mL}, 10 \mathrm{mmol})$ in dry DMF (40 mL) was stirred at $60^{\circ} \mathrm{C}$ for $3 \mathrm{~h}$. The reaction mixture was poured into ice water and neutralized with $2 \mathrm{~N} \mathrm{HCl}$. Precipitated product was filtered off and washed with water. The solid was treated with boiling EtOH $(50 \mathrm{~mL})$, the mixture was filtered, and the solvent was evaporated in vacuo to give an oily yellow residue. Adding $\mathrm{MeOH}( \pm 5 \mathrm{~mL})$, scratching with a glass rod and cooling crystallized the product. The off-white solid was filtered off, washed with a small volume of ice cold $\mathrm{MeOH}$ and air-dried. Yield: $3.7 \mathrm{~g}$ (92 \%), mp: 174$175^{\circ} \mathrm{C}(\mathrm{MeOH})$.

In some preparations traces of the 1,7-diPOM compound formed, hence the crude product mixture was purified by flash cromatography eluting with 50\% ethyl acetate in hexane. TLC: Rf 0.65. ${ }^{1} \mathrm{H}-\mathrm{NMR}\left(\mathrm{DMSO}-d_{6}\right): \delta 1.13\left(\mathrm{~s}, 9 \mathrm{H}, \mathrm{N}^{7}-\mathrm{POM}-\mathrm{CH}_{3}\right), 1.64-2.11\left(\mathrm{~m}, 8 \mathrm{H}, \mathrm{Cp}-\mathrm{CH}_{2}\right), 3.40(\mathrm{~m}, 1 \mathrm{H}$, $\mathrm{Cp}-\mathrm{CH}), 5.09$ (s, 2H, Ph-CH2), $6.20\left(\mathrm{~s}, 2 \mathrm{H}, \mathrm{N}^{7}-\mathrm{POM}-\mathrm{CH}_{2}\right), 7.30\left(\mathrm{~m}, 5 \mathrm{H}, \mathrm{C}_{6} H_{5}\right), 11.26\left(\mathrm{~s}, 1 \mathrm{H}, \mathrm{N}^{1}-\right.$ $\left.H) .{ }^{13} \mathrm{C}-\mathrm{NMR}\left(\mathrm{DMSO}-d_{6}\right): \delta 25.9\left(\mathrm{Cp}-\mathrm{CH}_{2}\right), 27.4\left(\mathrm{~N}^{7}-\mathrm{POM}-\mathrm{CH}_{3}\right)\right), 33\left(\mathrm{Cp}-\mathrm{CH}_{2}\right), 36.4(\mathrm{Cp}-\mathrm{CH})$, $39.1\left(\mathrm{~N}^{7}-\mathrm{POM}-\mathrm{C}\left(\mathrm{CH}_{3}\right)_{3}\right), 45.7\left(\mathrm{Ph}-\mathrm{CH}_{2}\right), 68.1\left(\mathrm{~N}^{7}-\mathrm{POM}-\mathrm{CH}_{2}\right), 106.9\left(C^{5}\right), 128.5,129,129.2(\mathrm{Ph}-$ $\left.C^{4}, C^{2}, C^{3}\right), 137.8\left(\mathrm{Ph}-C^{1}\right), 150.3\left(C^{8}\right), 155.5\left(C^{4}\right), 155\left(C^{2}\right), 160.1\left(C^{6}\right), 177.4(C=\mathrm{O}) . \mathrm{MS}(\mathrm{ESI}+)$ $\mathrm{m} / \mathrm{z}:[\mathrm{M}+\mathrm{H}]^{+}$Calcd for $\mathrm{C}_{23} \mathrm{H}_{28} \mathrm{~N}_{4} \mathrm{O}_{4} 425.49$; Found 425.51 .

\section{3-Benzyl-8-cyclopentyl-1,7-(dipivaloyloxymethyl)-1H-purine-2,6(3H,7H)-dione (8).}

A slurry of 7 (424 mg, $1 \mathrm{mmol}), \mathrm{K}_{2} \mathrm{CO}_{3}(152 \mathrm{mg}, 1.1 \mathrm{mmol})$ and POM-Cl (216 $\left.\mu \mathrm{L}, 1.5 \mathrm{mmol}\right)$ in dry DMF (4 mL) was stirred at $60^{\circ} \mathrm{C}$ for $5 \mathrm{~h}$. The reaction mixture was poured into ice water and 
neutralized with $2 \mathrm{~N}$ aqueous $\mathrm{HCl}$. The turbid supernatant was decanted from the gummy precipitate and the gum was dissolved in hot $\mathrm{MeOH}$. Addition of water precipitated the product as pale yellowish crystals. The product was recrystallized from 70\% aqueous MeOH. Yield: $450 \mathrm{mg}$ (83\%), mp: $128-129^{\circ} \mathrm{C}(70 \% \mathrm{MeOH})$. TLC: Rf 0.87.

${ }^{1} \mathrm{H}-\mathrm{NMR}\left(\mathrm{DMSO}-d_{6}\right): \delta 1.09\left(\mathrm{~s}, 9 \mathrm{H}, \mathrm{N}^{1}-\mathrm{POM}-\mathrm{CH}_{3}\right), 1.13\left(\mathrm{~s}, 9 \mathrm{H}, \mathrm{N}^{7}-\mathrm{POM}-\mathrm{CH}_{3}\right), 1.66-2.14(\mathrm{~m}$, 8H, Cp-CH $\mathrm{CH}_{2}, 3.40$ (m, 1H, Cp-CH), 5.17 (s, 2H, Ph-CH $), 5.88$ (s, 2H, N $\left.{ }^{1}-\mathrm{POM}-\mathrm{CH}_{2}\right), 6.22$ (s, $\left.2 \mathrm{H}, \mathrm{N}^{7}-\mathrm{POM}-\mathrm{CH}_{2}\right), 7.33\left(\mathrm{~m}, 5 \mathrm{H}, \mathrm{C}_{6} \mathrm{H}_{5}\right),{ }^{13} \mathrm{C}-\mathrm{NMR}$ (DMSO-d $\left.)_{6}\right): \delta 26.2\left(\mathrm{Cp}-\mathrm{CH}_{2}\right), 27.4(\mathrm{POM}-$ $\left.\mathrm{CH}_{3}\right), 27.5\left(\mathrm{POM}-\mathrm{CH}_{3}\right), 33\left(\mathrm{Cp}-\mathrm{CH}_{2}\right), 36.4(\mathrm{Cp}-\mathrm{CH}), 39.1\left(\mathrm{POM}-\mathrm{C}\left(\mathrm{CH}_{3}\right)_{3}\right), 39.2(\mathrm{POM}-$ $\left.C\left(\mathrm{CH}_{3}\right)_{3}\right), 45.8\left(\mathrm{Ph}-\mathrm{CH}_{2}\right), 65.7\left(\mathrm{POM}-\mathrm{CH}_{2}\right), 68.2\left(\mathrm{POM}-\mathrm{CH}_{2}\right), 106.2\left(C^{5}\right), 128.5,129,129.30(\mathrm{Ph}-$ $\left.C^{4}, C^{2}, C^{3}\right), 137.31\left(\mathrm{Ph}-C^{1}\right), 149.1\left(C^{8}\right), 151\left(C^{4}\right), 153.5\left(C^{2}\right), 161.2\left(C^{6}\right), 177.1(C=\mathrm{O}), 177.4$ $(C=\mathrm{O})$. MS (ESI+) m/z: $[\mathrm{M}+\mathrm{H}]^{+}$Calcd for $\mathrm{C}_{29} \mathrm{H}_{38} \mathrm{~N}_{4} \mathrm{O}_{6}$ 539.64; Found 539.66.

NOTE: Compound 8 can also be prepared in one step in a similar yield by the reaction of 6 ( 1 eq) with POM-Cl (3.5 eq) and $\mathrm{K}_{2} \mathrm{CO}_{3}$ (3.5 eq) in DMF (4 mL / mmol xanthine) for $24 \mathrm{~h}$ at $60^{\circ} \mathrm{C}$, dilution with water, extraction with DCM, drying of the organic layer over $\mathrm{Na}_{2} \mathrm{SO}_{4}$, evaporation and crystallizing the clear oil from $70 \%$ aqueous $\mathrm{MeOH}$.

\section{8-Cyclopentyl-1,7-(dipivaloyloxymethyl)-1H-purine-2,6(3H,7H)-dione (9).}

A $50 \mathrm{~mL}$ round-bottomed flask was charged with 8 (538 mg, $1 \mathrm{mmol})$, dry 10\% Pd/C (538 mg) and dry ammonium formate $(631 \mathrm{mg} 10 \mathrm{mmol})$. Dry MeOH $(25 \mathrm{~mL})$ was added and under efficient stirring the flask was immersed in an oil bath preheated to $140^{\circ} \mathrm{C}$. After $2 \mathrm{~h}$ TLC indicated the absence of starting material. The catalyst was removed by filtration over Celite ${ }^{\mathrm{TM}}$, the filter cake was washed with DCM (3 x $20 \mathrm{~mL})$ and acetone $(3 \times 20 \mathrm{~mL})$ and the combined filtrate and washings were evaporated in vacuo to give an analytically pure white solid in quantitative yield, mp $138-139^{\circ} \mathrm{C}(\mathrm{MeOH})$. TLC: Rf 0.73 .

${ }^{1} \mathrm{H}-\mathrm{NMR}\left(\mathrm{DMSO}-d_{6}\right): \delta 1.01\left(\mathrm{~s}, 9 \mathrm{H}, \mathrm{N}^{1}-\mathrm{POM}-\mathrm{CH}_{3}\right), 1.06\left(\mathrm{~s}, 9 \mathrm{H}, \mathrm{N}^{7}-\mathrm{POM}-\mathrm{CH}_{3}\right), 1.59-2.01(\mathrm{~m}$, $\left.8 \mathrm{H}, \mathrm{Cp}-\mathrm{CH}_{2}\right), 3.43(\mathrm{~m}, 1 \mathrm{H}, \mathrm{Cp}-\mathrm{CH}), 5.84$ (s, 2H, N$\left.{ }^{1}-\mathrm{POM}-\mathrm{CH}_{2}\right), 6.18\left(\mathrm{~s}, 2 \mathrm{H}, \mathrm{N}^{7}-\mathrm{POM}-\mathrm{CH}_{2}\right) \mathrm{N}^{3}-H$ appears as a broad signal between 3 and 5 ppm. ${ }^{13} \mathrm{C}-\mathrm{NMR}$ (DMSO- $\left.d_{6}\right): \delta 26.3\left(\mathrm{Cp}-\mathrm{CH}_{2}\right), 27.4$ (POM- $\left.\mathrm{CH}_{3}\right), 27.6\left(\mathrm{POM}-\mathrm{CH}_{3}\right), 32.9\left(\mathrm{Cp}-\mathrm{CH}_{2}\right), 36.30(\mathrm{Cp}-\mathrm{CH}), 39.1\left(\mathrm{POM}-\mathrm{C}\left(\mathrm{CH}_{3}\right)_{3}\right), 39.2$ $\left(\mathrm{POM}-C\left(\mathrm{CH}_{3}\right)_{3}\right), 65.6\left(\mathrm{POM}-\mathrm{CH}_{2}\right), 68\left(\mathrm{POM}-C \mathrm{H}_{2}\right), 105.9\left(C^{5}\right), 153.9\left(C^{8}\right), 155\left(C^{4}\right), 160.9\left(C^{2}\right)$, 
177.2 $\left(C^{6}\right), 177.7(C=\mathrm{O}), 177.8(C=\mathrm{O}) . \mathrm{MS}(\mathrm{ESI}+) \mathrm{m} / \mathrm{z}:[\mathrm{M}+\mathrm{H}]^{+}$Calcd for $\mathrm{C}_{22} \mathrm{H}_{32} \mathrm{~N}_{4} \mathrm{O}_{6} 449.51$;

Found 449.52

\section{8-Cyclopentyl-1H-purine-2,6(3H,7H)-dione (10).}

A solution of $9(448 \mathrm{mg}, 1 \mathrm{mmol})$ in $7 \mathrm{~N}$ methanolic $\mathrm{NH}_{3}(15 \mathrm{~mL})$ was stirred for $48 \mathrm{~h}$ at ambient temperature. Evaporation in vасио gave a solid residue that was recrystallized from $\mathrm{MeOH}$. Yield $215 \mathrm{mg}(95 \%)$ colourless crystals, m.p. > 300 ${ }^{\circ} \mathrm{C}(\mathrm{MeOH})$. TLC: Rf 0.00.

${ }^{1} \mathrm{H}-\mathrm{NMR}\left(\mathrm{DMSO}-d_{6}\right): \delta 1.61-2.03\left(\mathrm{~m}, 8 \mathrm{H}, \mathrm{Cp}-\mathrm{CH}_{2}\right), 3.09(\mathrm{~m}, 1 \mathrm{H}, \mathrm{Cp}-\mathrm{CH}), 3.60\left(\mathrm{~s}_{\mathrm{br}}, 1 \mathrm{H}, \mathrm{N} H\right)$, $11.38\left(\mathrm{~s}_{\mathrm{br}}, 2 \mathrm{H}, 2 \mathrm{x} \mathrm{NH}\right) .{ }^{13} \mathrm{C}-\mathrm{NMR}\left(\mathrm{DMSO}-\mathrm{d}_{6}\right): \delta 25.9\left(\mathrm{Cp}-\mathrm{CH}_{2}\right), 32.7\left(\mathrm{Cp}-\mathrm{CH}_{2}\right), 49.5(\mathrm{Cp}-\mathrm{CH})$, $107.2\left(C^{5}\right), 149.9\left(C^{8}\right), 152.3\left(C^{4}\right), 156.1\left(C^{2}\right), 158.6\left(C^{6}\right) . \mathrm{MS}(\mathrm{ESI}+) \mathrm{m} / \mathrm{z}:[\mathrm{M}+\mathrm{H}]^{+}$Calcd for $\mathrm{C}_{10} \mathrm{H}_{12} \mathrm{~N}_{4} \mathrm{O}_{2} 221.23$; Found 221.22

\section{8-Cyclopentyl-1,7-(dipivaloyloxymethyl)-3-(3-fluoropropyl)-1H-purine-2,6(3H,7H)-dione} (11).

A slurry of 9 (448 mg, $1 \mathrm{mmol}), \mathrm{K}_{2} \mathrm{CO}_{3}(152 \mathrm{mg}, 1.1 \mathrm{mmol})$ and 1-bromo-3-fluoropropane (137 $\mu \mathrm{L}, 1.5 \mathrm{mmol})$ in dry DMF (4 mL) was stirred for $24 \mathrm{~h}$ at $60^{\circ} \mathrm{C}$. Pouring the reaction mixture into ice water and neutralizing with $2 \mathrm{~N}$ aqueous $\mathrm{HCl}$ precipitated the product as a gum that solidified on standing. The solid was recrystallized from $\mathrm{MeOH}$. Yield: $482 \mathrm{mg}$ (95\%), mp: 116-117 $\mathrm{C}$ (MeOH). TLC: Rf 0.69.

${ }^{1} \mathrm{H}-\mathrm{NMR}\left(\mathrm{DMSO}-d_{6}\right): \delta 1.11\left(\mathrm{~s}, 9 \mathrm{H}, \mathrm{N}^{1}-\mathrm{POM}-\mathrm{CH}_{3}\right), 1.12\left(\mathrm{~s}, 9 \mathrm{H}, \mathrm{N}^{7}-\mathrm{POM}-\mathrm{CH}_{3}\right), 1.67-2.21(\mathrm{~m}$, $\left.10 \mathrm{H}, \mathrm{Cp}-\mathrm{CH}_{2}+\mathrm{N}^{3}-\mathrm{CH}_{2}-\mathrm{CH}_{2}\right), 3.43(\mathrm{~m}, 1 \mathrm{H}, \mathrm{Cp}-\mathrm{CH}), 4.13\left(\mathrm{t}, 2 \mathrm{H}, \mathrm{N}^{3}-\mathrm{CH}_{2}\right), 4.51$ (dt, J = 47.2, 5,7 $\left.\mathrm{Hz}, 2 \mathrm{H}, \mathrm{CH}_{2}-\mathrm{F}\right), 5.88\left(\mathrm{~s}, 2 \mathrm{H}, \mathrm{N}^{1}-\mathrm{POM}-\mathrm{CH}_{2}\right), 6.23$ (s, 2H, N $\left.{ }^{7}-\mathrm{POM}-\mathrm{CH}_{2}\right) .{ }^{13} \mathrm{C}-\mathrm{NMR}\left(\mathrm{DMSO}-d_{6}\right)$ : $\delta 26.2\left(\mathrm{Cp}-\mathrm{CH}_{2}\right), 27.4\left(\mathrm{POM}-\mathrm{CH}_{3}\right), 27.5\left(\mathrm{POM}-\mathrm{CH}_{3}\right), 29.5\left({ }^{2} \mathrm{~J}=19.2 \mathrm{~Hz}, \mathrm{CH}_{2}-\mathrm{CH}_{2} \mathrm{~F}\right), 32.9(\mathrm{Cp}-$ $\left.\mathrm{CH}_{2}\right), 36.4(\mathrm{Cp}-\mathrm{CH}), 39.1\left(\mathrm{POM}-\mathrm{C}\left(\mathrm{CH}_{3}\right)_{3}\right), 39.1\left({ }^{3} \mathrm{~J}=5.5 \mathrm{~Hz}, \mathrm{~N}^{3}-\mathrm{CH}_{2}\right), 39.2\left(\mathrm{POM}-\mathrm{C}\left(\mathrm{CH}_{3}\right)_{3}\right)$, $65.7\left(\mathrm{POM}-\mathrm{CH}_{2}\right), 68.1\left(\mathrm{POM}-\mathrm{CH}_{2}\right), 82.6\left({ }^{1} \mathrm{~J}=162.0 \mathrm{~Hz}, C \mathrm{H}_{2}-\mathrm{F}\right), 106.2\left(C^{5}\right), 149.2\left(C^{8}\right), 151.1$ $\left(C^{4}\right), 159.6\left(C^{2}\right), 161.1\left(C^{6}\right), 177.1(C=\mathrm{O}), 177.5(C=\mathrm{O}) .{ }^{19}$ F-NMR (DMSO- $\left.d_{6}\right): \delta-219.16 . \mathrm{MS}$ (ESI+) m/z: $[\mathrm{M}+\mathrm{H}]^{+}$Calcd for $\mathrm{C}_{25} \mathrm{H}_{37} \mathrm{FN}_{4} \mathrm{O}_{6}$ 509.58; Found 509.60.

\section{8-Cyclopentyl-3-(3-fluoropropyl)-1H-purine-2,6(3H,7H)-dione (12).}


A solution of $11(508 \mathrm{mg}, 1 \mathrm{mmol})$ in a mixture of EtOH $(10 \mathrm{~mL})$ and aqueous $\mathrm{NaOH}(2 \mathrm{~N}, 2 \mathrm{~mL}$, $4 \mathrm{mmol}$ ) was stirred at room temperature for $8 \mathrm{~h}$. Diluting the reaction mixture with water and neutralization with acetic acid precipitated the deprotected purine. Collecting the product by filtration, washing with water and drying furnished colourless crystals of 12. Yield $275 \mathrm{mg}(98 \%)$, mp 263-264 ${ }^{\circ} \mathrm{C}(50 \% \mathrm{MeOH})$. TLC: Rf 0.23.

${ }^{1} \mathrm{H}-\mathrm{NMR}\left(\mathrm{DMSO}-d_{6}\right): \delta 1.63-2.02\left(\mathrm{~m}, 10 \mathrm{H}, \mathrm{Cp}-\mathrm{CH}_{2}+\mathrm{N}^{3}-\mathrm{CH}_{2}-\mathrm{CH}_{2}\right), 3.14(\mathrm{~m}, 1 \mathrm{H}, \mathrm{Cp}-\mathrm{CH}), 4.04$ (t, 2H, N $\left.{ }^{3}-\mathrm{CH}_{2}\right), 4.48\left(\mathrm{dt}, J=47.2,5,7 \mathrm{~Hz}, 2 \mathrm{H}, \mathrm{CH}_{2}-\mathrm{F}\right), 10.98\left(\mathrm{~s}, 1 \mathrm{H}, \mathrm{N}^{1} H\right), 13.09\left(\mathrm{~s}, 1 \mathrm{H}, \mathrm{N}^{7} H\right)$. ${ }^{13} \mathrm{C}-\mathrm{NMR}\left(\mathrm{DMSO}-d_{6}\right): \delta 25.9\left(\mathrm{Cp}-\mathrm{CH}_{2}\right), 29.7\left({ }^{2} \mathrm{~J}=19.2 \mathrm{~Hz}, \mathrm{CH}_{2}-\mathrm{CH}_{2} \mathrm{~F}\right), 32.8\left(\mathrm{Cp}-\mathrm{CH}_{2}\right), 39.6$ $(\mathrm{Cp}-\mathrm{CH}), 39.7\left({ }^{3} J=5.5 \mathrm{~Hz}, \mathrm{~N}^{3}-C \mathrm{H}_{2}\right), 82.7\left({ }^{1} J=162.0 \mathrm{~Hz}, C \mathrm{H}_{2}-\mathrm{F}\right), 107.4\left(C^{5}\right), 150.1\left(C^{8}\right), 151.8$ $\left(C^{4}\right), 155.2\left(C^{2}\right), 158.6\left(C^{6}\right) .{ }^{19}$ F-NMR $\left(\mathrm{DMSO}-d_{6}\right): \delta-218.83$. MS (ESI+) m/z: $[\mathrm{M}+\mathrm{H}]^{+} \mathrm{Calcd}$ for $\mathrm{C}_{13} \mathrm{H}_{17} \mathrm{FN}_{4} \mathrm{O}_{2}$ 281.30; Found 281.32.

\section{8-Cyclopentyl-7-pivaloyloxymethyl-3-(3-fluoropropyl)-1H-purine-2,6(3H,7H)-dione (13).} A slurry of $12(2.8 \mathrm{~g}, 10 \mathrm{mmol})$ and $\mathrm{K}_{2} \mathrm{CO}_{3}(1.38 \mathrm{~g}, 10 \mathrm{mmol})$ in dry DMF (40 mL) was stirred for $0.5 \mathrm{~h}$ at ambient temperature. POM-Cl $(1.53 \mathrm{~mL}, 10.5 \mathrm{mmol})$ was added dropwise and the mixture was stirred at $60^{\circ} \mathrm{C}$ for $1 \mathrm{~h}$. The reaction mixture was poured into ice water, neutralized with $2 \mathrm{~N} \mathrm{HCl}$ and extracted with diethyl ether $(2 \times 100 \mathrm{~mL})$. Evaporation of the solvent gave semisolid material that was purified by flash chromatography eluting with $50 \%$ ethyl acetate in hexane. The 1,7-diPOM compound (100 mg) eluted first, followed by product 13. Evaporation of the solvent gave colourless crystals, $2.9 \mathrm{~g}(74 \%)$. An analytical sample was recrystallized from aqueous $80 \% \mathrm{MeOH}$, mp: $146-147^{\circ} \mathrm{C}(80 \% \mathrm{MeOH})$. TLC: Rf 0.35 .

${ }^{1} \mathrm{H}-\mathrm{NMR}\left(\mathrm{DMSO}-d_{6}\right): \delta 1.12\left(\mathrm{~s}, 9 \mathrm{H}, \mathrm{N}^{7}-\mathrm{POM}-\mathrm{CH}_{3}\right), 1.64-2.12\left(\mathrm{~m}, 10 \mathrm{H}, \mathrm{Cp}-\mathrm{CH}_{2}+\mathrm{N}^{3}-\mathrm{CH}_{2}-\right.$ $\left.\mathrm{CH}_{2}\right), 3.38$ (m, 1H, Cp-CH), $4.04\left(\mathrm{t}, 2 \mathrm{H}, \mathrm{N}^{3}-\mathrm{CH}_{2}\right), 4.51\left(\mathrm{dt}, J=47.2,5,7 \mathrm{~Hz}, 2 \mathrm{H}, \mathrm{CH}_{2}-\mathrm{F}\right), 6.19$ (s, $\left.2 \mathrm{H}, \mathrm{N}^{7}-\mathrm{POM}-\mathrm{CH}_{2}\right), 11.16\left(\mathrm{~s}, 1 \mathrm{H}, \mathrm{N}^{1}-H\right) .{ }^{13} \mathrm{C}-\mathrm{NMR}$ (DMSO- $\left.d_{6}\right): \delta 26.1\left(\mathrm{Cp}-\mathrm{CH}_{2}\right), 27.4(\mathrm{POM}-$ $\left.\left.\mathrm{CH}_{3}\right)\right), 29.6\left({ }^{2} \mathrm{~J}=19.2 \mathrm{~Hz}, \mathrm{CH}_{2}-\mathrm{CH}_{2} \mathrm{~F}\right), 33\left(\mathrm{Cp}-\mathrm{CH}_{2}\right), 36.4(\mathrm{Cp}-\mathrm{CH}), 39\left(\mathrm{~N}^{7}-\mathrm{POM}-\mathrm{C}\left(\mathrm{CH}_{3}\right)_{3}\right), 39.5$ $\left({ }^{3} J=5.5 \mathrm{~Hz}, \mathrm{~N}^{3}-C \mathrm{H}_{2}\right), 68\left(\mathrm{POM}-C \mathrm{H}_{2}\right), 82.7\left({ }^{1} J=162.0 \mathrm{~Hz}, C \mathrm{H}_{2}-\mathrm{F}\right), 106.9\left(C^{5}\right), 149.85\left(C^{8}\right)$, 151.4 $\left(C^{4}\right), 155.1\left(C^{2}\right), 160.1\left(C^{6}\right), 177.2(C=\mathrm{O}) .{ }^{19}$ F-NMR (DMSO- $\left.d_{6}\right): \delta-218.96 . \mathrm{MS}(\mathrm{ESI}+)$ $\mathrm{m} / \mathrm{z}:[\mathrm{M}+\mathrm{H}]^{+}$Calcd for $\mathrm{C}_{19} \mathrm{H}_{27} \mathrm{FN}_{4} \mathrm{O}_{4}$ 395.44; Found 395.45. 


\section{8-Cyclopentyl-7-pivaloyloxymethyl-3-(3-fluoropropyl)-1-(3-hydroxypropyl)-1H-purine- 2,6(3H,7H)-dione (14a).}

A mixture of $\mathrm{K}_{2} \mathrm{CO}_{3}(166 \mathrm{mg}, 1.2 \mathrm{mmol})$ and $13(394 \mathrm{mg}, 1 \mathrm{mmol})$ in dry DMF (5 mL) was stirred for $0.5 \mathrm{~h}, 1$-bromo-3-hydroxypropane $(134 \mu \mathrm{L}, 1.5 \mathrm{mmol})$ was added and the suspension was stirred at $70^{\circ} \mathrm{C}$ for $2 \mathrm{~h}$. After cooling to room temperature the mixture was poured into ice water $(100 \mathrm{~mL})$ and the aqueous solution was extracted with diethyl ether $(2 \mathrm{x} 75 \mathrm{~mL})$. The pooled organic extracts were washed with water $(100 \mathrm{~mL})$, dried over anhydrous $\mathrm{Na}_{2} \mathrm{SO}_{4}$, filtered and evaporated to give a clear, colourless oil. The addition of $40 \%$ aqueous methanol (1 mL) followed by scratching with a glass rod gave a semi-solid material which crystallized upon standing overnight in an open vial. Filtration and drying in air gave $\mathbf{1 4 a}$ that was pure by TLC as colourless, waxy crystals $450 \mathrm{mg}, 98 \%$, mp. 80-81 ${ }^{\circ} \mathrm{C}$. TLC: Rf 0.25.

${ }^{1} \mathrm{H}-\mathrm{NMR}\left(\mathrm{CDCl}_{3}\right): \delta 1.20\left(\mathrm{~s}, 9 \mathrm{H}, \mathrm{N}^{7}-\mathrm{POM}-\mathrm{CH}_{3}\right), 1.58-2.31\left(\mathrm{~m}, 12 \mathrm{H}, \mathrm{Cp}-\mathrm{CH}_{2}+\mathrm{N}^{1}-\mathrm{CH}_{2}-\mathrm{CH}_{2}+\right.$ $\left.\mathrm{N}^{3}-\mathrm{CH}_{2}-\mathrm{CH}_{2}\right), 3.25(\mathrm{~m}, 1 \mathrm{H}, \mathrm{Cp}-\mathrm{CH}), 3.53\left(\right.$ br s, $\left.3 \mathrm{H}, \mathrm{CH} \mathrm{H}_{2} \mathrm{OH}+\mathrm{OH}\right), 4.19+4.29\left(2 \mathrm{t}, 4 \mathrm{H}, \mathrm{N}^{1}-\mathrm{CH}_{2}\right.$ $\left.+\mathrm{N}^{3}-\mathrm{CH}_{2}\right), 4.53\left(\mathrm{dt}, J=47.2,5,7 \mathrm{~Hz}, 2 \mathrm{H}, \mathrm{CH}_{2}-\mathrm{F}\right), 6.24\left(\mathrm{~s}, 2 \mathrm{H}, \mathrm{N}^{7}-\mathrm{POM}-\mathrm{CH}_{2}\right) .{ }^{13} \mathrm{C}-\mathrm{NMR}$ $\left(\mathrm{CDCl}_{3}\right): \delta 26.2\left(\mathrm{Cp}-\mathrm{CH}_{2}\right), 27.3\left(\mathrm{POM}-\mathrm{CH}_{3}\right), 29.6\left({ }^{2} \mathrm{~J}=19.2 \mathrm{~Hz}, \mathrm{CH}_{2}-\mathrm{CH}_{2} \mathrm{~F}\right), 31.2\left(\mathrm{~N}^{1}-\mathrm{CH}_{2}-\right.$ $\left.\mathrm{CH}_{2}\right), 33.1\left(\mathrm{Cp}-\mathrm{CH}_{2}\right), 36.7(\mathrm{Cp}-\mathrm{CH}), 38.1\left(\mathrm{POM}-\mathrm{C}\left(\mathrm{CH}_{3}\right)_{3}\right), 40.7\left({ }^{3} \mathrm{~J}=5.5 \mathrm{~Hz}, \mathrm{~N}^{3}-\mathrm{CH}_{2}\right), 40.8\left(\mathrm{~N}^{1}-\right.$ $\left.\mathrm{CH}_{2}\right), 58.9\left(\mathrm{CH}_{2}-\mathrm{OH}\right), 66.9\left(\mathrm{POM}-\mathrm{CH}_{2}\right), 82.3\left({ }^{1} \mathrm{~J}=162.0 \mathrm{~Hz}, C \mathrm{H}_{2}-\mathrm{F}\right), 106.7\left(C^{5}\right), 148.75\left(C^{8}\right)$, $152\left(C^{4}\right), 155.5\left(C^{2}\right), 160.62\left(C^{6}\right), 177.7(C=\mathrm{O}) .{ }^{19} \mathrm{~F}-\mathrm{NMR}\left(\mathrm{CDCl}_{3}\right): \delta-220.48 . \mathrm{MS}(\mathrm{ESI}+) \mathrm{m} / \mathrm{z}$ : $[\mathrm{M}+\mathrm{H}]^{+}$Calcd for $\mathrm{C}_{22} \mathrm{H}_{33} \mathrm{FN}_{4} \mathrm{O}_{5} 453.52$; Found 453.54.

\section{8-Cyclopentyl-3-(3-fluoropropyl)-1-(3-hydroxypropyl)-1H-purine-2,6(3H,7H)-dione (15a).} A solution of 14a (452 mg, $1 \mathrm{mmol})$ in methanolic ammonia $(7 \mathrm{~N}, 20 \mathrm{~mL})$ was stirred for $72 \mathrm{~h}$ at room temperature. Evaporation and recrystallization of the residue from $80 \%$ aqueous $\mathrm{MeOH}$ yielded 15a as colorless crystals. Yield $285 \mathrm{mg}(84 \%)$, m.p. $213-214^{\circ} \mathrm{C}(80 \% \mathrm{MeOH})$. TLC: Rf 0.06 .

${ }^{1} \mathrm{H}-\mathrm{NMR}\left(\mathrm{DMSO}-d_{6}\right): \delta 1.55-2.21\left(\mathrm{~m}, 12 \mathrm{H}, \mathrm{Cp}-\mathrm{CH}_{2}+\mathrm{N}^{1}-\mathrm{CH}_{2}-\mathrm{CH}_{2}+\mathrm{N}^{3}-\mathrm{CH}_{2}-\mathrm{CH}_{2}\right), 3.14(\mathrm{~m}$, $1 \mathrm{H}, \mathrm{Cp}-\mathrm{CH}), 3.46\left(\mathrm{~m}, 2 \mathrm{H}, \mathrm{CH}_{2} \mathrm{OH}\right), 3.93+4.11\left(2 \mathrm{t}, 4 \mathrm{H}, \mathrm{N}^{1}-\mathrm{CH}_{2}+\mathrm{N}^{3}-\mathrm{CH}_{2}\right), 4.58(\mathrm{~m}+\mathrm{t}, \mathrm{J}=47.2$, $\left.5,7 \mathrm{~Hz}, 3 \mathrm{H}, \mathrm{CH}_{2}-\mathrm{F}+\mathrm{OH}\right), 13.13\left(\mathrm{~s}, 1 \mathrm{H}, \mathrm{N}^{7}-H\right) .{ }^{13} \mathrm{C}-\mathrm{NMR}\left(\mathrm{DMSO}-d_{6}\right): \delta 25.9\left(\mathrm{Cp}-\mathrm{CH}_{2}\right), 29.6\left({ }^{2} J\right.$ $\left.=19.2 \mathrm{~Hz}, \mathrm{CH}_{2}-\mathrm{CH}_{2} \mathrm{~F}\right), 31.9\left(\mathrm{~N}^{1}-\mathrm{CH}_{2}-\mathrm{CH}_{2}\right), 32.8\left(\mathrm{Cp}-\mathrm{CH}_{2}\right), 39.2\left(\mathrm{~N}^{1}-\mathrm{CH}_{2}\right), 39.6(\mathrm{Cp}-\mathrm{CH}), 59.7$ $\left(C \mathrm{H}_{2}-\mathrm{OH}\right), 82.8\left({ }^{1} J=162.0 \mathrm{~Hz}, C \mathrm{H}_{2}-\mathrm{F}\right), 107.1\left(C^{5}\right), 148.4\left(C^{8}\right), 151.6\left(C^{4}\right), 154.8\left(C^{2}\right), 158.7$ 
$\left(C^{6}\right) .{ }^{19} \mathrm{~F}-\mathrm{NMR}\left(\mathrm{DMSO}-d_{6}\right): \delta-218.84$. MS (ESI+) $\mathrm{m} / \mathrm{z}:[\mathrm{M}+\mathrm{H}]^{+}$Calcd for $\mathrm{C}_{16} \mathrm{H}_{23} \mathrm{FN}_{4} \mathrm{O}_{3} 339.38$; Found 339.39.

\section{8-Cyclopentyl-3-(3-fluoropropyl)-1-(3-oxopropyl)-1H-purine-2,6(3H,7H)-dione (15b).} A mixture of 8-cyclopentyl-3-(3-fluoropropyl)-7-pivaloyloxymethylxanthine 13 (197 mg, 0.5 $\mathrm{mmol})$ and $\mathrm{K}_{2} \mathrm{CO}_{3}(83 \mathrm{mg}, 0.6 \mathrm{mmol})$ in dry DMF $(5 \mathrm{~mL})$ was stirred for $0.5 \mathrm{~h}$, then 2bromoethyl-1,3-dioxolane ( $88 \mu \mathrm{L}, 0.75 \mathrm{mmol})$ and a catalytic amount of KI (25 $\mathrm{mg})$ were added, and the suspension was stirred at room temperature for $24 \mathrm{~h}$. The mixture was poured onto icewater $(100 \mathrm{~mL})$ and the aqueous solution was extracted with diethyl ether $(2 \mathrm{x} 75 \mathrm{~mL})$. The pooled organic extracts were washed with water $(100 \mathrm{~mL})$, dried over anhydrous $\mathrm{Na}_{2} \mathrm{SO}_{4}$, filtered and evaporated in vacuo to give a clear yellow oil. The oil was dissolved in EtOH (10 mL) and $2 \mathrm{~N}$ aqueous $\mathrm{NaOH}$ ( $1 \mathrm{~mL}, 2 \mathrm{mmol}$ ) was added. After stirring for $1 \mathrm{~h}$ at room temperature the mixture was poured into ice-water $(100 \mathrm{~mL})$, acidified to $\mathrm{pH} 4$ by the addition of $2 \mathrm{~N}$ aqueous $\mathrm{HCl}$, and extracted with diethyl ether $(2 \times 100 \mathrm{~mL})$. The pooled organic phases were dried over anhydrous $\mathrm{Na}_{2} \mathrm{SO}_{4}$, filtered and the solvent evaporated in vacuo to give a colourless powder. This was taken up in $0.5 \mathrm{~N}$ aqueous $\mathrm{HCl}(10 \mathrm{~mL})$ and the turbid mixture was stirred $2 \mathrm{~h}$ at reflux. After cooling the solution was adjusted to $\mathrm{pH} 5-6$ with $1 \mathrm{~N}$ aqueous $\mathrm{NaOH}$ and precipitated $\mathbf{1 5 b}$ was extracted into dichloromethane $(2 \times 25 \mathrm{~mL})$. The pooled organic extracts were washed with water $(50 \mathrm{~mL})$, dried over anhydrous $\mathrm{Na}_{2} \mathrm{SO}_{4}$, filtered and evaporated to leave a solid residue. Recrystallization from 50\% aqueous $\mathrm{MeOH}$ gave off-white crystals. Yield $148 \mathrm{mg}(88 \%)$, m.p. $223-224^{\circ} \mathrm{C}(50 \%$ MeOH. ${ }^{1} \mathrm{H}-\mathrm{NMR}\left(\mathrm{CDCl}_{3}\right): \delta 1.51-2.19\left(\mathrm{~m}, 10 \mathrm{H}, \mathrm{Cp}-\mathrm{CH}_{2}+\mathrm{N}^{3}-\mathrm{CH}_{2}-\mathrm{CH}_{2}\right), 2.83\left(\mathrm{~m}, 3 \mathrm{H}, \mathrm{N}^{1}-\mathrm{CH}_{2}-\right.$ $\left.\mathrm{CH}_{2}\right), 3.24(\mathrm{~m}, 1 \mathrm{H}, \mathrm{Cp}-\mathrm{CH}), 4.32\left(\mathrm{t}, 2 \mathrm{H}, \mathrm{N}^{3}-\mathrm{CH}_{2}\right), 4.57\left(\mathrm{dm}, J=47.2,5,7 \mathrm{~Hz}, 4 \mathrm{H}, \mathrm{CH}_{2}-\mathrm{F}+\mathrm{N}^{1}-\right.$ $\left.\mathrm{CH}_{2}\right), 9.87(\mathrm{~s}, 1 \mathrm{H}, \mathrm{CHO}), 12.28\left(\mathrm{~s}_{\mathrm{br}}, 1 \mathrm{H}, \mathrm{N}^{7}-\mathrm{H}\right) .{ }^{13} \mathrm{C}-\mathrm{NMR}\left(\mathrm{CDCl}_{3}\right): \delta 25.8\left(\mathrm{Cp}-\mathrm{CH}_{2}\right), 29.5\left({ }^{2} J=\right.$ $\left.19.2 \mathrm{~Hz}, \mathrm{CH}_{2}-\mathrm{CH}_{2} \mathrm{~F}\right), 32.8\left(\mathrm{Cp}-\mathrm{CH}_{2}\right), 36.1\left(\mathrm{~N}^{1}-\mathrm{CH}_{2}\right), 40.2(\mathrm{Cp}-\mathrm{CH}), 40.9\left({ }^{3} \mathrm{~J}=5.5 \mathrm{~Hz}, \mathrm{~N}^{3}-C \mathrm{H}_{2}\right)$, $43\left(\mathrm{~N}^{1}-\mathrm{CH}_{2}-\mathrm{CH}_{2}\right), 82.3\left({ }^{1} J=162.0 \mathrm{~Hz}, C \mathrm{CH}_{2}-\mathrm{F}\right), 106.9\left(C^{5}\right), 149.6\left(C^{8}\right), 151.3\left(C^{4}\right), 155.6\left(C^{2}\right)$, $160.3\left(C^{6}\right), 200.4(C=\mathrm{O}) .{ }^{19} \mathrm{~F}-\mathrm{NMR}\left(\mathrm{CDCl}_{3}\right): \delta$ - 220.50. MS (ESI+) m/z: $[\mathrm{M}+\mathrm{H}]^{+} \mathrm{Calcd}$ for $\mathrm{C}_{16} \mathrm{H}_{21} \mathrm{FN}_{4} \mathrm{O}_{3}$ 337.36; Found 337.38.

8-Cyclopentyl-3-(3-fluoropropyl)-1-(2-oxopropyl)-1H-purine-2,6(3H,7H)-dione (15c). 
A mixture of 13 (197 mg, $0.5 \mathrm{mmol})$ in dry DMF (5 mL) and $\mathrm{K}_{2} \mathrm{CO}_{3}(83 \mathrm{mg}, 0.6 \mathrm{mmol})$ was stirred for $0.5 \mathrm{~h}$, chloroacetone $(60 \mu \mathrm{L}, 0.75 \mathrm{mmol})$ was added, and the suspension was stirred at ambient temperature for $24 \mathrm{~h}$. The mixture was poured onto ice water $(100 \mathrm{~mL})$ and the water was extracted with diethyl ether $(2 \times 75 \mathrm{~mL})$. The pooled organic extracts were washed with water (100 mL), dried over anhydrous $\mathrm{Na}_{2} \mathrm{SO}_{4}$, filtered and evaporated to a clear yellow oil. The oil was dissolved in $\mathrm{EtOH}(10 \mathrm{~mL})$ and $2 \mathrm{~N}$ aqueous $\mathrm{NaOH}(1 \mathrm{~mL}, 2 \mathrm{mmol})$ was added. After stirring for $4 \mathrm{~h}$ at ambient temperature the mixture was poured into ice water $(100 \mathrm{~mL})$, acidified to $\mathrm{pH} 4$ by the addition of $2 \mathrm{~N}$ aqueous $\mathrm{HCl}$, and extracted with ethyl acetate $(3 \times 100 \mathrm{~mL})$. The pooled organic phases were dried over anhydrous $\mathrm{Na}_{2} \mathrm{SO}_{4}$, filtered and the solvent was evaporated to a colorless powder that was extracted with ethyl acetate $(5 \mathrm{~mL})$. Filtration and air-drying provided 15c as colorless crystals. Yield $132 \mathrm{mg}(78 \%)$, m.p. $216-218^{\circ} \mathrm{C}$. TLC: Rf 0.21.

${ }^{1} \mathrm{H}-\mathrm{NMR}$ (DMSO-d $)_{6}$ : $\delta 1.03\left(\mathrm{~d}, 3 \mathrm{H}, \mathrm{CH}_{3}\right), 1.61-2.20\left(\mathrm{~m}, 10 \mathrm{H}, \mathrm{Cp}-\mathrm{CH}_{2}+\mathrm{N}^{3}-\mathrm{CH}_{2}-\mathrm{CH}_{2}\right), 2.20(\mathrm{~s}$, $\left.3 \mathrm{H}, \mathrm{CH}_{3}\right), 3.16(\mathrm{~m}, 1 \mathrm{H}, \mathrm{Cp}-\mathrm{CH}), 4.07\left(\mathrm{t}, 2 \mathrm{H}, \mathrm{N}^{3}-\mathrm{CH}_{2}\right), 4.26\left(\mathrm{dt}, J=47.2,5,7 \mathrm{~Hz}, 2 \mathrm{H}, \mathrm{CH}_{2}-\mathrm{F}\right)$, $4.75\left(\mathrm{~s}, 2 \mathrm{H}, \mathrm{N}^{1}-\mathrm{CH}_{2}\right), 13.21\left(\mathrm{sbr}, 1 \mathrm{H}, \mathrm{N}^{7}-H\right) .{ }^{13} \mathrm{C}-\mathrm{NMR}\left(\mathrm{DMSO}-d_{6}\right): \delta 25.9\left(\mathrm{Cp}-\mathrm{CH}_{2}\right), 27.9\left(\mathrm{CH}_{3}\right)$, $29.6\left({ }^{2} \mathrm{~J}=19.2 \mathrm{~Hz}, \mathrm{CH}_{2}-\mathrm{CH}_{2} \mathrm{~F}\right), 32.8\left(\mathrm{Cp}-\mathrm{CH}_{2}\right), 39.7(\mathrm{Cp}-\mathrm{CH}), 40.5\left({ }^{3} \mathrm{~J}=5.5 \mathrm{~Hz}, \mathrm{~N}^{3}-\mathrm{CH}_{2}\right), 50.7$ $\left(\mathrm{N}^{1}-C \mathrm{H}_{2}\right), 82.6\left({ }^{1} J=162 \mathrm{~Hz}, C \mathrm{H}_{2}-\mathrm{F}\right), 106.8\left(C^{5}\right), 149.5\left(C^{8}\right), 151.4\left(C^{4}\right), 154.2\left(C^{2}\right), 159.3\left(C^{6}\right)$, 203.1 $(C=\mathrm{O}) .{ }^{19} \mathrm{~F}-\mathrm{NMR}\left(\mathrm{DMSO}-d_{6}\right): \delta$-218.94. MS (ESI+) m/z: $[\mathrm{M}+\mathrm{H}]^{+}$Calcd for $\mathrm{C}_{16} \mathrm{H}_{21} \mathrm{FN}_{4} \mathrm{O}_{3}$ 337.36; Found 337.36.

\section{(士)-8-Cyclopentyl-3-(3-fluoropropyl)-1-(2-hydroxypropyl)-1H-purine-2,6(3H,7H)-dione} (15d).

$\mathrm{K}_{2} \mathrm{CO}_{3}$ (166 mg, $\left.1.2 \mathrm{mmol}\right)$ was added to a solution of 13 (394 mg, $\left.1 \mathrm{mmol}\right)$ in dry DMF (5 mL) and the mixture was stirred for $0.5 \mathrm{~h}$. Chloroacetone $(120 \mu \mathrm{L}, 1.5 \mathrm{mmol})$ was added, and the suspension was stirred at ambient temperature for $24 \mathrm{~h}$. The mixture was poured onto ice water $(100 \mathrm{~mL})$ and the aqueous solution was extracted with diethyl ether $(2 \times 75 \mathrm{~mL})$. The pooled organic extracts were washed with water $(100 \mathrm{~mL})$, dried over anhydrous $\mathrm{Na}_{2} \mathrm{SO}_{4}$, filtered and evaporated in vacuo to give a clear yellow oil. The oil was dissolved in dry $\mathrm{MeOH}(10 \mathrm{~mL})$ and under stirring $\mathrm{NaBH}_{4}(45 \mathrm{mg}, 1.2 \mathrm{mmol}$ ) was added in three portions over $15 \mathrm{~min}$. The mixture was stirred for $0.5 \mathrm{~h}$ longer, methanolic ammonia $(7 \mathrm{~N}, 30 \mathrm{~mL})$ was added and the mixture was stirred for $48 \mathrm{~h}$ at ambient temperature. The solvent was evaporated, the residue was taken up in 
ethyl acetate, the organic layer washed with water, dried over anhydrous $\mathrm{Na}_{2} \mathrm{SO}_{4}$, filtered, and evaporated. Recrystallization from $80 \%$ aqueous $\mathrm{MeOH}$ gave $\mathbf{1 5 d}$ as colorless crystals. Yield 300 mg (88\%), m.p. $209-210^{\circ} \mathrm{C}(80 \% \mathrm{MeOH})$. TLC: Rf 0.11.

${ }^{1} \mathrm{H}-\mathrm{NMR}\left(\mathrm{DMSO}-d_{6}\right): \delta 1.03\left(\mathrm{~d}, 3 \mathrm{H}, \mathrm{CH}_{3}\right), 1.58-2.31\left(\mathrm{~m}, 10 \mathrm{H}, \mathrm{Cp}-\mathrm{CH}_{2}+\mathrm{N}^{3}-\mathrm{CH}_{2}-\mathrm{CH}_{2}\right), 3.15$ $(\mathrm{m}, 1 \mathrm{H}, \mathrm{Cp}-\mathrm{CH}), 3.72(\mathrm{~m}, 1 \mathrm{H}, \mathrm{CHOH}), 3.95+4.09\left(2 \mathrm{t}, 4 \mathrm{H}, \mathrm{N}^{1}-\mathrm{CH}_{2}+\mathrm{N}^{3}-\mathrm{CH}_{2}\right), 4.52(\mathrm{dm}, J=$ 47.2, 5,7 Hz, 3H, $\left.\mathrm{CH}_{2}-\mathrm{F}+\mathrm{OH}\right), 12.82\left(\mathrm{~s}_{\mathrm{br}}, 1 \mathrm{H}, \mathrm{N}^{7}-\mathrm{H}\right) .{ }^{13} \mathrm{C}-\mathrm{NMR}\left(\mathrm{DMSO}-d_{6}\right): \delta 21.8\left(\mathrm{CH}_{3}\right), 25.9$ $\left(\mathrm{Cp}-\mathrm{CH}_{2}\right), 29.6\left({ }^{2} \mathrm{~J}=19.2 \mathrm{~Hz}, \mathrm{CH}_{2}-\mathrm{CH}_{2} \mathrm{~F}\right), 32.8\left(\mathrm{Cp}-\mathrm{CH}_{2}\right), 39.7(\mathrm{Cp}-\mathrm{CH}), 40.4\left({ }^{3} \mathrm{~J}=5.5 \mathrm{~Hz}, \mathrm{~N}^{3}-\right.$ $\left.\mathrm{CH}_{2}\right), 48.3\left(\mathrm{~N}^{1}-C \mathrm{H}_{2}\right), 64.4(C \mathrm{H}-\mathrm{OH}), 82.5\left({ }^{1} \mathrm{~J}=162.0 \mathrm{~Hz}, C \mathrm{H}_{2}-\mathrm{F}\right), 107.2\left(C^{5}\right), 148.4\left(C^{8}\right), 151.9$ $\left(C^{4}\right), 155.1\left(C^{2}\right), 158.6\left(C^{6}\right) .{ }^{19}$ F-NMR $\left(\right.$ DMSO-d $\left._{6}\right): \delta-218.80$ and $-218.93(5 \%)$. MS (ESI+) $\mathrm{m} / \mathrm{z}:[\mathrm{M}+\mathrm{H}]^{+}$Calcd for $\mathrm{C}_{16} \mathrm{H}_{23} \mathrm{FN}_{4} \mathrm{O}_{3} 339.38$; Found 339.38.

\section{( \pm )-8-Cyclopentyl-3-(3-fluoro-2-hydroxypropyl)1-propyl-1H-purine-2,6(3H,7H)-dione (17).}

A mixture of 8-cyclopentyl-1-propyl-7-pivaloyloxymethylxanthine 16 (197 mg, $0.5 \mathrm{mmol}){ }^{15}$ $\mathrm{K}_{2} \mathrm{CO}_{3}(4 \mathrm{mg}, 0.005 \mathrm{mmol}, 5 \mathrm{~mol} \%)$ and epifluorohydrin $(53 \mu \mathrm{L}, 0.75 \mathrm{mmol})$ in dry DMF (10 $\mathrm{mL})$ was stirred at $75^{\circ} \mathrm{C}$ for $6 \mathrm{~h},{ }^{14}$ cooled to ambient temperature, poured onto ice-water (150 $\mathrm{mL})$, and extracted with diethylether $(2 \times 50 \mathrm{~mL})$. The oil obtained by vacuum evaporation and azeotroping with acetonitrile $(2 \times 20 \mathrm{~mL})$ was dissolved in $\mathrm{EtOH}(10 \mathrm{~mL})$ containing $2 \mathrm{~N}$ aqueous $\mathrm{NaOH}(1 \mathrm{~mL}, 2 \mathrm{mmol})$. The mixture was stirred at ambient temperature for $2 \mathrm{~h}$, poured onto icewater $(150 \mathrm{~mL})$, acidified to $\mathrm{pH} 5-6$ by the addition of $0.5 \mathrm{~N}$ aqueous $\mathrm{HCl}$, and extracted with dichloromethane $(2 \times 50 \mathrm{~mL})$. Drying of the combined organic reaper dawlayers over anhydrous $\mathrm{Na}_{2} \mathrm{SO}_{4}$, filtration and rotary evaporation of the solvent in vacuo gave $\mathbf{1 7}$ as a solid residue that was recrystallized 2 times from ethyl acetate. Yield $152 \mathrm{mg}(89 \%)$, colourless crystals, m.p. 212$213^{\circ} \mathrm{C}$ (ethyl acetate). TLC: Rf 0.51 .

${ }^{1} \mathrm{H}-\mathrm{NMR}\left(\mathrm{DMSO}-d_{6}\right): \delta 0.86\left(\mathrm{t}, J=7.4 \mathrm{~Hz}, 3 \mathrm{H}, \mathrm{CH}_{3}\right), 1.54-2.17\left(\mathrm{~m}, 10 \mathrm{H}, \mathrm{Cp}-\mathrm{CH}_{2}+\mathrm{N}^{1}-\mathrm{CH}_{2}-\right.$ $\left.\mathrm{CH}_{2}\right), 3.14(\mathrm{~m}, J=7.9 \mathrm{~Hz}, 1 \mathrm{H}, \mathrm{Cp}-\mathrm{CH}), 3.72(\mathrm{~m}, 1 \mathrm{H}, \mathrm{CH}-\mathrm{OH}), 3.69-5.58\left(\mathrm{~m}, 7 \mathrm{H}, \mathrm{N}^{1}-\mathrm{CH}_{2}+\mathrm{N}^{3}-\right.$ $\left.\mathrm{CH}_{2}+\mathrm{CH}_{2}-\mathrm{F}+\mathrm{CH}-\mathrm{OH}\right), 5.37\left(\mathrm{~s}_{\mathrm{br}}, 1 \mathrm{H}, \mathrm{CH}-\mathrm{OH}\right), 12.82\left(\mathrm{~s}_{\mathrm{br}}, 1 \mathrm{H}, \mathrm{N}^{7}-H\right) .{ }^{13} \mathrm{C}-\mathrm{NMR}\left(\mathrm{DMSO}-d_{6}\right): \delta$ $12.1\left(\mathrm{CH}_{3}\right), 21.7\left(\mathrm{~N}^{1}-\mathrm{CH}_{2}-\mathrm{CH}_{2}\right), 25.9\left(\mathrm{Cp}-\mathrm{CH}_{2}\right), 32.8\left(\mathrm{Cp}-\mathrm{CH}_{2}\right), 39.7(\mathrm{Cp}-\mathrm{CH}), 42.9\left(\mathrm{~N}^{1}-\mathrm{CH}_{2}\right)$, $45.9\left(\mathrm{~N}^{3}-\mathrm{CH}_{2}\right), 67.3(\mathrm{CH}-\mathrm{OH}), 86.1\left({ }^{1} \mathrm{~J}=162.0 \mathrm{~Hz}, C \mathrm{H}_{2}-\mathrm{F}\right), 107.1\left(C^{5}\right), 148.7\left(C^{8}\right), 151.8\left(C^{4}\right)$, $154.8\left(C^{2}\right), 158.5\left(C^{6}\right) .{ }^{19} \mathrm{~F}-\mathrm{NMR}\left(\mathrm{DMSO}-d_{6}\right): \delta$-227.92. MS (ESI+) m/z: $[\mathrm{M}+\mathrm{H}]^{+}$Calcd for $\mathrm{C}_{16} \mathrm{H}_{23} \mathrm{FN}_{4} \mathrm{O}_{3}$ 339.38; Found 339.39. 


\section{N-(6-Amino-1-(2,4-dimethoxybenzyl)-2,4-dioxo-3-propyl-1,2,3,4-tetrahydro-pyrimidin-5-yl)- cyclopent-3-enecarboxamide (19a).}

At ambient temperature the DMB protected diamine 18 (3.34 g, $10 \mathrm{mmol})$ was suspended in a mixture of dioxane $(100 \mathrm{~mL})$ and water $(40 \mathrm{~mL}) .{ }^{16}$ Under efficient stirring 1-(3dimethylaminopropyl)-3-ethylcarbodiimide hydrochloride (EDAC, $1.92 \mathrm{~g}, 10 \mathrm{mmol}$ ) and a catalytic amount ( $150 \mathrm{mg}$ ) of 4-dimethylaminopyridine (DMAP) was added. After the addition of 3-cyclopentene-1-carboxylic acid $(1.12 \mathrm{~g}, 10 \mathrm{mmol})$ the mixture was stirred for $24 \mathrm{~h}$ and poured onto ice-water $(150 \mathrm{~mL})$. The formed yellow precipitate was collected by filtration, washed with water $(50 \mathrm{~mL})$, and recrystallized from $\mathrm{MeOH}$. Yield $2.9 \mathrm{~g}(65 \%)$, m.p. $189^{\circ} \mathrm{C}$ $(\mathrm{MeOH})$.

${ }^{1} \mathrm{H}-\mathrm{NMR}\left(\mathrm{CDCl}_{3}\right): \delta 0.98\left(\mathrm{t}, J=7.4 \mathrm{~Hz}, 3 \mathrm{H}, \mathrm{CH}_{3}\right), 1.71\left(\mathrm{~m}, J=7.4 \mathrm{~Hz}, 2 \mathrm{H}, \mathrm{CH}_{3}-\mathrm{CH}_{2}\right), 2.72(\mathrm{~d}, J$ $\left.=7.9 \mathrm{~Hz}, 4 \mathrm{H}, \mathrm{Cp}-\mathrm{CH}_{2}\right), 3.22(\mathrm{~m}, J=7.9 \mathrm{~Hz}, 1 \mathrm{H}, \mathrm{Cp}-H), 3.83\left(\mathrm{~s}, 3 \mathrm{H}, 4-\mathrm{OCH}_{3}\right), 3.94(\mathrm{~s}, 3 \mathrm{H}, 2-$ $\left.\mathrm{OCH}_{3}\right), 3.86\left(\mathrm{~m}, 2 \mathrm{H}, \mathrm{N}^{1}-\mathrm{CH}_{2}\right), 5.14$ (s, 2H, Ph-CH $), 5.72$ (s, 2H, Cpen-H), 6.14 (s, 2H, NH$H_{2}$, 6.50 (dd, $J=8.4,2.4$ Hz, 1H, Ph-H-5), 6.57 (d, $J=2.3$ Hz, 1H, Ph- H-3), 7.39 (s, 1H, -NH-), 7.57 $(\mathrm{d}, J=8.4 \mathrm{~Hz}, 1 \mathrm{H}, \mathrm{Ph}-\mathrm{H}-6) .{ }^{13} \mathrm{C}-\mathrm{NMR}\left(\mathrm{CDCl}_{3}\right): \delta 11.4\left(\mathrm{CH}_{3}\right), 21.2\left(\mathrm{CH}_{3}-\mathrm{CH}_{2}\right), 37.1(\mathrm{Cp}-\mathrm{CH})$, $37.4\left(\mathrm{Cp}-\mathrm{CH}_{2}\right), 39.8\left(\mathrm{Ph}-\mathrm{CH}_{2}\right), 43.5\left(\mathrm{~N}^{1}-\mathrm{CH}_{2}\right), 55.5\left(4-\mathrm{OCH}_{3}\right), 55.8\left(2-\mathrm{OCH}_{3}\right), 92.1\left(C^{5}\right), 98.5$ $\left(\mathrm{Ph}-C^{3}\right), 106.1\left(\mathrm{Ph}-C^{5}\right), 115.8\left(\mathrm{Ph}-C^{1}\right), 129.2(\mathrm{Cpen}-C), 132.2\left(\mathrm{Ph}-C^{6}\right), 147.8\left(\mathrm{C}^{2}\right), 151.2$ $\left(C^{6}\right), 156.7\left(C^{4}\right), 159.8\left(\mathrm{Ph}-C^{2}\right), 161.2\left(\mathrm{Ph}-C^{4}\right) 176.1(C=\mathrm{O})$. MS $(\mathrm{ESI}+) \mathrm{m} / \mathrm{z}:[\mathrm{M}+\mathrm{H}]^{+}$Calcd for $\mathrm{C}_{22} \mathrm{H}_{28} \mathrm{~N}_{4} \mathrm{O}_{5} 429.21$; Found 429.23.

\section{N-(6-Amino-1-(2,4-dimethoxybenzyl)-2,4-dioxo-3-propyl-1,2,3,4-tetrahydro-pyrimidin-5-yl)- cyclopent-1-enecarboxamide (19b).}

At ambient temperature the DMB protected diamine $18(3.34 \mathrm{~g}, 10 \mathrm{mmol})$ was suspended in a mixture of dioxane $(100 \mathrm{~mL})$ and water $(40 \mathrm{~mL}) .{ }^{16}$ Under efficient stirring 1-(3dimethylaminopropyl)-3-ethylcarbodiimide hydrochloride (EDAC, $1.92 \mathrm{~g}, 10 \mathrm{mmol}$ ) and a catalytic amount (150 mg) of 4-dimethylaminopyridine (DMAP) was added. After the addition of 3-cyclopentene-1-carboxylic acid $(1.12 \mathrm{~g}, 10 \mathrm{mmol})$ the mixture was stirred for $24 \mathrm{~h}$ and poured onto ice-water $(150 \mathrm{~mL})$. The formed yellow precipitate was collected by centrifugation, washed 
with water $(50 \mathrm{~mL})$, and dried. Yield $2.9 \mathrm{~g}(65 \%)$, m.p. $183-184^{\circ} \mathrm{C}$. Very insoluble material. MS (ESI+) m/z: [M+H] ${ }^{+}$Calcd for $\mathrm{C}_{22} \mathrm{H}_{28} \mathrm{~N}_{4} \mathrm{O}_{5} 429.21$; Found 429.21 .

\section{8-(Cyclopent-3-enyl)-3-(2,4-dimethoxybenzyl)-1-propyl-1H-purine-2,6(3H,7H)-dione (20a).} A mixture of carboxamide 19a $(4.3 \mathrm{~g}, 10 \mathrm{mmol})$ in $2 \mathrm{~N} \mathrm{NaOH}(50 \mathrm{~mL}, 100 \mathrm{mmol})$ and dioxane $\left(40 \mathrm{~mL}\right.$ ) was stirred at $85^{\circ} \mathrm{C}$ for $12 \mathrm{~h}$. Acidification to $\mathrm{pH} 4$ with concentrated aqueous $\mathrm{HCl}$ precipitated a solid that was collected by filtration, washed with water, and recrystallized from ethanol to furnish the title xanthine as yellow crystals. Yield $3.44 \mathrm{~g}(84 \%)$, m.p. $250-251^{\circ} \mathrm{C}$ (EtOH).

${ }^{1} \mathrm{H}-\mathrm{NMR}\left(\mathrm{CDCl}_{3}\right): \delta 0.87\left(\mathrm{t}, J=7.4 \mathrm{~Hz}, 3 \mathrm{H}, \mathrm{CH}_{3}\right), 1.58\left(\mathrm{~m}, J=7.4 \mathrm{~Hz}, 2 \mathrm{H}, \mathrm{CH}_{3}-\mathrm{CH}_{2}\right), 2.68(\mathrm{~m}, J$ $\left.=7.9 \mathrm{~Hz}, 4 \mathrm{H}, \mathrm{Cp}-\mathrm{CH}_{2}\right), 3.51(\mathrm{~m}, J=7.9 \mathrm{~Hz}, 1 \mathrm{H}, \mathrm{Cp}-\mathrm{H}), 3.71\left(\mathrm{~s}, 3 \mathrm{H}, 4-\mathrm{OCH}_{3}\right), 3.81(\mathrm{~s}, 3 \mathrm{H}, 2-$ $\mathrm{OCH}_{3}$ ), $3.86\left(\mathrm{~m}, 2 \mathrm{H}, \mathrm{N}^{1}-\mathrm{CH}_{2}\right.$ ), 5.09 (s, 2H, Ph-CH ${ }_{2}$ ), 5.67 (s, 2H, Cpen- $H$ ), 6.32 (dd, $J=8.4,2.4$ Hz, 1H, Ph-H-5), 6.46 (d, $J=2.3$ Hz, 1H, Ph-H-3), 6.72 (d, $J=8.4$ Hz, 1H, Ph- $H-6), 12.97$ ( $\mathrm{s}_{\mathrm{br}}$, $\left.1 \mathrm{H}, \mathrm{N}^{7}-\mathrm{H}\right) .{ }^{13} \mathrm{C}-\mathrm{NMR}\left(\mathrm{CDCl}_{3}\right): \delta 11.5\left(\mathrm{CH}_{3}\right), 21.3\left(\mathrm{CH}_{3}-\mathrm{CH}_{2}\right), 37.2(\mathrm{Cp}-\mathrm{CH}), 38.6\left(\mathrm{Cp}-\mathrm{CH}_{2}\right)$, $41.5\left(\mathrm{Ph}-\mathrm{CH}_{2}\right), 42.5\left(\mathrm{~N}^{1}-\mathrm{CH}_{2}\right), 55.4\left(4-\mathrm{OCH}_{3}\right), 55.6\left(2-\mathrm{OCH}_{3}\right), 98.4\left(\mathrm{Ph}-\mathrm{C}^{3}\right), 104.4\left(\mathrm{Ph}-\mathrm{C}^{5}\right), 106.9$ $\left(C^{5}\right), 117.3\left(\mathrm{Ph}-C^{1}\right), 127.3\left(\mathrm{Ph}-C^{6}\right), 129.4($ Cpen- $C), 148.4\left(C^{8}\right), 151.2\left(C^{4}\right), 154.5\left(C^{2}\right), 157.9$ $\left(C^{6}\right), 158.3\left(\mathrm{Ph}-C^{2}\right), 160.3\left(\mathrm{Ph}-C^{4}\right)$. MS (ESI+) m/z: $[\mathrm{M}+\mathrm{H}]^{+}$Calcd for $\mathrm{C}_{22} \mathrm{H}_{26} \mathrm{~N}_{4} \mathrm{O}_{4} 411.20$; Found 411.21 .

\section{8-(Cyclopent-1-enyl)-3-(2,4-dimethoxybenzyl)-1-propyl-1 $H$-purine-2,6(3H,7H)-dione (20b).} A mixture of carboxamide $19 \mathrm{~b}(4.3 \mathrm{~g}, 10 \mathrm{mmol})$ in $2 \mathrm{~N} \mathrm{NaOH}(50 \mathrm{~mL}, 100 \mathrm{mmol})$ and dioxane $\left(40 \mathrm{~mL}\right.$ ) was stirred at $85^{\circ} \mathrm{C}$ for $12 \mathrm{~h}$. Acidification to $\mathrm{pH} 4$ with concentrated aqueous $\mathrm{HCl}$ precipitated a solid that was collected by filtration, washed with water, and dried to furnish the title xanthine as orange-red crystals. Yield $2.95 \mathrm{~g}(72 \%)$, m.p. $280-281^{\circ} \mathrm{C}$. Very insoluble material. MS (ESI+) m/z: [M+H] ${ }^{+}$Calcd for $\mathrm{C}_{22} \mathrm{H}_{26} \mathrm{~N}_{4} \mathrm{O}_{4} 411.20$; Found 411.19.

cis-2-Benzyloxycyclopentane-1-carboxylic acid.

a) cis-Ethyl 2-benzyloxycyclopentane-1-carboxylate. ${ }^{17}$

Under argon benzyl-2,2,2-trichloroacetimidate $(4.45 \mathrm{~g}, 3.34 \mathrm{~mL}, 18 \mathrm{mmol})$ was added to a magnetically stirred solution of of cis-ethyl 2-hydroxycyclopentane-1-carboxylate (2.37 g, 2.21 
$\mathrm{mL}, 15 \mathrm{mmol})$ in a solvent mixture of dichloromethane $(10 \mathrm{~mL})$ and hexane $(20 \mathrm{~mL})$. After the addition of neat trifluoromethanesulfonic acid $(0.2 \mathrm{~mL})$ the clear yellow solution became turbid (slightly exothermic) and after $5 \mathrm{~min}$ the colour changed to light orange. The mixture was stirred at ambient temperature for $3 \mathrm{~h}$ (TLC Si 60, hexane / ethyl acetate, $80+20, \mathrm{R}_{\mathrm{f}} 0.75$ ), the formed solid was removed by filtration, and the filter cake was washed with a mixture of DCM and hexane $(10+20,2 \times 25 \mathrm{~mL})$. The combined filtrates were washed with sat. aqueous $\mathrm{NaHCO}_{3}(50$ $\mathrm{mL})$ and water $(50 \mathrm{~mL})$, the organic layer was dried over anhydrous $\mathrm{Na}_{2} \mathrm{SO}_{4}$, filtered and rotaevaporated in vacuo furnishing the title compound as a yellow oil (3.72 $\mathrm{g}$, quant.) that was used without further purification for the next step. An aliquot of the benzyl ether was purified by column chromatography on silica gel using $15 \%$ ethyl acetate in hexane as an eluent.

${ }^{1} \mathrm{H} \mathrm{NMR}\left(\mathrm{CDCl}_{3}\right): \delta 1.27\left(\mathrm{t}, J=7 \mathrm{~Hz}, 3 \mathrm{H}, \mathrm{CH}_{3}\right), 1.54-2.07\left(\mathrm{~m}, 6 \mathrm{H}\right.$, cyclopentane $\left.\mathrm{CH}_{2}\right), 2.93$ (ddd, $J=5.9,5.9,5.8 \mathrm{~Hz}, 1 \mathrm{H}, \mathrm{Cp}-\mathrm{C}-1-H), 4.07-4.31\left(\mathrm{~m}, 3 \mathrm{H}, \mathrm{CH}_{2} \mathrm{CH}_{3}+\mathrm{Cp}-\mathrm{C}-2-H\right), 4.50$ and 4.61 (AB system, $\left.J=12.2 \mathrm{~Hz}, 2 \mathrm{H}, \mathrm{CH}_{2} \mathrm{C}_{6} \mathrm{H}_{5}\right), 7.21-7.47\left(\mathrm{~m}, 5 \mathrm{H}, \mathrm{C}_{6} H_{5}\right) ;{ }^{13} \mathrm{C} \mathrm{NMR}_{\left(\mathrm{CDCl}_{3}\right): \delta}$ $14.3,22.1,25.5,31.1,49.6,60.3,71.1,81.7,127.4,128.2,128.4,138.7,172.8$.

b) cis-2-Benzyloxycyclopentane-1-carboxylic acid.

A solution of crude cis-ethyl 2-benzyloxycyclopentane-1-carboxylate (4.96 g, $20 \mathrm{mmol}$ ) and 4M $\mathrm{NaOH}(20 \mathrm{~mL}, 80 \mathrm{mmol})$ in ethanol $(50 \mathrm{~mL})$ was stirred at ambient temperature for $48 \mathrm{~h}$. The reaction mixture was concentrated in vacuo $\left(40^{\circ} \mathrm{C}\right)$, water $(50 \mathrm{~mL})$ was added to the aqueous residue, and the resultant basic solution was extracted with diethyl ether $(2 \times 50 \mathrm{~mL})$. The aqueous layer was acidified to $\mathrm{pH} 1$ with aqueous $\mathrm{HCl}(10 \mathrm{~N}, 8.2 \mathrm{~mL}, 82 \mathrm{mmol})$, saturated with solid $\mathrm{NaCl}$, and extracted with DCM $(2 \times 50 \mathrm{~mL})$. The combined organic extracts were dried over anhydrous $\mathrm{Na}_{2} \mathrm{SO}_{4}$, filtered and rota-evaporated in vacuo providing the title compound $(2.42 \mathrm{~g}, 67 \%)$ as a yellow oil (TLC Si 60, hexane / ethyl acetate / acetic acid, $80+20+0.2$ ).

${ }^{1} \mathrm{H}$ NMR $\left(\mathrm{CDCl}_{3}\right): \delta 1.58-2.36\left(\mathrm{~m}, 6 \mathrm{H}\right.$, cyclopentane $\left.\mathrm{CH}_{2}\right), 2.92-3.03(\mathrm{~m}, 1 \mathrm{H}, \mathrm{Cp}-\mathrm{C}-1-H), 4.25$ - $4.36(\mathrm{~m}, 1 \mathrm{H}, \mathrm{Cp}-\mathrm{C}-2-H), 4.50-4.71\left(\mathrm{~m}, 2 \mathrm{H}, \mathrm{CH}_{2} \mathrm{C}_{6} \mathrm{H}_{5}\right), 7.24-7.48\left(\mathrm{~m}, 5 \mathrm{H}, \mathrm{C}_{6} \mathrm{H}_{5}\right), 10.92\left(\mathrm{~s}_{\mathrm{br}}\right.$, $1 \mathrm{H}, \mathrm{COOH}) ;{ }^{13} \mathrm{C} \mathrm{NMR}\left(\mathrm{CDCl}_{3}\right): \delta 23.6,28.6,31.1,50.7,71.5,83.5,127.4,128.2,128.4,138.2$, 181.7 . 
cis-8-(2-Benzyloxycyclopentyl)-3-(2,4-dimethoxybenzyl)-1-propyl-1H-purine-2,6(3H,7H)dione (20c).

Under an argon atmosphere neat isobutyl chloroformate $(10 \mathrm{mmol}, 1.3 \mathrm{~mL})$ and 4methylmorpholine (10 mmol, $1.1 \mathrm{~mL})$ were added to a well stirred ice cold solution of the DMB protected diamine $18(3.34 \mathrm{~g}, 10 \mathrm{mmol})$ in dry DMF $(30 \mathrm{~mL}) .{ }^{16}$ At this temperature a solution of 2-benzyloxycyclopentanecarboxylic acid (2.2 g, $10 \mathrm{mmol})$ in dry DMF (5 mL) was added dropwise. The mixture was stirred for $12 \mathrm{~h}$ and allowed to warm to ambient temperature during this time. The reaction mixture was poured onto ice-water $(150 \mathrm{~mL})$, the formed yellow precipitate was collected by filtration, washed with water $(50 \mathrm{~mL})$, and dried to give the intermediate carboxamide in $79 \%$ yield. The amide $(3.4 \mathrm{~g}, 6.5 \mathrm{mmol})$ was stirred for $12 \mathrm{~h}$ at $85^{\circ} \mathrm{C}$ in a mixture of $2 \mathrm{~N} \mathrm{NaOH}(32.5 \mathrm{~mL}, 65 \mathrm{mmol})$ and dioxane $(22 \mathrm{~mL})$. After cooling to ambient temperature acidification to $\mathrm{pH} 4$ with concentrated aqueous $\mathrm{HCl}$ precipitated a solid that was collected by filtration, washed with water, and recrystallized from ethanol to furnish the title xanthine as slightly red crystals. Yield $2.69 \mathrm{~g}(74 \%)$, m.p. $94-96^{\circ} \mathrm{C}(\mathrm{EtOH})$.

${ }^{1} \mathrm{H}-\mathrm{NMR}\left(\mathrm{DMSO}-d_{6}\right): \delta 0.88\left(\mathrm{t}, J=7.4 \mathrm{~Hz}, 3 \mathrm{H}, \mathrm{CH}_{3}\right), 1.46-2.17\left(\mathrm{~m}, 8 \mathrm{H}, \mathrm{CH}_{3}-\mathrm{CH}_{2}+\mathrm{Cp}-\mathrm{CH}_{2}\right)$, 3.01-3.26 (m, 1H, Cp-C-1-H), $3.71\left(\mathrm{~s}, 3 \mathrm{H}, 4-\mathrm{OCH}_{3}\right), 3.82\left(\mathrm{~s}, 3 \mathrm{H}, 2-\mathrm{OCH}_{3}\right), 3.87\left(\mathrm{~m}, 2 \mathrm{H}, \mathrm{N}^{1}-\mathrm{CH}_{2}\right)$, 4.08-4.23 (m, 1H, Cp-C-2-H), 4.38 (s, 2H, Ph-CH2-O), 5.07 (s, 2H, Ph-CH $H_{2}-\mathrm{N}$ ), 6.37 (dd, J = 8.4, $\left.2.4 \mathrm{~Hz}, 1 \mathrm{H}, \mathrm{N}-\mathrm{CH}_{2}-\mathrm{Ph}-H-5\right), 6.59$ (d, J=2.3 Hz, 1H, N-CH $\left.-\mathrm{Ph}-H-3\right), 6.72$ (d, J=8.4 Hz, 1H, N$\left.\mathrm{CH}_{2}-\mathrm{Ph}-H-6\right), 7.05-7.38$ (m, 5H, O-CH2 $-\mathrm{Ph}$ ), $13.30\left(\mathrm{~s}_{\mathrm{br}}, 1 \mathrm{H}, \mathrm{N}^{7}-H\right) .{ }^{13} \mathrm{C}-\mathrm{NMR}$ (DMSO- $\left.d_{6}\right): \delta 11.6$ $\left(\mathrm{CH}_{3}\right), 21.4\left(\mathrm{CH}_{3}-\mathrm{CH}_{2}\right), 23.0\left(\mathrm{Cp}-C^{4}\right), 30.8\left(\mathrm{Cp}-C^{5}\right), 31.9\left(\mathrm{Cp}-C^{3}\right), 41.6\left(\mathrm{~N}-C_{2}-\mathrm{Ph}\right), 42.6(\mathrm{~N}-$ $\left.\mathrm{CH}_{2}-\mathrm{CH}_{2}-\right), 45.9\left(\mathrm{Cp}-C^{1}\right), 55.6\left(4-\mathrm{OCH}_{3}\right), 55.9\left(2-\mathrm{OCH}_{3}\right), 70.8\left(\mathrm{O}-\mathrm{CH}_{2}-\mathrm{Ph}\right), 85.1\left(\mathrm{Cp}-C^{2}\right), 98.8$ $\left(\mathrm{N}-\mathrm{CH}_{2}-\mathrm{Ph}-C^{3}\right), 104.9\left(\mathrm{~N}-\mathrm{CH}_{2}-\mathrm{Ph}-C^{5}\right), 106.7(C 5), 117.3\left(\mathrm{~N}-\mathrm{CH}_{2}-\mathrm{Ph}-C^{1}\right), 127.3\left(\mathrm{~N}-\mathrm{CH}_{2}-\mathrm{Ph}-C^{6}\right)$, $127.7\left(\mathrm{O}-\mathrm{CH}_{2}-\mathrm{Ph}\right), 128.5\left(\mathrm{O}-\mathrm{CH}_{2}-\mathrm{Ph}\right), 139.1\left(\mathrm{O}-\mathrm{CH}_{2}-\mathrm{Ph}\right), 148.5\left(C^{8}\right), 151.2\left(C^{4}\right), 154.4\left(C^{2}\right)$, $156.7\left(C^{6}\right), 157.9\left(\mathrm{~N}-\mathrm{CH}_{2}-\mathrm{Ph}-C^{2}\right), 160.0\left(\mathrm{~N}-\mathrm{CH}_{2}-\mathrm{Ph}-C^{4}\right) . \mathrm{MS}(\mathrm{ESI}+) \mathrm{m} / \mathrm{z}:[\mathrm{M}+\mathrm{H}]^{+} \mathrm{Calcd}$ for $\mathrm{C}_{29} \mathrm{H}_{34} \mathrm{~N}_{4} \mathrm{O}_{5}$ 519.25; Found 519.27.

\section{3-(2,4-Dimethoxybenzyl)-8-(cyclopent-3-enyl)-7-pivaloyloxymethyl-1-propyl-1H-purine- 2,6(3H,7H)-dione (21a).}

At ambient temperature and under the exclusion of moisture $\mathrm{K}_{2} \mathrm{CO}_{3}(1.06 \mathrm{~g}, 7.7 \mathrm{mmol})$ was added to a well stirred suspension of $\mathbf{2 0 a}(2.87 \mathrm{~g}, 7 \mathrm{mmol})$ in dry DMF $(30 \mathrm{~mL})$. The mixture was heated 
to $60^{\circ} \mathrm{C}$ and stirred at that temperature for $0.5 \mathrm{~h}$. PomCl $(1.42 \mathrm{~mL}, 9.8 \mathrm{mmol})$ was added and stirring was continued for $5 \mathrm{~h}$. The mixture was cooled to ambient temperature, poured onto icewater $(200 \mathrm{~mL})$, and extracted with diethyl ether $(2 \times 100 \mathrm{~mL})$. The combined organic extracts were washed with water $(2 \times 100 \mathrm{~mL})$, brine $(100 \mathrm{~mL})$, and dried over anhydrous sodium sulfate. Filtration and evaporation in vacuo left a yellow solid that was recrystallized from ethanol to provide 21a as orange crystals. Yield $3.37 \mathrm{~g}(92 \%)$, m.p. $122-123^{\circ} \mathrm{C}(\mathrm{EtOH})$.

${ }^{1} \mathrm{H}-\mathrm{NMR}\left(\mathrm{CDCl}_{3}\right): \delta 0.96\left(\mathrm{t}, J=7.4 \mathrm{~Hz}, 3 \mathrm{H}, \mathrm{CH}_{3}\right), 1.22\left(\mathrm{~s}, 9 \mathrm{H}, \mathrm{N}^{7}-\mathrm{POM}-\mathrm{CH}_{3}\right), 1.69(\mathrm{~m}, J=7.4$ $\left.\mathrm{Hz}, 2 \mathrm{H}, \mathrm{CH}_{3}-\mathrm{CH}_{2}\right), 2.82\left(\mathrm{~d}, J=7.9 \mathrm{~Hz}, 4 \mathrm{H}, \mathrm{Cp}-\mathrm{CH}_{2}\right), 3.71(\mathrm{~m}, J=7.9 \mathrm{~Hz}, 1 \mathrm{H}, \mathrm{Cp}-H), 3.80(\mathrm{~s}$, $\left.3 \mathrm{H}, 4-\mathrm{OCH}_{3}\right), 3.82\left(\mathrm{~s}, 3 \mathrm{H}, 2-\mathrm{OCH}_{3}\right), 3.99\left(\mathrm{~m}, 2 \mathrm{H}, \mathrm{N}^{1}-\mathrm{CH}_{2}\right), 5.28\left(\mathrm{~s}, 2 \mathrm{H}, \mathrm{Ph}-\mathrm{CH}_{2}\right), 5.76(\mathrm{~s}, 2 \mathrm{H}$, Cpen- $H$ ), 6.28 (s, 2H, N7-POM-CH $\left.H_{2}\right), 6.43$ (dd, $\left.J=8.4,2.4 \mathrm{~Hz}, 1 \mathrm{H}, \mathrm{Ph}-H-5\right), 6.46$ (d, $J=2.3 \mathrm{~Hz}$, $1 \mathrm{H}, \mathrm{Ph}-H-3), 7.11(\mathrm{~d}, J=8.4 \mathrm{~Hz}, 1 \mathrm{H}, \mathrm{Ph}-\mathrm{H}-6) .{ }^{13} \mathrm{C}-\mathrm{NMR}\left(\mathrm{CDCl}_{3}\right): \delta 11.3\left(\mathrm{CH}_{3}\right), 21.3\left(\mathrm{CH}_{3}-\mathrm{CH}_{2}\right)$, $26.9\left(\mathrm{~N}^{7}-\mathrm{POM}-\mathrm{CH}_{3}\right), 34.4(\mathrm{Cp}-\mathrm{CH}), 38.7\left(\mathrm{~N}^{7}-\mathrm{POM}-C\left(\mathrm{CH}_{3}\right)_{3}\right), 38.9\left(\mathrm{Cp}-\mathrm{CH}_{2}\right), 41.6\left(\mathrm{Ph}-\mathrm{CH}_{2}\right)$, $42.8\left(\mathrm{~N}^{1}-\mathrm{CH}_{2}\right), 55.3\left(4-\mathrm{OCH}_{3}\right), 55.4\left(2-\mathrm{OCH}_{3}\right), 66.8\left(\mathrm{~N}^{7}-\mathrm{POM}-\mathrm{CH}_{2}\right), 98.5\left(\mathrm{Ph}-C^{3}\right), 103.9\left(\mathrm{Ph}-C^{5}\right)$, $106.6\left(C^{5}\right), 117.3\left(\mathrm{Ph}-C^{1}\right), 128.9\left(\mathrm{Ph}-C^{6}\right), 129.4($ Cpen- $C), 148.4\left(C^{8}\right), 151.2\left(C^{4}\right), 154.7\left(C^{2}\right)$, $158.3\left(C^{6}\right) 158.7\left(\mathrm{Ph}-C^{2}\right), 158.8\left(C^{4}\right), 160.3\left(\mathrm{Ph}-C^{4}\right), 177.3(C=\mathrm{O}) . \mathrm{MS}(\mathrm{ESI}+) \mathrm{m} / \mathrm{z}:[\mathrm{M}+\mathrm{H}]^{+}$Calcd for $\mathrm{C}_{28} \mathrm{H}_{36} \mathrm{~N}_{4} \mathrm{O}_{6}$ 525.26; Found 525.26.

\section{3-(2,4-Dimethoxybenzyl)-8-(cyclopent-1-enyl)-7-pivaloyloxymethyl-1-propyl-1H-purine-} 2,6(3H,7H)-dione (21b).

At ambient temperature and under the exclusion of moisture $\mathrm{K}_{2} \mathrm{CO}_{3}(1.06 \mathrm{~g}, 7.7 \mathrm{mmol})$ was added to a well stirred suspension of $\mathbf{2 0 b}(2.87 \mathrm{~g}, 7 \mathrm{mmol})$ in dry DMF $(30 \mathrm{~mL})$. The mixture was heated to $60^{\circ} \mathrm{C}$ and stirred at that temperature for $0.5 \mathrm{~h}$. PomCl $(1.42 \mathrm{~mL}, 9.8 \mathrm{mmol})$ was added and stirring was continued for $5 \mathrm{~h}$ at $60^{\circ} \mathrm{C}$. The mixture was cooled to ambient temperature, poured onto ice-water $(200 \mathrm{~mL})$, and the precipitated solid product was collected by filtration.

Recrystallization from ethanol furnished 21b as brick-red crystals. Yield 3.48 g (95\%), m.p. 92$94^{\circ} \mathrm{C}(\mathrm{EtOH})$.

${ }^{1} \mathrm{H}-\mathrm{NMR}\left(\mathrm{DMSO}-d_{6}\right): \delta 0.87\left(\mathrm{t}, J=7.4 \mathrm{~Hz}, 3 \mathrm{H}, \mathrm{CH}_{3}\right), 1.15\left(\mathrm{~s}, 9 \mathrm{H}, \mathrm{N}^{7}-\mathrm{POM}-\mathrm{CH}_{3}\right), 1.58(\mathrm{~m}, J=$ $\left.7.4 \mathrm{~Hz}, 2 \mathrm{H}, \mathrm{CH}_{3}-\mathrm{CH}_{2}\right), 1.93\left(\mathrm{~m}, J=7.4 \mathrm{~Hz}, 2 \mathrm{H}, \mathrm{Cp}-\mathrm{C}^{4}-\mathrm{CH}_{2}\right), 2.51-2.83\left(2 \mathrm{~m}, 4 \mathrm{H}, \mathrm{Cp}-\mathrm{C}^{3}-\mathrm{CH}_{2}+\right.$ $\left.\mathrm{Cp}-\mathrm{C}^{5}-\mathrm{CH}_{2}\right), 3.80\left(\mathrm{~s}, 3 \mathrm{H}, 4-\mathrm{OCH}_{3}\right), 3.83\left(\mathrm{~s}, 3 \mathrm{H}, 2-\mathrm{OCH}_{3}\right), 3.88\left(\mathrm{~m}, 2 \mathrm{H}, \mathrm{N}^{1}-\mathrm{CH}_{2}\right), 5.09(\mathrm{~s}, 2 \mathrm{H}, \mathrm{Ph}-$ $\left.\mathrm{CH}_{2}\right), 6.26\left(\mathrm{~s}, 2 \mathrm{H}, \mathrm{N}^{7}-\mathrm{POM}-\mathrm{CH}_{2}\right), 6.42\left(\mathrm{dd}, J=8.4,2.4 \mathrm{~Hz}, 2 \mathrm{H}, \mathrm{Ph}-\mathrm{H}-5+\mathrm{Cp}-\mathrm{C}^{2}-\mathrm{CH}\right), 6.59(\mathrm{~d}, J$ 
$=2.3 \mathrm{~Hz}, 1 \mathrm{H}, \mathrm{Ph}-H-3), 6.77$ (d, $J=8.4 \mathrm{~Hz}, 1 \mathrm{H}, \mathrm{Ph}-H-6) .{ }^{13} \mathrm{C}-\mathrm{NMR}\left(\mathrm{DMSO}-\mathrm{d}_{6}\right): \delta 11.56\left(\mathrm{CH}_{3}\right)$, $21.3\left(\mathrm{CH}_{3}-\mathrm{CH}_{2}\right), 22.8(\mathrm{Cp}-\mathrm{C} 4), 27.0\left(\mathrm{~N}^{7}-\mathrm{POM}-\mathrm{CH}_{3}\right), 34.4\left(\mathrm{Cp}-\mathrm{C}^{3}\right), 34.7\left(\mathrm{Cp}-\mathrm{C}^{5}\right), 38.8\left(\mathrm{~N}^{7}-\mathrm{POM}-\right.$ $\left.C\left(\mathrm{CH}_{3}\right)_{3}\right), 41.5\left(\mathrm{Ph}-\mathrm{CH}_{2}\right), 42.6\left(\mathrm{~N}^{1}-\mathrm{CH}_{2}\right), 55.7\left(4-\mathrm{OCH}_{3}\right), 56\left(2-\mathrm{OCH}_{3}\right), 69.1\left(\mathrm{~N}^{7}-\mathrm{POM}-\mathrm{CH}_{2}\right), 98.9$ $\left(\mathrm{Ph}-C^{3}\right), 104.9\left(\mathrm{Ph}-C^{5}\right), 107.1\left(C^{5}\right), 116.8\left(\mathrm{Ph}-C^{1}\right), 127.6\left(\mathrm{Ph}-C^{6}\right), 131.5\left(\mathrm{Cp}-C^{2}\right), 137.9\left(\mathrm{Cp}-C^{1}\right)$, $148.2\left(C^{8}\right), 150.2\left(C^{4}\right), 150.9\left(C^{2}\right), 154.4\left(C^{6}\right) 157.9\left(\mathrm{Ph}-C^{2}\right), 160.3\left(\mathrm{Ph}-C^{4}\right), 176.7(C=\mathrm{O})$. MS (ESI+) m/z: $[\mathrm{M}+\mathrm{H}]^{+}$Calcd for $\mathrm{C}_{28} \mathrm{H}_{36} \mathrm{~N}_{4} \mathrm{O}_{6}$ 525.26; Found 525.26.

cis-8-(2-Benzyloxycyclopentyl)-3-(2,4-dimethoxybenzyl)-7-pivaloyloxymethyl-1-propyl-1Hpurine-2,6(3H,7H)-dione (21c).

At ambient temperature and under the exclusion of moisture $\mathrm{K}_{2} \mathrm{CO}_{3}(760 \mathrm{mg}, 5.5 \mathrm{mmol})$ was added to a well stirred suspension of 20c $(2.59 \mathrm{~g}, 5 \mathrm{mmol})$ in dry DMF $(30 \mathrm{~mL})$ and the mixture was stirred at that temperature for $0.5 \mathrm{~h}$. PomCl $(0.9 \mathrm{~mL}, 6.25 \mathrm{mmol})$ was added and stirring was continued for $48 \mathrm{~h}$. The mixture was poured onto ice-water $(200 \mathrm{~mL})$, and the precipitated solid product was collected by filtration. Recrystallization from aqueous methanol furnished $\mathbf{2 1 c}$ as fawn crystals. Yield $3.02 \mathrm{~g}(88 \%)$, m.p. $118-120^{\circ} \mathrm{C}\left(\mathrm{MeOH}_{\mathrm{aq}}\right)$.

${ }^{1} \mathrm{H}-\mathrm{NMR}\left(\mathrm{DMSO}-d_{6}\right.$ ): $\delta 0.98$ (t, $J=7.4 \mathrm{~Hz}, 3 \mathrm{H}, \mathrm{CH}_{3}$ ), 1.20 (s, 9H, N ${ }^{7}-\mathrm{POM}-\mathrm{CH}_{3}$ ), 1.59-2.23 (m, $\left.8 \mathrm{H}, \mathrm{CH}_{3}-\mathrm{CH}_{2}+\mathrm{Cp}-\mathrm{CH}_{2}\right), 3.25-3.48\left(\mathrm{~m}, 1 \mathrm{H}, \mathrm{Cp}-\mathrm{C}^{1}-\mathrm{H}\right), 3.79$ (s, 3H, 4-OCH $), 3.82$ (s, 3H, 2$\left.\mathrm{OCH}_{3}\right), 3.94\left(\mathrm{~m}, 2 \mathrm{H}, \mathrm{N}^{1}-\mathrm{CH}_{2}\right), 4.11-4.25\left(\mathrm{~m}, 1 \mathrm{H}, \mathrm{Cp}-\mathrm{C}^{2}-\mathrm{H}\right), 4.41$ (s, 2H, Ph-CH$\left.{ }_{2}-\mathrm{O}\right), 5.06$ (s, $2 \mathrm{H}$, $\left.\mathrm{Ph}-\mathrm{CH}_{2}-\mathrm{N}\right), 6.23\left(\mathrm{~s}, 2 \mathrm{H}, \mathrm{N}^{7}-\mathrm{POM}-\mathrm{CH}_{2}\right), 6.39$ (dd, $\left.J=8.4,2.4 \mathrm{~Hz}, 1 \mathrm{H}, \mathrm{N}-\mathrm{CH}_{2}-\mathrm{Ph}-H^{5}\right), 6.56$ (d, $J=$ $\left.2.3 \mathrm{~Hz}, 1 \mathrm{H}, \mathrm{N}-\mathrm{CH}_{2}-\mathrm{Ph}-H^{3}\right), 6.70\left(\mathrm{~d}, J=8.4 \mathrm{~Hz}, 1 \mathrm{H}, \mathrm{N}-\mathrm{CH}_{2}-\mathrm{Ph}-H^{6}\right), 7.01-7.34\left(\mathrm{~m}, 5 \mathrm{H}, \mathrm{O}^{-} \mathrm{CH}_{2}-\right.$ Ph). ${ }^{13} \mathrm{C}-\mathrm{NMR}$ (DMSO- $\left.d_{6}\right): \delta 11.3\left(\mathrm{CH}_{3}\right), 21.3\left(\mathrm{CH}_{3}-\mathrm{CH}_{2}\right), 22.7\left(\mathrm{Cp}-\mathrm{C}^{4}\right), 26.9\left(\mathrm{~N}^{7}-\mathrm{POM}-\mathrm{CH}_{3}\right)$, $30.8\left(\mathrm{Cp}-C^{5}\right), 31.9\left(\mathrm{Cp}-C^{3}\right), 38.8\left(\mathrm{~N}^{7}-\mathrm{POM}-\mathrm{C}\left(\mathrm{CH}_{3}\right)_{3}\right), 41.6\left(\mathrm{~N}-\mathrm{CH}_{2}-\mathrm{Ph}\right), 43.3\left(\mathrm{~N}-\mathrm{CH}_{2}-\mathrm{CH}_{2}\right), 45.9$ $\left(\mathrm{Cp}-\mathrm{C}^{1}\right), 55.3\left(4-\mathrm{OCH}_{3}\right), 55.4\left(2-\mathrm{OCH}_{3}\right), 66.7\left(\mathrm{~N}^{7}-\mathrm{POM}-\mathrm{CH}_{2}\right), 72.0\left(\mathrm{O}-\mathrm{CH}_{2}-\mathrm{Ph}\right), 85.6\left(\mathrm{Cp}-\mathrm{C}^{2}\right)$, $98.5\left(\mathrm{~N}-\mathrm{CH}_{2}-\mathrm{Ph}-C^{3}\right), 103.9\left(\mathrm{~N}-\mathrm{CH}_{2}-\mathrm{Ph}-C^{5}\right), 106.6\left(C^{5}\right), 117.2\left(\mathrm{~N}^{-} \mathrm{CH}_{2}-\mathrm{Ph}-C^{1}\right), 127.5\left(\mathrm{~N}^{-} \mathrm{CH}_{2}-\mathrm{Ph}-\right.$ $\left.C^{6}\right), 127.6\left(\mathrm{O}-\mathrm{CH}_{2}-\mathrm{Ph}\right), 128.3\left(\mathrm{O}-\mathrm{CH}_{2}-\mathrm{Ph}\right), 138.3\left(\mathrm{O}_{-} \mathrm{CH}_{2}-\mathrm{Ph}\right), 148.4\left(C^{8}\right), 151.1\left(C^{4}\right), 154.4\left(C^{2}\right)$, $156.6\left(C^{6}\right), 158.3\left(\mathrm{~N}-\mathrm{CH}_{2}-\mathrm{Ph}-C^{2}\right), 160.3\left(\mathrm{~N}^{-} \mathrm{CH}_{2}-\mathrm{Ph}-C^{4}\right), 177.2(C=\mathrm{O}) . \mathrm{MS}(\mathrm{ESI}+) \mathrm{m} / \mathrm{z}:[\mathrm{M}+\mathrm{H}]^{+}$ Calcd for $\mathrm{C}_{35} \mathrm{H}_{44} \mathrm{~N}_{4} \mathrm{O}_{7} 633.32$; Found 633.31 .

8-(Cyclopent-3-enyl)-7-pivaloyloxymethyl-1-propyl-1H-purine-2,6(3H,7H)-dione (22a). 
Under stirring xanthine 21a (2.62 g, $5 \mathrm{mmol}$ ) was dissolved in trifluoroacetic acid (TFA, $20 \mathrm{~mL}$ ) and the solution was heated to $50^{\circ} \mathrm{C}$. After $7 \mathrm{~h}$ TFA was evaporated in vacuo and the solid residue recrystallized from aqueous $\mathrm{MeOH}$ to yield 22a as fawn crystals. Yield $1.5 \mathrm{~g}(80 \%)$, m.p. 141$143^{\circ} \mathrm{C}\left(\mathrm{MeOH}_{\mathrm{aq}}\right)$.

${ }^{1} \mathrm{H}-\mathrm{NMR}$ (DMSO- $\left.d_{6}\right): \delta 0.86\left(\mathrm{t}, J=7.4 \mathrm{~Hz}, 3 \mathrm{H}, \mathrm{CH}_{3}\right), 1.25\left(\mathrm{~s}, 9 \mathrm{H}, \mathrm{N}^{7}-\mathrm{POM}-\mathrm{CH}_{3}\right), 1.51(\mathrm{~m}, J=$ $\left.7.4 \mathrm{~Hz}, 2 \mathrm{H}, \mathrm{CH}_{3}-\mathrm{CH}_{2}\right), 2.72\left(\mathrm{~m}, J=7.9 \mathrm{~Hz}, 4 \mathrm{H}, \mathrm{Cp}-\mathrm{CH}_{2}\right), 3.83$ (m, 3H, Cp- $\left.H+\mathrm{N}^{1}-\mathrm{CH}_{2}\right), 5.75$ (s, $2 \mathrm{H}, \mathrm{Cpen}-H), 6.22\left(\mathrm{~s}, 2 \mathrm{H}, \mathrm{N}^{7}-\mathrm{POM}-\mathrm{CH}_{2}\right), 11.94\left(\mathrm{~s}_{\mathrm{br}}, 1 \mathrm{H}, \mathrm{N}^{3}-H\right) .{ }^{13} \mathrm{C}-\mathrm{NMR}\left(\mathrm{DMSO}-d_{6}\right)$ : $\delta 11.6$ $\left(\mathrm{CH}_{3}\right), 21.3\left(\mathrm{CH}_{3}-\mathrm{CH}_{2}\right), 27.1\left(\mathrm{~N}^{7}-\mathrm{POM}-\mathrm{CH}_{3}\right), 33.7(\mathrm{Cp}-\mathrm{CH}), 38.8\left(\mathrm{~N}^{7}-\mathrm{POM}-\mathrm{C}\left(\mathrm{CH}_{3}\right)_{3}\right), 38.9(\mathrm{Cp}-$ $\left.C \mathrm{H}_{2}\right), 41.6\left(\mathrm{~N}^{1}-C \mathrm{H}_{2}\right), 67.5\left(\mathrm{~N}^{7}-\mathrm{POM}-C \mathrm{H}_{2}\right), 106.1\left(C^{5}\right), 129.4($ Cpen- $C), 147.5\left(C^{8}\right), 151.2\left(C^{4}\right)$, $154.9\left(C^{2}\right), 159.8\left(C^{6}\right), 176.7(C=\mathrm{O})$. MS (ESI+) m/z: $[\mathrm{M}+\mathrm{H}]^{+}$Calcd for $\mathrm{C}_{19} \mathrm{H}_{26} \mathrm{~N}_{4} \mathrm{O}_{4} 375.20$; Found 375.20 .

\section{8-(Cyclopent-1-enyl)-7-pivaloyloxymethyl-1-propyl-1H-purine-2,6(3H,7H)-dione (22b).} Under stirring xanthin $21 \mathrm{~b}$ (2.62 g, $5 \mathrm{mmol}$ ) was dissolved in trifluoroacetic acid (TFA, $20 \mathrm{~mL}$ ) and the solution was heated to $50^{\circ} \mathrm{C}$. After $7 \mathrm{~h}$ TFA was evaporated in vacuo and the solid residue recrystallized from aqueous $\mathrm{MeOH}$ to yield 22b as off-white crystals. Yield $0.98 \mathrm{~g}(53 \%)$, m.p. $193^{\circ} \mathrm{C}\left(\mathrm{MeOH}_{\mathrm{aq}}\right)$.

${ }^{1} \mathrm{H}-\mathrm{NMR}$ (DMSO- $d_{6}$ ): $\delta 0.87$ (t, $J=7.4 \mathrm{~Hz}, 3 \mathrm{H}, \mathrm{CH}_{3}$ ), 1.14 (s, 9H, N $\left.{ }^{7}-\mathrm{POM}_{-} \mathrm{CH}_{3}\right), 1.55$ (m, $J=7.4$ $\mathrm{Hz}, 2 \mathrm{H}, \mathrm{CH}_{3}-\mathrm{CH}_{2}$ ), 1.96 (m, J = 7.4 Hz, 2H, Cp-C-4-CH $\mathrm{CH}_{2}$, 2.54-2.87 (2 m, 4H, Cp-C-3-CH + Cp-C-5-CH $\left.\mathrm{CH}_{2}\right), 3.84\left(\mathrm{~m}, 2 \mathrm{H}, \mathrm{N}^{1}-\mathrm{CH}_{2}\right), 6.24$ (s, 2H, N7-POM-CH $\left.\mathrm{N}_{2}\right), 6.49$ (m, 1H, Cp-C-2-CH ), $12.01(\mathrm{~s}, 1 \mathrm{H}, \mathrm{NH}) .{ }^{13} \mathrm{C}-\mathrm{NMR}$ (DMSO- $\left.d_{6}\right): \delta 11.6\left(\mathrm{CH}_{3}\right), 21.3\left(\mathrm{CH}_{3}-\mathrm{CH}_{2}\right), 22.7\left(\mathrm{Cp}-\mathrm{C}^{4}\right), 27.1\left(\mathrm{~N}^{7}-\right.$ POM- $\left.\mathrm{CH}_{3}\right), 34.4\left(\mathrm{Cp}-C^{3}\right), 34.8\left(\mathrm{Cp}-C^{5}\right), 38.8\left(\mathrm{~N}^{7}-\mathrm{POM}-\mathrm{C}\left(\mathrm{CH}_{3}\right)_{3}\right), 41.7\left(\mathrm{~N}^{1}-\mathrm{CH}_{2}\right), 68.9\left(\mathrm{~N}^{7}-\mathrm{POM}-\right.$ $\left.C \mathrm{H}_{2}\right), 106.8\left(C^{5}\right), 131.6\left(\mathrm{Cp}-C^{2}\right), 137.4\left(\mathrm{Cp}-C^{1}\right), 147.5\left(C^{8}\right), 150.2\left(C^{4}\right), 155.1\left(C^{2}\right), 159.1\left(C^{6}\right)$, 176.6 (C=O). MS (ESI+) m/z: $[\mathrm{M}+\mathrm{H}]^{+}$Calcd for $\mathrm{C}_{19} \mathrm{H}_{26} \mathrm{~N}_{4} \mathrm{O}_{4}$ 375.20; Found 375.21.

cis-8-(2-Benzyloxycyclopentyl)-7-pivaloyloxymethyl-1-propyl-1H-purine-2,6(3H,7H)-dione (22c).

Under stirring xanthine 21c (2.53 g, 4 mmol) was dissolved in trifluoroacetic acid (TFA, $20 \mathrm{~mL}$ ) and the solution was heated to $50^{\circ} \mathrm{C}$. After $7 \mathrm{~h}$ TFA was evaporated in vacuo and the oily residue 
was purified by chromatography on silica gel (eluent $10 \%$ acetonitrile in ethyl acetate) to provide the deprotected xanthine 22c as a dark-brown viscous oil. Yield $1.64 \mathrm{~g}(85 \%)$.

${ }^{1} \mathrm{H}-\mathrm{NMR}\left(\mathrm{DMSO}-d_{6}\right): \delta 0.87\left(\mathrm{t}, J=7.4 \mathrm{~Hz}, 3 \mathrm{H}, \mathrm{CH}_{3}\right), 1.09\left(\mathrm{~s}, 9 \mathrm{H}, \mathrm{N}^{7}-\mathrm{POM}-\mathrm{CH}_{3}\right), 1.57-2.15(\mathrm{~m}$, $\left.8 \mathrm{H}, \mathrm{CH}_{3}-\mathrm{CH}_{2}+\mathrm{Cp}-\mathrm{CH}_{2}\right), 3.20-3.43(\mathrm{~m}, 1 \mathrm{H}, \mathrm{Cp}-1-\mathrm{H}), 3.84\left(\mathrm{~m}, 2 \mathrm{H}, \mathrm{N}^{1}-\mathrm{CH}_{2}\right), 4.04-4.21(\mathrm{~m}, 1 \mathrm{H}$, Cp-C-2-H), 4.43 (s, 2H, Ph-CH2-O), 6.26 (s, 2H, N7-POM-CH $\mathrm{CH}_{2}$ ), 7.25 (m, 5H, O-CH $-\mathrm{Ph}$ ), 11.94 $\left(\mathrm{s}_{\mathrm{br}}, 1 \mathrm{H}, \mathrm{N}^{3}-H\right) .{ }^{13} \mathrm{C}-\mathrm{NMR}\left(\mathrm{DMSO}-d_{6}\right): \delta 11.6\left(\mathrm{CH}_{3}\right), 21.2\left(\mathrm{CH}_{3}-\mathrm{CH}_{2}\right), 21.5\left(\mathrm{Cp}-\mathrm{C}^{4}\right), 26.9\left(\mathrm{~N}^{7}-\right.$ POM- $\left.C \mathrm{H}_{3}\right), 30.9\left(\mathrm{Cp}-C^{5}\right), 33.1\left(\mathrm{Cp}-C^{3}\right), 38.7\left(\mathrm{~N}^{7}-\mathrm{POM}-C\left(\mathrm{CH}_{3}\right)_{3}\right), 42.7\left(\mathrm{~N}^{1}-C \mathrm{H}_{2}\right), 45.9\left(\mathrm{Cp}-C^{1}\right)$, $66.7\left(\mathrm{~N}^{7}-\mathrm{POM}-\mathrm{CH}_{2}\right), 71.1\left(\mathrm{O}-\mathrm{CH}_{2}-\mathrm{Ph}\right), 85.3\left(\mathrm{Cp}-C^{2}\right), 106.6\left(C^{5}\right), 127.8\left(\mathrm{O}-\mathrm{CH}_{2}-\mathrm{Ph}\right), 128.5(\mathrm{O}-$ $\left.\mathrm{CH}_{2}-\mathrm{Ph}\right), 138.9\left(\mathrm{O}-\mathrm{CH}_{2}-\mathrm{Ph}\right), 147.6\left(C^{8}\right), 151.2\left(\mathrm{C}^{4}\right), 154.9\left(C^{2}\right), 157.9\left(C^{6}\right), 176.8(C=\mathrm{O}) . \mathrm{MS}$ (ESI+) m/z: $[\mathrm{M}+\mathrm{H}]^{+}$Calcd for $\mathrm{C}_{26} \mathrm{H}_{34} \mathrm{~N}_{4} \mathrm{O}_{5}$ 483.25; Found 483.24.

\section{8-(Cyclopent-3-enyl)-3-(3-fluoropropyl)-7-pivaloyloxymethyl-1-propyl-1H-purine- 2,6(3H,7H)-dione (23a).}

At ambient temperature and under the exclusion of moisture $\mathrm{K}_{2} \mathrm{CO}_{3}(730 \mathrm{mg}, 5.3 \mathrm{mmol})$ was added to a well stirred solution of $22 \mathbf{a}(1.65 \mathrm{~g}, 4.4 \mathrm{mmol})$ in dry DMF (20 mL). The mixture was heated to $60^{\circ} \mathrm{C}$ and stirred at that temperature for $0.5 \mathrm{~h}$. 1-Bromo-3-fluoropropane $(565 \mu \mathrm{L}, 6.16$ mmol) was added and stirring was continued for $18 \mathrm{~h}$. The mixture was cooled to ambient temperature, poured onto ice-water $(150 \mathrm{~mL})$, and extracted with diethyl ether $(2 \times 100 \mathrm{~mL})$. The combined organic extracts were washed with water $(2 \times 100 \mathrm{~mL})$, brine $(100 \mathrm{~mL})$, and dried over anhydrous sodium sulfate. Filtration and evaporation in vacuo left a solid that was recrystallized from 50\% aqueous $\mathrm{MeOH}$ to give 23a as orange-brown crystals. Yield $1.82 \mathrm{~g}$ (95\%), m.p. 62$64^{\circ} \mathrm{C}(50 \% \mathrm{MeOH})$.

${ }^{1} \mathrm{H}-\mathrm{NMR}\left(\mathrm{CDCl}_{3}\right): \delta 0.95\left(\mathrm{t}, J=7.4 \mathrm{~Hz}, 3 \mathrm{H}, \mathrm{CH}_{3}\right), 1.20\left(\mathrm{~s}, 9 \mathrm{H}, \mathrm{N}^{7}-\mathrm{POM}-\mathrm{CH}_{3}\right), 1.67(\mathrm{~m}, J=7.4$ $\left.\mathrm{Hz}, 2 \mathrm{H}, \mathrm{CH}_{3}-\mathrm{CH}_{2}\right), 2.19\left(\mathrm{dt}, J=27.3,6.1 \mathrm{~Hz}, 2 \mathrm{H}, \mathrm{CH}_{2}-\mathrm{CH}_{2} \mathrm{~F}\right), 2.83\left(\mathrm{~d}, J=7.9 \mathrm{~Hz}, 4 \mathrm{H}, \mathrm{Cp}-\mathrm{CH}_{2}\right)$, $3.70(\mathrm{~m}, J=7.9 \mathrm{~Hz}, 1 \mathrm{H}, \mathrm{Cp}-H), 3.97\left(\mathrm{~m}, J=7.1 \mathrm{~Hz}, 2 \mathrm{H}, \mathrm{N}^{1}-\mathrm{CH}_{2}\right), 4.26\left(\mathrm{t}, J=6.7 \mathrm{~Hz}, 2 \mathrm{H}, \mathrm{N}^{3}-\right.$ $\left.\mathrm{CH}_{2}\right), 4.55\left(\mathrm{dt}, \mathrm{J}=47.2,5.7 \mathrm{~Hz}, 2 \mathrm{H}, \mathrm{CH}_{2} \mathrm{~F}\right), 5.76(\mathrm{~s}, 2 \mathrm{H}, \mathrm{Cpen}-\mathrm{H}), 6.25$ (s, 2H, N $\left.{ }^{7} \mathrm{POM}-\mathrm{CH}_{2}\right)$.

${ }^{13} \mathrm{C}-\mathrm{NMR}\left(\mathrm{CDCl}_{3}\right): \delta 11.3\left(\mathrm{CH}_{3}\right), 21.3\left(\mathrm{CH}_{3}-\mathrm{CH}_{2}\right), 26.9\left(\mathrm{~N}^{7}-\mathrm{POM}-\mathrm{CH}_{3}\right), 29.3\left({ }^{2} \mathrm{~J}=19.2 \mathrm{~Hz}, \mathrm{CH}_{2^{-}}\right.$ $\left.\mathrm{CH}_{2} \mathrm{~F}\right), 34.4(\mathrm{Cp}-\mathrm{CH}), 38.9\left(\mathrm{Cp}-\mathrm{CH}_{2}\right), 39.1\left(\mathrm{~N}^{7}-\mathrm{POM}-\mathrm{C}\left(\mathrm{CH}_{3}\right)_{3}\right), 40.1\left({ }^{3} \mathrm{~J}=5.5 \mathrm{~Hz}, \mathrm{~N}^{3}-\mathrm{CH}_{2}\right), 42.8$ $\left(\mathrm{N}^{1}-\mathrm{CH}_{2}\right), 66.7\left(\mathrm{~N}^{7}-\mathrm{POM}-\mathrm{CH}_{2}\right), 80.4\left({ }^{1} \mathrm{~J}=162.0 \mathrm{~Hz}, C \mathrm{H}_{2} \mathrm{~F}\right), 106.6\left(C^{5}\right), 128.9(\mathrm{Cpen}-C), 147.8$ 
$\left(C^{8}\right), 151.2\left(C^{4}\right), 154.5\left(C^{2}\right), 158.9\left(C^{6}\right), 177.2(C=\mathrm{O}) .{ }^{19} \mathrm{~F}-\mathrm{NMR}\left(\mathrm{CDCl}_{3}\right): \delta$ - 219.96. MS (ESI +$)$ m/z: $[\mathrm{M}+\mathrm{H}]^{+}$Calcd for $\mathrm{C}_{22} \mathrm{H}_{31} \mathrm{FN}_{4} \mathrm{O}_{4}$ 435.23; Found 435.23.

\section{8-(Cyclopent-1-enyl)-3-(3-fluoropropyl)-7-pivaloyloxymethyl-1-propyl-1H-purine- 2,6(3H,7H)-dione (23b).}

At ambient temperature and under the exclusion of moisture $\mathrm{K}_{2} \mathrm{CO}_{3}(730 \mathrm{mg}, 5.3 \mathrm{mmol})$ was added to a well stirred solution of $22 \mathbf{b}$ (1.65 g, $4.4 \mathrm{mmol})$ in dry DMF (20 mL). The mixture was heated to $60^{\circ} \mathrm{C}$ and stirred at that temperature for $0.5 \mathrm{~h}$. 1-Bromo-3-fluoropropane $(565 \mu \mathrm{L}, 6.16$ mmol) was added and stirring was continued for $18 \mathrm{~h}$ at $60^{\circ} \mathrm{C}$. The mixture was cooled to ambient temperature and poured onto ice-water $(150 \mathrm{~mL})$. After standing overnight at $4{ }^{\circ} \mathrm{C}$ the solid was collected by filtration recrystallized from $50 \%$ aqueous $\mathrm{MeOH}$ to give $\mathbf{2 3 b}$ as yellow crystals. Yield $1.89 \mathrm{~g}(98 \%)$, m.p. $195^{\circ} \mathrm{C}(50 \% \mathrm{MeOH})$.

${ }^{1} \mathrm{H}-\mathrm{NMR}\left(\mathrm{CDCl}_{3}\right): \delta 0.98\left(\mathrm{t}, J=7.4 \mathrm{~Hz}, 3 \mathrm{H}, \mathrm{CH}_{3}\right), 1.24\left(\mathrm{~s}, 9 \mathrm{H}, \mathrm{N}^{7}-\mathrm{POM}-\mathrm{CH}_{3}\right), 1.68(\mathrm{~m}, J=7.4$ $\mathrm{Hz}, 2 \mathrm{H}, \mathrm{CH}_{3}-\mathrm{CH}_{2}$ ), 1.97-2.39 (m, 4H, Cp-C-4- $\left.\mathrm{CH}_{2}+\mathrm{CH}_{2}-\mathrm{CH}_{2} \mathrm{~F}\right), 2.59-2.75$ (m, 2H, Cp-CH $)$, 2.82-2.98 (m, 2H, Cp-CH $\mathrm{CH}_{2}, 4.00\left(\mathrm{~m}, J=7.1 \mathrm{~Hz}, 2 \mathrm{H}, \mathrm{N}^{1}-\mathrm{CH}_{2}\right), 4.30\left(\mathrm{t}, J=6.7 \mathrm{~Hz}, 2 \mathrm{H}, \mathrm{N}^{3}-\mathrm{CH}_{2}\right)$, $4.57\left(\mathrm{dt}, J=47.2,5.7 \mathrm{~Hz}, 2 \mathrm{H}, \mathrm{CH}_{2} \mathrm{~F}\right), 6.31\left(\mathrm{~s}, 2 \mathrm{H}, \mathrm{N}^{7}-\mathrm{POM}-\mathrm{CH}_{2}\right), 6.41(\mathrm{~m}, 1 \mathrm{H}, \mathrm{Cp}-\mathrm{CH}) .{ }^{13} \mathrm{C}-$ NMR $\left(\mathrm{CDCl}_{3}\right): \delta 11.3\left(\mathrm{CH}_{3}\right), 21.3\left(\mathrm{CH}_{3}-\mathrm{CH}_{2}\right), 26.9\left(\mathrm{~N}^{7}-\mathrm{POM}-\mathrm{CH}_{3}\right), 29.2\left({ }^{2} \mathrm{~J}=19.2 \mathrm{~Hz}, \mathrm{CH}_{2}-\right.$ $\left.\mathrm{CH}_{2} \mathrm{~F}\right), 34.4(\mathrm{Cp}-\mathrm{C} 3), 34.8(\mathrm{Cp}-\mathrm{C} 5), 38.9\left(\mathrm{~N}^{7}-\mathrm{POM}-C\left(\mathrm{CH}_{3}\right)_{3}\right), 40.1\left({ }^{3} \mathrm{~J}=5.5 \mathrm{~Hz}, \mathrm{~N}^{3}-\mathrm{CH}_{2}\right), 42.9$ $\left(\mathrm{N}^{1}-C \mathrm{H}_{2}\right), 68.4\left(\mathrm{~N}^{7}-\mathrm{POM}-C \mathrm{H}_{2}\right), 80.4\left({ }^{1} J=162.0 \mathrm{~Hz}, C \mathrm{H}_{2} \mathrm{~F}\right), 106.3\left(C^{5}\right), 131.8\left(\mathrm{Cp}-C^{2}\right), 137.5$ $\left(\mathrm{Cp}-C^{1}\right), 147.9\left(C^{8}\right), 150.4\left(C^{4}\right), 151.1\left(C^{2}\right), 154.6\left(C^{6}\right) 177.1(C=\mathrm{O}) .{ }^{19} \mathrm{~F}-\mathrm{NMR}\left(\mathrm{CDCl}_{3}\right): \delta$ 219.11. MS (ESI+) m/z: $[\mathrm{M}+\mathrm{H}]^{+}$Calcd for $\mathrm{C}_{22} \mathrm{H}_{31} \mathrm{FN}_{4} \mathrm{O}_{4} 435.23$; Found 435.22.

cis-8-(2-Benzyloxycyclopentyl)-3-(3-fluoropropyl)-)-7-pivaloyloxymethyl-1-propyl-1Hpurine-2,6(3H,7H)-dione (23c).

At ambient temperature and under the exclusion of moisture $\mathrm{K}_{2} \mathrm{CO}_{3}(456 \mathrm{mg}, 3.3 \mathrm{mmol})$ was added to a well stirred solution of $\mathbf{2 3 b}(1.45 \mathrm{~g}, 3 \mathrm{mmol})$ in dry DMF (20 mL). The mixture was heated to $60^{\circ} \mathrm{C}$ and stirred at that temperature for $0.5 \mathrm{~h}$. 1-Bromo-3-fluoropropane $(303 \mu \mathrm{L}, 3.3$ mmol) was added and stirring was continued for $24 \mathrm{~h}$ at $60^{\circ} \mathrm{C}$. The mixture was cooled to ambient temperature and poured onto ice-water $(150 \mathrm{~mL})$. The aqueous mixture was extracted with diethyl ether $(2 \times 100 \mathrm{~mL})$, the combined organic extracts were washed with water $(2 \times 100 \mathrm{~mL})$ and 
brine $(100 \mathrm{~mL})$, and dried over anhydrous sodium sulfate. Filtration and rota-evaporation in vacuo gave $706 \mathrm{mg}(43 \%)$ of a chromatographically pure light brown oil.

${ }^{1} \mathrm{H}-\mathrm{NMR}\left(\mathrm{CDCl}_{3}\right): \delta 0.97\left(\mathrm{t}, J=7.4 \mathrm{~Hz}, 3 \mathrm{H}, \mathrm{CH}_{3}\right), 1.19$ (s, 9H, N7-POM-CH$), 1.59-2.38(\mathrm{~m}$, $\left.\left.10 \mathrm{H}, \mathrm{CH}_{2}-\mathrm{CH}_{3}+\mathrm{Cp}-\mathrm{CH}_{2}+\mathrm{CH}_{2}-\mathrm{CH}_{2} \mathrm{~F}\right)\right), 3.16-3.41\left(\mathrm{~m}, 1 \mathrm{H}, \mathrm{Cp}-\mathrm{H}^{1}\right), 3.84\left(\mathrm{~m}, 2 \mathrm{H}, \mathrm{N}^{1}-\mathrm{CH}_{2}\right), 4.11-$ $4.23\left(\mathrm{~m}, 1 \mathrm{H}, \mathrm{Cp}-\mathrm{H}^{2}\right), 4.41\left(\mathrm{~m}, 2 \mathrm{H}, \mathrm{Ph}-\mathrm{CH}_{2}-\mathrm{O}\right), 3.97\left(\mathrm{~m}, 2 \mathrm{H}, \mathrm{N}^{1}-\mathrm{CH}_{2}\right), 4.26\left(\mathrm{~m}, 2 \mathrm{H}, \mathrm{N}^{3}-\mathrm{CH}_{2}\right), 4.55$ (dt, $\left.J=47.1,5.6 \mathrm{~Hz}, 2 \mathrm{H}, \mathrm{CH}_{2} \mathrm{~F}\right), 6.25$ (s, 2H, N $\left.{ }^{7}-\mathrm{POM}-\mathrm{CH}_{2}\right), 7.18-7.30$ (m, 5H, O-CH $\left.-\mathrm{Ph}\right) .{ }^{13} \mathrm{C}-$ $\mathrm{NMR}\left(\mathrm{CDCl}_{3}\right)$ : $\delta 11.4\left(\mathrm{CH}_{3}\right), 21.3\left(\mathrm{CH}_{3}-\mathrm{CH}_{2}\right), 21.5\left(\mathrm{Cp}-C^{4}\right), 26.9\left(\mathrm{~N}^{7}-\mathrm{POM}-C_{3}\right), 29.3\left({ }^{2} J=19.2\right.$ $\left.\mathrm{Hz}, \mathrm{CH}_{2}-\mathrm{CH}_{2} \mathrm{~F}\right), 30.9\left(\mathrm{Cp}-C^{5}\right), 33.1\left(\mathrm{Cp}-C^{3}\right), 38.9\left(\mathrm{~N}^{7}-\mathrm{POM}-\mathrm{C}\left(\mathrm{CH}_{3}\right)_{3}\right), 40.0\left({ }^{3} J=5.5 \mathrm{~Hz}, \mathrm{~N}^{3}-\right.$ $\left.C \mathrm{H}_{2}\right), 42.7\left(\mathrm{~N}^{1}-C \mathrm{H}_{2}\right), 45.8\left(\mathrm{Cp}-C^{1}\right), 66.7\left(\mathrm{~N}^{7}-\mathrm{POM}-\mathrm{CH}_{2}\right), 70.9\left(\mathrm{O}-\mathrm{CH}_{2}-\mathrm{Ph}\right), 80.3\left({ }^{1} \mathrm{~J}=162.0 \mathrm{~Hz}\right.$, $\left.\mathrm{CH}_{2} \mathrm{~F}\right), 85.3\left(\mathrm{Cp}-\mathrm{C}^{2}\right), 106.6\left(C^{5}\right), 127.7\left(\mathrm{O}-\mathrm{CH}_{2}-\mathrm{Ph}\right), 128.9\left(\mathrm{O}-\mathrm{CH}_{2}-\mathrm{Ph}\right), 139.0\left(\mathrm{O}-\mathrm{CH}_{2}-\mathrm{Ph}\right), 147.7$ $\left(C^{8}\right), 151.1\left(C^{4}\right), 154.7\left(C^{2}\right), 158.2\left(C^{6}\right), 177.1(C=\mathrm{O}) .{ }^{19} \mathrm{~F}-\mathrm{NMR}\left(\mathrm{CDCl}_{3}\right): \delta-217.90 . \mathrm{MS}(\mathrm{ESI}+)$ $\mathrm{m} / \mathrm{z}:[\mathrm{M}+\mathrm{H}]^{+}$Calcd for $\mathrm{C}_{29} \mathrm{H}_{39} \mathrm{FN}_{4} \mathrm{O}_{5}$ 543.29; Found 543.30.

\section{8-(Cyclopent-3-enyl)-3-(3-fluoropropyl)-1-propyl-1H-purine-2,6(3H,7H)-dione (24a).}

At ambient temperature compound 23a (1.3 g, $3 \mathrm{mmol})$ was stirred overnight in $7 \mathrm{~N}$ methanolic ammonia $(25 \mathrm{~mL})$. After evaporation of the solvent the solid residue was recrystallized from methanol to furnish the deprotected xanthine 24a as fawn crystals. Yield $750 \mathrm{mg}$ (78\%), m.p. 198$200^{\circ} \mathrm{C}(\mathrm{MeOH})$.

${ }^{1} \mathrm{H}-\mathrm{NMR}\left(\mathrm{DMSO}-d_{6}\right): \delta 0.87\left(\mathrm{t}, J=7.4 \mathrm{~Hz}, 3 \mathrm{H}, \mathrm{CH}_{3}\right), 1.57\left(\mathrm{~m}, J=7.4 \mathrm{~Hz}, 2 \mathrm{H}, \mathrm{CH}_{3}-\mathrm{CH}_{2}\right), 2.07$ (dt, $\left.J=27.3,6.1 \mathrm{~Hz}, 2 \mathrm{H}, \mathrm{CH}_{2}-\mathrm{CH}_{2} \mathrm{~F}\right), 2.71\left(\mathrm{~m}, J=7.9 \mathrm{~Hz}, 4 \mathrm{H}, \mathrm{Cp}-\mathrm{CH}_{2}\right), 3.58(\mathrm{~m}, J=7.9 \mathrm{~Hz}$, $1 \mathrm{H}, \mathrm{Cp}-H), 3.85\left(\mathrm{~m}, J=7.1 \mathrm{~Hz}, 2 \mathrm{H}, \mathrm{N}^{1}-\mathrm{CH}_{2}\right), 4.11\left(\mathrm{t}, J=6.7 \mathrm{~Hz}, 2 \mathrm{H}, \mathrm{N}^{3}-\mathrm{CH}_{2}\right), 4.51(\mathrm{dt}, J=47.2$, $\left.5.7 \mathrm{~Hz}, 2 \mathrm{H}, \mathrm{CH}_{2} \mathrm{~F}\right), 5.76(\mathrm{~s}, 2 \mathrm{H}, \mathrm{Cpen}-H), 13.21\left(\mathrm{~s}_{\mathrm{br}}, 1 \mathrm{H}, \mathrm{N}^{7}-H\right) .{ }^{13} \mathrm{C}-\mathrm{NMR}$ (DMSO- $\left.d_{6}\right): \delta 11.6$ $\left(\mathrm{CH}_{3}\right), 21.3\left(\mathrm{CH}_{3}-\mathrm{CH}_{2}\right), 27.9\left(\mathrm{~N}^{7}-\mathrm{POM}-\mathrm{CH}_{3}\right), 29.2\left(\mathrm{~J}=19.2 \mathrm{~Hz}, \mathrm{CH}_{2}-\mathrm{CH}_{2} \mathrm{~F}\right), 37.1(\mathrm{Cp}-\mathrm{CH}), 38.7$ $\left(\mathrm{Cp}-\mathrm{CH}_{2}\right), 41.1\left(\mathrm{~J}=5.5 \mathrm{~Hz}, \mathrm{~N}^{3}-\mathrm{CH}_{2}\right), 42.5\left(\mathrm{~N}^{1}-\mathrm{CH}_{2}\right), 74.3\left(\mathrm{~N}^{7}-\mathrm{POM}-\mathrm{CH}_{2}\right), 80.9(\mathrm{~J}=162.0 \mathrm{~Hz}$, $\left.\mathrm{CH}_{2} \mathrm{~F}\right), 106.8(C-5), 129.7$ (Cpen- $\left.C\right), 148.0(C-8), 151.2(C-4), 154.3(C-2), 158.1(C-6) .{ }^{19} \mathrm{~F}-$ NMR (DMSO- $\left.d_{6}\right): \delta-218.41$. MS (ESI+) m/z: $[\mathrm{M}+\mathrm{H}]^{+}$Calcd for $\mathrm{C}_{16} \mathrm{H}_{21} \mathrm{FN}_{4} \mathrm{O}_{2} 321.16$; Found 321.15.

\section{8-(Cyclopent-1-enyl)-3-(3-fluoropropyl)-1-propyl-1H-purine-2,6(3H,7H)-dione (24b).}


At ambient temperature compound 23b (1.3 g, $3 \mathrm{mmol})$ was stirred overnight in $7 \mathrm{~N}$ methanolic ammonia $(25 \mathrm{~mL})$. After evaporation of the solvent the solid residue was recrystallized from methanol to provide the deprotected xanthine $\mathbf{2 4 b}$ as fawn crystals. Yield $720 \mathrm{mg}$ (75\%), m.p. $278^{\circ} \mathrm{C}(\mathrm{MeOH})$.

${ }^{1} \mathrm{H}-\mathrm{NMR}\left(\mathrm{DMSO}-d_{6}\right): \delta 0.88\left(\mathrm{t}, J=7.4 \mathrm{~Hz}, 3 \mathrm{H}, \mathrm{CH}_{3}\right), 1.57\left(\mathrm{~m}, J=7.4 \mathrm{~Hz}, 2 \mathrm{H}, \mathrm{CH}_{3}-\mathrm{CH}_{2}\right), 1.85-$

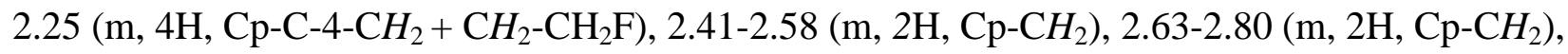
$3.85\left(\mathrm{~m}, J=7.1 \mathrm{~Hz}, 2 \mathrm{H}, \mathrm{N}^{1}-\mathrm{CH}_{2}\right), 4.24\left(\mathrm{t}, J=6.7 \mathrm{~Hz}, 2 \mathrm{H}, \mathrm{N}^{3}-\mathrm{CH}_{2}\right), 4.52(\mathrm{dt}, J=47.2,5.7 \mathrm{~Hz}, 2 \mathrm{H}$, $\left.\mathrm{CH}_{2} \mathrm{~F}\right), 6.46(\mathrm{~m}, 1 \mathrm{H}, \mathrm{Cp}-\mathrm{C}-2-\mathrm{CH}), 13.38\left(\mathrm{~s}_{\mathrm{br}}, 1 \mathrm{H}, \mathrm{N}^{7}-\mathrm{H}\right) .{ }^{13} \mathrm{C}-\mathrm{NMR}\left(\mathrm{DMSO}-d_{6}\right): \delta 11.7\left(\mathrm{CH}_{3}\right)$, $21.5\left(\mathrm{CH}_{3}-\mathrm{CH}_{2}\right), 29.2\left({ }^{2} \mathrm{~J}=19.2 \mathrm{~Hz}, \mathrm{CH}_{2}-\mathrm{CH}_{2} \mathrm{~F}\right), 33.1\left(\mathrm{Cp}-C^{3}\right), 33.4\left(\mathrm{Cp}-C^{5}\right), 40.0\left({ }^{3} J=5.5 \mathrm{~Hz}\right.$, $\left.\mathrm{N}^{3}-C \mathrm{H}_{2}\right), 42.2\left(\mathrm{~N}^{1}-C \mathrm{H}_{2}\right), 81.0\left({ }^{1} J=162.0 \mathrm{~Hz}, C \mathrm{H}_{2} \mathrm{~F}\right), 107.3\left(C^{5}\right), 131.1\left(\mathrm{Cp}-C^{2}\right), 137.1\left(\mathrm{Cp}-C^{1}\right)$, $147.9\left(C^{8}\right), 149.3\left(C^{4}\right), 151.5\left(C^{2}\right), 156.1\left(C^{6}\right) .{ }^{19} \mathrm{~F}-\mathrm{NMR}\left(\mathrm{DMSO}-d_{6}\right): \delta-218.88 . \mathrm{MS}(\mathrm{ESI}+) \mathrm{m} / \mathrm{z}$ : $[\mathrm{M}+\mathrm{H}]^{+}$Calcd for $\mathrm{C}_{16} \mathrm{H}_{21} \mathrm{FN}_{4} \mathrm{O}_{2}$ 321.16; Found 321.16.

cis-8-(2-Benzyloxycyclopentyl)-3-(3-fluoropropyl)-1-propyl-1H-purine-2,6(3H,7H)-dione (24c).

At ambient temperature compound 23c (543 mg, $1 \mathrm{mmol}$ ) was stirred in $7 \mathrm{~N}$ methanolic ammonia $(25 \mathrm{~mL})$ for $24 \mathrm{~h}$. After evaporation of the solvent the oily residue was purified by chromatography on silica gel (eluent $5 \%$ acetonitrile in ethyl acetate) to give the deprotected xanthine $\mathbf{2 4 c}$ as a light yellow oil. Yield $348 \mathrm{mg}(81 \%)$.

${ }^{1} \mathrm{H}-\mathrm{NMR}\left(\mathrm{DMSO}-d_{6}\right): \delta 1.01\left(\mathrm{t}, J=7.4 \mathrm{~Hz}, 3 \mathrm{H}, \mathrm{CH}_{3}\right), 1.60-2.41\left(\mathrm{~mm}, 10 \mathrm{H}, \mathrm{CH}_{3}-\mathrm{CH}_{2}+\mathrm{Cp}-\mathrm{CH}_{2}\right.$ $\left.+\mathrm{FCH}_{2}-\mathrm{CH}_{2}\right)$ ), 3.29-3.50 (m, 1H, Cp-1-H), 4.04 (m, 2H, N1-CH2), 4.13-4.26 (m, 1H, Cp-C-2-H), $4.36\left(\mathrm{~m}, 2 \mathrm{H}, \mathrm{Ph}-\mathrm{CH}_{2}-\mathrm{O}\right), 4.21\left(\mathrm{~m}, 2 \mathrm{H}, \mathrm{N}^{3}-\mathrm{CH}_{2}\right), 4.60\left(\mathrm{dt}, \mathrm{J}=47.2,5.7 \mathrm{~Hz}, 2 \mathrm{H}, \mathrm{CH}_{2} \mathrm{~F}\right), 7.18-7.31$ (m, 5H, O-CH $2-\mathrm{Ph}), 12.50\left(\mathrm{~s} b r, 1 \mathrm{H}, \mathrm{N}^{7}-H\right) .{ }^{13} \mathrm{C}-\mathrm{NMR}$ (DMSO-d $)$ : $\delta 11.4\left(C_{3}\right), 21.4\left(\mathrm{CH}_{3}-\mathrm{CH}_{2}\right)$, $22.9\left(\mathrm{Cp}-C^{4}\right), 29.1\left(\mathrm{Cp}-C^{5}\right), 29.2\left({ }^{2} J=19.2 \mathrm{~Hz}, C \mathrm{H}_{2}-\mathrm{CH}_{2} \mathrm{~F}\right), 31.1\left(\mathrm{Cp}-C^{3}\right), 40.1\left({ }^{3} J=5.5 \mathrm{~Hz}, \mathrm{~N}^{3}-\right.$ $\left.\mathrm{CH}_{2}\right), 42.7\left(\mathrm{~N}^{1}-\mathrm{CH}_{2}\right), 46.3\left(\mathrm{Cp}-\mathrm{C}^{1}\right), 71.6\left(\mathrm{O}-\mathrm{CH}_{2}-\mathrm{Ph}\right), 81.5\left({ }^{1} \mathrm{~J}=162.0 \mathrm{~Hz}, \mathrm{CH}_{2} \mathrm{~F}\right), 84.8\left(\mathrm{Cp}-C^{2}\right)$, $106.8\left(C^{5}\right), 127.5\left(\mathrm{O}-\mathrm{CH}_{2}-\mathrm{Ph}\right), 128.2\left(\mathrm{O}-\mathrm{CH}_{2}-\mathrm{Ph}\right), 138.4\left(\mathrm{O}-\mathrm{CH}_{2}-\mathrm{Ph}\right), 148.9\left(C^{8}\right), 151.1\left(\mathrm{C}^{4}\right)$, $155.6\left(C^{2}\right), 157.5\left(C^{6}\right) .{ }^{19} \mathrm{~F}-\mathrm{NMR}\left(\mathrm{DMSO}-d_{6}\right): \delta 219.87 . \mathrm{MS}(\mathrm{ESI}+) \mathrm{m} / \mathrm{z}:[\mathrm{M}+\mathrm{H}]^{+}$Calcd for $\mathrm{C}_{23} \mathrm{H}_{29} \mathrm{FN}_{4} \mathrm{O}_{3}$ 429.22; Found 429.22.

3-(3-Fluoropropyl)-8-(3-hydroxycyclopentyl)-1-propyl-1H-purine-2,6(3H,7H)-dione (25). 
Under an inertgas atmosphere and external cooling with ice a solution of 9-BBN in THF $(0.5 \mathrm{M}, 8$ $\mathrm{mL}, 4 \mathrm{mmol}$ ) was added to a well stirred solution of cyclopentenylxanthine $\mathbf{2 4 a}(320 \mathrm{mg}, 1 \mathrm{mmol})$ in dry THF $(10 \mathrm{~mL})$. The ice bath was removed and the mixture was stirred at ambient temperature for $16 \mathrm{~h}$. Water $(2 \mathrm{~mL})$ was added cautiously to destroy excess borane. Sodium hydroxide $(1 \mathrm{~N}, 1.1 \mathrm{~mL}, 1.1 \mathrm{mmol})$ and then $30 \%$ hydrogen peroxide $(380 \mu \mathrm{L}, 3.7 \mathrm{mmol})$ were added, and the solution was stirred at ambient temperature for $0.5 \mathrm{~h}$. Brine $(75 \mathrm{~mL})$ was added, the phases were separated and the aqueous phase was extracted with THF ( $2 \times 25 \mathrm{~mL})$. The pooled organic phases were washed with brine and dried dried over anhydrous sodium sulfate. Filtration and evaporation in vaсuo left a residue that was purified by flash chromatography eluting with 5\% ethyl acetate in methanol. The product fractions were pooled and the solvents evaporated in vacuo. The solid material was triturated with diethyl ether $(5 \mathrm{~mL})$ treated with ultrasound (20 s) and collected by fitration to give the title compound $\mathbf{2 5}$ (mixture of cis and trans isomers) as colourless crystals. Yield $220 \mathrm{mg}(65 \%)$, m.p. $205-206^{\circ} \mathrm{C}$.

${ }^{1} \mathrm{H}-\mathrm{NMR}$ (DMSO-d $\left.d_{6}\right): \delta 0.88(\mathrm{t}, J=7.4 \mathrm{~Hz}, 3 \mathrm{H}, \mathrm{CH}), 1.35-2.33\left(\mathrm{~m}, 10 \mathrm{H}, 3 \mathrm{Cp}-\mathrm{CH}_{2}+\mathrm{CH}_{3}-\mathrm{CH}_{2}\right.$ $\left.+\mathrm{CH}_{2}-\mathrm{CH}_{2} \mathrm{~F}\right), 3.39(\mathrm{~m}, J=7.9 \mathrm{~Hz}, 1 \mathrm{H}, \mathrm{Cp}-H), 3.85\left(\mathrm{~m}, J=7.1 \mathrm{~Hz}, 2 \mathrm{H}, \mathrm{N}^{1}-\mathrm{CH}_{2}\right), 4.11(\mathrm{t}, J=6.7$ $\left.\mathrm{Hz}, 2 \mathrm{H}, \mathrm{N}^{3}-\mathrm{CH}_{2}\right), 4.29(\mathrm{~s} \mathrm{br}, 1 \mathrm{H}, \mathrm{Cp}-\mathrm{OH}), 4.51\left(\mathrm{dt}, J=47.2,5.7 \mathrm{~Hz}, 2 \mathrm{H}, \mathrm{CH}_{2} \mathrm{~F}\right), 4.69(\mathrm{~s} \mathrm{br}, 1 \mathrm{H}$, $\mathrm{OH}), 13.14\left(\mathrm{~s}_{\mathrm{br}}, 1 \mathrm{H}, \mathrm{N}^{7}-H\right) .{ }^{13} \mathrm{C}-\mathrm{NMR}\left(\mathrm{DMSO}-d_{6}\right): \delta 11.6\left(\mathrm{CH}_{3}\right), 21.3\left(\mathrm{CH}_{3}-\mathrm{CH}_{2}\right), 29.2\left({ }^{2} J=19.2\right.$ $\left.\mathrm{Hz}, \mathrm{CH}_{2}-\mathrm{CH}_{2} \mathrm{~F}\right), 30.6\left(\mathrm{Cp}-\mathrm{CH}_{2}\right), 35.1\left(\mathrm{Cp}-\mathrm{CH}_{2}\right), 35.3\left(\mathrm{Cp}-\mathrm{CH}_{2}\right), 36.9(\mathrm{Cp}-\mathrm{CH}), 41.4\left(\mathrm{~N}^{1}-C_{2}\right)$, $42.2\left({ }^{3} J=5.5 \mathrm{~Hz}, \mathrm{~N}^{3}-C \mathrm{H}_{2}\right), 71.9(\mathrm{Cp}-C \mathrm{HOH}), 82.4\left({ }^{1} J=162.0 \mathrm{~Hz}, C \mathrm{H}_{2} \mathrm{~F}\right), 106.6\left(C^{5}\right), 147.9$ $\left(C^{8}\right), 151.2\left(C^{4}\right), 154.3\left(C^{2}\right), 158.47\left(C^{6}\right) .{ }^{19}$ F-NMR (DMSO- $\left.d_{6}\right): \delta-218.39$. MS (ESI+) m/z: $[\mathrm{M}+\mathrm{H}]^{+}$Calcd for $\mathrm{C}_{16} \mathrm{H}_{23} \mathrm{FN}_{4} \mathrm{O}_{3} 339.18$; Found 339.18.

cis-3-(3-Fluoropropyl)-8-(2-hydroxycyclopentyl)-1-propyl-1H-purine-2,6(3H,7H)-dione (26). At ambient temperature and under the exclusion of moisture methanesulfonic acid $(1.5 \mathrm{~mL})$ was added to a well stirred solution of $\mathbf{2 4 c}(215 \mathrm{mg}, 0.5 \mathrm{mmol})$ in dry DCM (3.5 mL). The mixture was stirred at ambient temperature for $12 \mathrm{~h}$ and poured onto ice-water $(30 \mathrm{~mL})$. Extraction with ethyl acetate $(2 \times 25 \mathrm{~mL})$, washing of the pooled organic extracts with sat. aqueous $\mathrm{Na}_{2} \mathrm{CO}_{3}(2 \times$ $50 \mathrm{~mL}$ ) and brine $(50 \mathrm{~mL})$, drying over anhydrous sodium sulphate, filtration and rotaevaporation in vacuo yielded a solid residue. The residue was purified by chromatography on 
silica gel (eluent $30 \%$ acetonitrile in ethyl acetate) to provide the deprotected xanthine $\mathbf{2 6}$ as a low melting yellow solid. Yield $154 \mathrm{mg}(91 \%)$.

${ }^{1} \mathrm{H}-\mathrm{NMR}\left(\mathrm{DMSO}-d_{6}\right): \delta 0.88\left(\mathrm{t}, J=7.4 \mathrm{~Hz}, 3 \mathrm{H}, \mathrm{CH}_{3}\right), 1.44-2.27\left(\mathrm{~m}, 10 \mathrm{H}, \mathrm{CH}_{3}-\mathrm{CH}_{2}+\mathrm{Cp}-\mathrm{CH}_{2}+\right.$ $\left.\mathrm{CH}_{2}-\mathrm{CH}_{2} \mathrm{~F}\right), 2.81-3.08\left(\mathrm{~m}, 1 \mathrm{H}, \mathrm{Cp}-H^{1}\right), 3.63-3.95\left(\mathrm{~m}, 2 \mathrm{H}, \mathrm{N}^{1}-\mathrm{CH}_{2}\right), 4.03-4.19\left(\mathrm{~m}, 2 \mathrm{H}, \mathrm{N}^{3}-\mathrm{CH}_{2}\right)$, 4.15-4.29 (m, $\left.1 \mathrm{H}, \mathrm{Cp}-H^{2}\right), 4.53\left(\mathrm{dt}, J=47.2,5.7 \mathrm{~Hz}, 2 \mathrm{H}, \mathrm{CH}_{2} \mathrm{~F}\right), 4.89\left(\mathrm{~s}_{\mathrm{br}}, 1 \mathrm{H}, \mathrm{OH}\right), 13.17\left(\mathrm{~s}_{\mathrm{br}}\right.$, $\left.1 \mathrm{H}, \mathrm{N}^{7}-H\right) .{ }^{13} \mathrm{C}-\mathrm{NMR}\left(\mathrm{DMSO}-d_{6}\right): \delta 11.6\left(\mathrm{CH}_{3}\right), 21.3\left(\mathrm{CH}_{3}-\mathrm{CH}_{2}\right), 22.3\left(\mathrm{Cp}-C^{4}\right), 29.2\left({ }^{2} J=19.2\right.$ $\left.\mathrm{Hz}, \mathrm{CH}_{2}-\mathrm{CH}_{2} \mathrm{~F}\right), 29.4\left(\mathrm{Cp}-C^{5}\right), 30.3\left(\mathrm{Cp}-C^{3}\right), 40.2\left({ }^{3} J=5.5 \mathrm{~Hz}, \mathrm{~N}^{3}-C \mathrm{H}_{2}\right), 42.5\left(\mathrm{~N}^{1}-C \mathrm{H}_{2}\right), 48.1$ $\left(\mathrm{Cp}-C^{1}\right), 77.6\left(\mathrm{Cp}-C^{2}\right), 82.1\left({ }^{1} J=162.0 \mathrm{~Hz}, C \mathrm{H}_{2} \mathrm{~F}\right), 106.7\left(C^{5}\right), 148.2\left(C^{8}\right), 151.2\left(\mathrm{C}^{4}\right), 154.3\left(C^{2}\right)$, 157.1 $\left(C^{6}\right) .{ }^{19}$ F-NMR (DMSO- $\left.d_{6}\right): \delta-218.35$. MS (ESI+) m/z: $[\mathrm{M}+\mathrm{H}]^{+}$Calcd for $\mathrm{C}_{16} \mathrm{H}_{23} \mathrm{FN}_{4} \mathrm{O}_{3}$ 339.18; Found 339.18.

\section{Competitive Radioligand Binding Assays}

Frontal cortices (for $\mathrm{A}_{1} \mathrm{AR}$ assays) and corpora striata (for $\mathrm{A}_{2 \mathrm{~A}} \mathrm{AR}$ assays) from pig brains were homogenized for $1 \mathrm{~min}$ in 10 volumes of ice-cold $320 \mathrm{mM}$ sucrose, containing soybean trypsin inhibitor $(20 \mu \mathrm{g} / \mathrm{mL})$, bacitracin $(200 \mu \mathrm{g} / \mathrm{mL})$, and benzamidine $\mathrm{HCl}(160 \mu \mathrm{g} / \mathrm{mL})$ by means of a Potter at 20,000 rpm under external ice cooling. The homogenate was centrifuged at 1,000 X $g$ for $10 \mathrm{~min}$ at $4^{\circ} \mathrm{C}$ (Beckmann Optima L, SW41Ti rotor). The pellet was discarded and the supernatant was centrifuged at $50,000 \mathrm{X} g$ for $15 \mathrm{~min}$ at $4{ }^{\circ} \mathrm{C}$. The resulting pellet was washed once with buffer (50 mM Tris - HCl, pH 7.4, containing $2 \mathrm{U} / \mathrm{mL}$ adenosine deaminase) and resuspended in 10 volumes of buffer (same volume as for sucrose, see above), thereafter stored in aliquots (600 $\mu \mathrm{L})$ at $-80^{\circ} \mathrm{C}$.

The assays were performed in triplicate by incubating aliquots of the membrane fractions (65 $120 \mu \mathrm{g}$ protein per sample) in Tris $\mathrm{HCl}, \mathrm{pH} 7.4$, containing adenosine deaminase (2 $\mathrm{U} / \mathrm{mL})$. Cortical homogenates containing $\mathrm{A}_{1} \mathrm{ARs}$ were additionally incubated with $\left[{ }^{3} \mathrm{H}\right] \mathrm{CPFPX}(2 \mathrm{nM})$, striatal homogenates containing $\mathrm{A}_{2 \mathrm{~A}} \mathrm{AR}$ were additionally incubated with $\left[{ }^{3} \mathrm{H}\right] \mathrm{ZM} 241385$ (1.8 $\mathrm{nM}$ ), all with different competitor concentrations in a total assay volume of $200 \mu \mathrm{L}$ at $20^{\circ} \mathrm{C}$ for 90 min. Filtration over GF/C-sheets presoaked in $0.3 \%$ polyethylenimine separated bound from free ligand using a sample harvester (Brandel, USA). Filtrates were discarded. The filters with the adhering pellets were washed with ice cold buffer $(4 \times 2 \mathrm{~mL})$, punched-out into scintillation vials and incubated overnight with scintillation cocktail (8 mL, Ready Save, Beckman Coulter, Krefeld, 
Germany). Radioactivity was measured in a liquid scintillation counter. Protein estimation was performed with a commercial assay (Bio-Rad DC Protein Assay) after solubilization in 15\% $\mathrm{NH}_{4} \mathrm{OH}$ containing $2 \% \mathrm{SDS}(\mathrm{w} / \mathrm{v})$; human serum albumin served as a standard. A computerassisted curve-fitting program (Graph Pad Prism, version 4.0) calculated $\mathrm{IC}_{50^{-}}$and $\mathrm{K}_{\mathrm{i}}$-values.

\section{Incubation of Human Liver Microsomes with n.c.a. $\left[{ }^{18}\right.$ F $]$ CPFPX}

Human liver microsomes ( $0.8 \mathrm{mg}$ protein) were dispersed in $0.1 \mathrm{M}$ phosphate buffer ( $\mathrm{pH} 7.4$ ) containing $3.3 \mathrm{mM} \mathrm{MgCl} 2$ and an NADPH-generating system consisting of $1.3 \mathrm{mM} \mathrm{NADP}, 3.3$ $\mathrm{mM}$ glucose 6-phosphate and $0.4 \mathrm{U}$ glucose 6-phosphate dehydrogenase in a final volume of 1 $\mathrm{mL}$. Incubation was at $37^{\circ} \mathrm{C}$. The addition of n.c.a. $\left[{ }^{18} \mathrm{~F}\right] \mathrm{CPFPX}(500 \mathrm{kBq})$ initiated the reaction, which was stopped after $30 \mathrm{~min}$ by addition of acetonitrile $(2 \mathrm{~mL})$. After 2 min of vortex mixing and centrifugation $\left(20.800 \mathrm{X} \mathrm{g}, 4^{\circ} \mathrm{C}, 1 \mathrm{~min}\right.$.) the supernatant was vacuum evaporated to dryness at ambient temperature. The residue was taken up in $55 \mu \mathrm{L}$ of a solution prepared by mixing $5 \mu \mathrm{L}$ of a DMSO solution containing compounds 10, 12, 15a,c,d, 17, 24a,b, 25, 26, M1 and CPFPX (0.2 $\mu \mathrm{g}$ each) and HPLC eluent $(50 \mu \mathrm{L})$. The resulting suspension was centrifuged $\left(20,800 \mathrm{X} \mathrm{g}, 4^{\circ} \mathrm{C}, 1\right.$ min) to remove sediment.

\section{High-performance liquid chromatography}

Analysis of standards, putative metabolites, and liver microsome extracts employed a Kromasil 100-5 C18 column ( 250 x 4.6 mm) (CS-Chromatographie Service GmbH, Langerwehe, Germany) in a HPLC system consisting of a WellChrom K - 1001 pump (Knauer, Berlin, Germany), a K 2001 UV detector (Knauer, Berlin, Germany), and a manual sample injector (Type 7125, Rheodyne, Bensheim, Germany) fitted with a $250 \mu 1$ sample loop. Isocratic elution with water / acetonitrile/ acetic acid (70/30/0.2, v/ v / v) was at a flow rate of $1 \mathrm{~mL} / \mathrm{min}$. UV monitoring at $275 \mathrm{~nm}$ detected CPFPX and its putative metabolites. For measurement of radioactivity the outflow of the UV detector was connected in series to an on-line $\mathrm{NaI}(\mathrm{Tl})$ well-type scintillation detector with a $250 \mu \mathrm{L}$ detection loop. Chromatograms were corrected for the transit time between the detectors. 


\section{References}

(1) Phelps, M. E. Positron emission tomography provides molecular imaging of biological processes. Proc. Natl. Acad. Sci. U.S.A. 2000, 97, 9226-9233.

(2) Bauer, A.; Holschbach, M. H.; Meyer, P. T.; Boy, C.; Herzog, H.; Olsson, R. A.; Coenen, H. $\mathrm{H}$. and Zilles, K. In vivo imaging of adenosine A 1 receptors in the human brain with $\left[{ }^{18} \mathrm{~F}\right] \mathrm{CPFPX}$ and positron emission tomography. Neuroimage 2003, 19, 1760-1769.

(3) Meyer, P. T.; Bier, D.; Holschbach, M. H.; Boy, C.; Olsson, R. A.; Coenen, H. H.; Zilles, K. and Bauer, A. Quantification of Cerebral A1 Adenosine Receptors in Humans using $\left[{ }^{18} \mathrm{~F}\right] \mathrm{CPFPX}$ and PET. J. Cereb. Blood Flow Metab. 2004, 24, 323-333.

(4) Bier, D.; Holschbach, M. H.; Wutz, W.; Olsson, R. A. and Coenen, H. H. Metabolism of the A1 adenosine receptor positron emission tomography ligand [18F] 8-cyclopentyl-3-(3fluoropropyl)-1-propylxanthine ( $\left.\left[{ }^{18} \mathrm{~F}\right] \mathrm{CPFPX}\right)$ in rodents and humans. Drug Metab. Dispos. 2006, $34,570-576$.

(5) Lohmann, S. M. and Miech, R. P. Theophylline metabolism by the rat liver microsomal system. J. Pharmacol. Exp. Ther. 1976, 196, 213-225.

(6) Mansuy, D. The great diversity of reactions catalyzed by cytochromes P450. Comp. Biochem. Physiol., Part C: Toxicol. Pharmacol. 1998, 121, 5-14.

(7) Guengerich, F. P. Common and Uncommon Cytochrome P450 Reactions Related to Metabolism and Chemical Toxicity. Chem. Res. Toxicol. 2001, 14, 611-650.

(8) De Montellano, P. R. O. (2005). Cytochrome P450: structure, mechanism, and biochemistry. Ortiz de Montellano (Ed.) Kluwer Elsevier; New York.

(9) Papesch, V. and Schroeder, E. F. Synthesis of 1-mono-and 1, 3-di-substituted 6-aminouracils. Diuretic activity. J. Org. Chem. 1951, 16, 1879-1890.

(10) Speer, J. H. and Raymond, A. L. Some alkyl homologs of theophylline. J. Am. Chem. Soc. 1953, 75, 114-115. 
(11) Blicke, F. F. and Godt Jr, H. C. Reactions of 1,3-Dimethyl-5,6-diaminouracil. J. Am. Chem. Soc. 1954, 76, 2798-2800.

(12) Traube, W. Der synthetische Aufbau der Harnsäure, des Xanthins, Theobromins, Theophyllins und Koffeins aus der Cyanessigsäure. Ber. Dtsch. Chem. Ges. 1900, 33, 3035-3056.

(13) Ram, S. and Spicer, L. D. Debenzylation of N-benzylamino derivatives by catalytic transfer hydrogenation with ammonium formate. Synth. Commun. 1987, 17, 415-418.

(14) Jindrich, J.; Dvoráková, H. and Holy, A. Synthesis of isomeric N-(3-fluoro-2-hydroxypropyl) and N-(2-fluoro-3-hydroxypropyl) derivatives of purine and pyrimidine bases. Collect. Czech. Chem. Commun. 1992, 57, 1466-1482.

(15) Holschbach, M. H.; Fein, T.; Krummeich, C.; Lewis, R. G.; Wutz, W.; Schwabe, U.; Unterlugauer, D. and Olsson, R. A. A1 adenosine receptor antagonists as ligands for positron emission tomography (PET) and single photon emission tomography (SPET). J. Med. Chem. 1998, $41,555-563$.

(16) Holschbach, M. H.; Bier, D.; Wutz, W.; Willbold, S. and Olsson, R. A. Synthesis of the Main Metabolite in Human Blood of the A1 Adenosine Receptor Ligand $\left[{ }^{18}\right.$ F]CPFPX. Org. Lett. 2009, $11,4266-4269$.

(17) Widmer, U. A Convenient Benzylation Procedure for beta-Hydroxy Esters. SynthesisStuttgart 1987, 568-570.

(18) Scammells, P. J.; Baker, S. P.; Belardinelli, L. and Olsson, R. A. Substituted 1,3dipropylxanthines as irreversible antagonists of A1 adenosine receptors. J. Med. Chem. 1994, 37, 2704-2712.

(19) Obach, R. S.; Baxter, J. G.; Liston, T. E.; Silber, B. M.; Jones, B. C.; Macintyre, F.; Rance, D. J. and Wastall, P. The prediction of human pharmacokinetic parameters from preclinical and in vitro metabolism data. J. Pharmacol. Exp. Ther. 1997, 283, 46-58. 
(20) Ito, K. and Houston, J. B. Comparison of the use of liver models for predicting drug clearance using in vitro kinetic data from hepatic microsomes and isolated hepatocytes. Pharm. Res. 2004, 21, 785-792.

(21) Holschbach, M. H.; Olsson, R. A.; Bier, D.; Wutz, W.; Sihver, W.; Schüller, M.; Palm, B. and Coenen, H. H. Synthesis and evaluation of no-carrier-added 8-cyclopentyl-3-(3$\left[{ }^{18} \mathrm{~F}\right]$ fluoropropyl)-1-propylxanthine $\left(\left[{ }^{18} \mathrm{~F}\right] \mathrm{CPFPX}\right)$ : a potent and selective A1-adenosine receptor antagonist for in vivo imaging. J. Med. Chem. 2002, 45, 5150-5156.

(22) Guengerich, F. P. and Munro, A. W. Unusual cytochrome P450 enzymes and reactions. J. Biol. Chem. 2013, 288, 17065-17073.

(23) Park, B. K.; Kitteringham, N. R. and O'Neill, P. M. Metabolism of fluorine-containing drugs. Annu. Rev. Pharmacol. Toxicol. 2001, 41, 443-470.

(24) Swallow, S. Fluorine in medicinal chemistry. Prog. Med. Chem. 2015, 54, 65-133.

(25) Stevens, J. C.; White, R. B.; Hsu, S. H. and Martinet, M. Human Liver CYP2B6-Catalyzed Hydroxylation of RP 73401. J. Pharmacol. Exp. Ther. 1997, 282, 1389-1395.

(26) Sarabu, R.; Bizzarro, F. T.; Corbett, W. L.; Dvorozniak, M. T.; Geng, W.; Grippo, J. F.; Haynes, N.-E.; Hutchings, S.; Garofalo, L.; Guertin, K. R.; Hilliard, D. W.; Kabat, M.; Kester, R. F.; Ka, W.; Liang, Z.; Mahaney, P. E.; Marcus, L.; Matschinsky, F. M.; Moore, D.; Racha, J.; Radinov, R.; Ren, Y.; Qi, L.; Pignatello, M.; Spence, C. L.; Steele, T.; Tengi, J. and Grimsby, J. Discovery of piragliatin--first glucokinase activator studied in type 2 diabetic patients. J. Med. Chem. 2012, 55, 7021-7036.

(27) Partridge, J. J.; Chadha, N. K. and Uskokovic, M. R. Asymmetric synthesis of loganin. Stereospecific formation of (1R, 2R)-and (1S, 2S)-2-methyl-3-cyclopenten-1-ol and (2R)-and (2S)-2-methylcyclopentanone. J. Am. Chem. Soc. 1973, 95, 532-540.

(28) Ly, T.; Krout, M.; Pham, D. K.; Tani, K.; Stoltz, B. M. and Julian, R. R. Synthesis of 2quinuclidonium by eliminating water: Experimental quantification of the high basicity of extremely twisted amides. J. Am. Chem. Soc. 2007, 129, 1864-1865. 
(29) Erden, I.; Gaertner, C. and Azimi, M. S. Triphenylphosphine Reduction of Saturated Endoperoxides. Org. Lett. 2009, 11, 3986-3989.

(30) Holschbach, M. H.; Wutz, W.; Schüller, M.; Bier, D. and Coenen, H. H. Tritium-labelled 8cyclopentyl-3-(3-fluoropropyl)-1-propylxanthine ([$\left.\left.{ }^{3} \mathrm{H}\right] \mathrm{CPFPX}\right)$, a potent and selective antagonist for the A1 adenosine receptor. J. Labelled Compd. Radiopharm. 2003, 46, 365-372.

(31) Hutzenlaub, W. and Pfleiderer, W. Purine, XIII1) Vereinfachte Synthesen für 7-Methyl- und 1,7-Dimethyl-xanthin und -harnsäure. Liebigs Ann. Chem. 1979, 11, 1847-1854.

(32) Goldner, H.; Dietz, G. and Carstens, E. Eine neue Xanthin-Synthese (A new xanthine synthesis). Liebigs Ann. Chem. 1965, 691, 142-158. 


\section{Table of Contents Graphic}

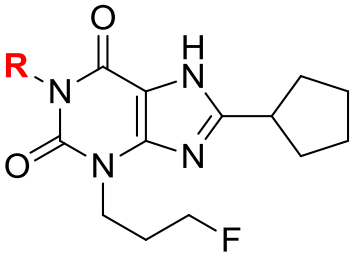

10, 15a-d

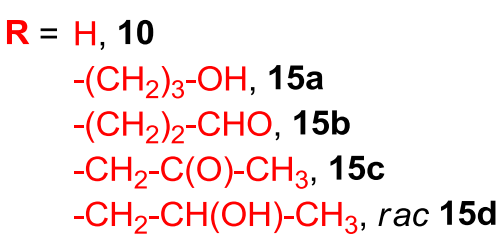

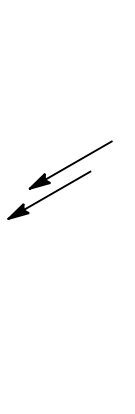

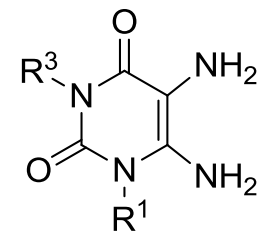

$\mathrm{R}^{1}=\mathrm{Bn}, \mathrm{R}^{3}=\mathrm{H}, \mathbf{4}$

$\mathrm{R}^{1}=\mathrm{DMB}, \mathrm{R}^{3}=\operatorname{Pr}, \mathbf{1 8}$
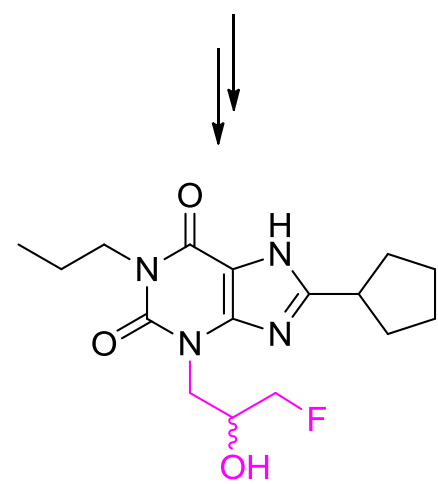

rac 17

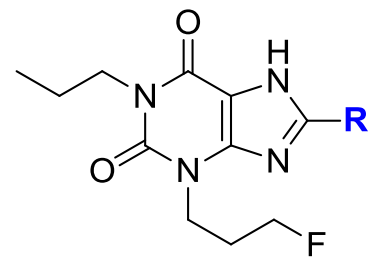

24a, 24b, 25, 26
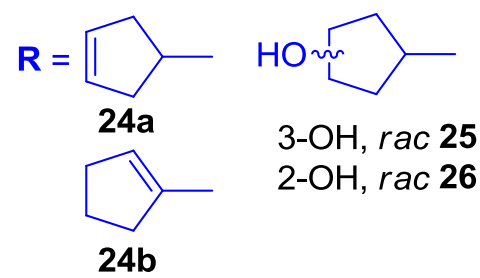